\author{
UNIVERSIDADE DE SÃO PAULO \\ ESCOLA DE ENGENHARIA DE SÃO CARLOS \\ DEPARTAMENTO DE HIDRÁULICA E SANEAMENTO
}

CAMILA TOLLEDO SANTOS

INFLUÊNCIA DO TAMANHO MOLECULAR APARENTE DE SUBSTÂNCIAS HÚMICAS AQUÁTICAS NA EFICIÊNCIA DA COAGULAÇÃO POR HIDROXICLORETO DE ALUMÍNIO

São Carlos

2009 



\section{INFLUÊNCIA DO TAMANHO MOLECULAR APARENTE DE SUBSTÂNCIAS HÚMICAS AQUÁTICAS NA EFICIÊNCIA DA COAGULAÇÃO POR HIDROXICLORETO DE ALUMÍNIO}

Dissertação apresentada a Escola de Engenharia de São Carlos da Universidade de São Paulo, como parte dos requisitos para obtenção do título de Mestre em Ciências: Engenharia Hidráulica e Saneamento.

Área de Concentração: Hidráulica e Saneamento

Orientador: Prof. Dr. Luiz Di Bernardo

\section{SÃO CARLOS}



Aos meus pais: Marco Antonio Lima Santos e Maria José Tolledo Gonçalves, por serem minha base! 



\section{AGRADECIMENTOS}

A Deus, pelo dom da vida e por sempre me cercar de pessoas boas!

Ao Prof. Dr. Luiz Di Bernardo, pela orientação e pelos valiosos ensinamentos durante todo o mestrado!

Ao Departamento de Hidráulica e Saneamento da Escola de Engenharia de São Carlos Universidade de São Paulo - pela oportunidade da realização do mestrado.

A CAPES pela concessão da bolsa de mestrado.

A Dra. Angela Di Bernardo Dantas, por todo apoio, atenção e contribuições!

A Eliane Sloboda, pela ajuda inestimável durante a realização dos ensaios!

A Sá, Pavi e Rose, pela disposição em ajudar!

Ao Paulo Voltan por toda ajuda!

Ao Luís Constantino, pela ajuda na coleta da água bruta usada no trabalho.

Aos técnicos do Laboratório de Saneamento do SHS: Juliana, Júlio e Paulo, pela realização das análises, pelo convívio, receptividade e amizade!

Ao técnico Chico, pela ajuda nos pequenos problemas do dia-a-dia do laboratório!

A Diva Langraf, do Laboratório de Química Ambiental do IQSC, pela disponibilidade para realização das análises de carbono orgânico e empréstimo de equipamentos.

A Prof. Dra. Eny Vieira, IQSC, pela ajuda com empréstimo de material e disponibilização do laboratório.

A colega Emanuelle Simas, IQSC, pelas dicas sobre extração em Sohxlet.

A amiga Renata Pereira de Oliveira, pelas horas árduas de trabalho em equipe!

Aos amigos Micheli Gonçalves e Tiago Soares, pela companhia e amizade constantes!

Aos amigos Fábio Yamada e Sônia, pela acolhida inicial na cidade de São Carlos!

Aos amigos de Pós Graduação do SHS, pelo convívio saudável que deixará saudades.

Ao Vitor Tosetto, pela presença e força para finalização do trabalho! 



\section{RESUMO}

SANTOS, C. T. Influência do Tamanho Molecular Aparente de Substâncias Húmicas Aquáticas na Eficiência da Coagulação por Hidroxicloreto de Alumínio. 2009. 109 p. Dissertação de Mestrado. Escola de Engenharia de São Carlos, Universidade de São Paulo, São Carlos, 2009.

Estações de tratamento de água que tratam águas com cor elevada, causada pela presença de substâncias húmicas, e baixa turbidez têm apresentado problemas operacionais, principalmente na coagulação. As substâncias húmicas aquáticas (SHA) apresentam moléculas de massa molecular variada, grande parte entre $500 \mathrm{Da}$ e $10 \mathrm{kDa}$. Por esse motivo, as condições de coagulação (tipo e dosagem de coagulante e pH de coagulação) podem ser totalmente distintas no tratamento de águas com a mesma coloração, devido à presença de SHA com propriedades estruturais diferentes, conforme já observado em pesquisas recentes. Neste contexto, o presente trabalho estudou a influência do tamanho molecular aparente das SHA na coagulação por hidroxicloreto de alumínio e fez a comparação dos custos entre este coagulante e dois estudados anteriormente - sulfato de alumínio e cloreto férrico - para mesma eficiência de remoção de cor. Para isso, realizaram-se ensaios de coagulação seguida de filtração em jarteste com quatro águas de estudo preparadas com frações de diferentes tamanhos moleculares aparentes de SHA, com cor verdadeira de $100 \mathrm{uH}$ e turbidez de 5,0 uT. A partir dos resultados encontrados, pode-se afirmar que há influência do tamanho molecular aparente de diferentes frações de substâncias húmicas aquáticas na coagulação por hidroxicloreto de alumínio. Observou-se a tendência de maior consumo de coagulante para a coagulação de frações de SHA de menores tamanhos moleculares aparentes, em uma faixa determinada de $\mathrm{pH}$. Em relação aos custos, o cloreto férrico foi o coagulante que apresentou menor valor para tratamento (por filtração direta) de águas com elevada cor aparente devida a presença de SHA.

Palavras-chave: substâncias húmicas aquáticas, tamanho molecular aparente, coagulação, remoção de cor, hidroxicloreto de alumínio. 



\begin{abstract}
SANTOS, C. T. Influence of Apparent Molecular Size from Aquatic Humic Substances in the Efficiency of Coagulation by Aluminum Hydroxychloride. 2009. 109 p. Master of Sciences Degree Thesis. São Carlos School of Engineering, University of São Paulo, São Carlos, 2009.
\end{abstract}

The water treatment plants that treat waters with high brown color caused by the presence of humic substances, and low turbidity have been presenting operational problems, mostly in the coagulation. The aquatic humic substances (AHS) present molecules of different molecular mass, most part between $500 \mathrm{Da}$ and $10 \mathrm{kDa}$. Therefore, the coagulation terms (coagulant type and dosage and coagulation $\mathrm{pH}$ ) can be totally distinct in waters treatment with the same coloration, due to the presence of AHS with different structural properties, as already observed in recent researches. In this context, the present work presented the influence of AHS's apparent molecular size in the coagulation for aluminum hydroxychloride and did the costs comparison between this coagulant and two studied previously - aluminum sulfate and ferric chloride - for same efficiency of the color removal. For that, it accomplished coagulation rehearsals followed by filtration in jar-test with four waters of study prepared with fractions of different AHS's apparent molecular sizes, with true color of $100 \mathrm{uH}$ and turbidity of $5.0 \mathrm{uT}$. From the found results, it can affirm that there is influence of the apparent molecular size of different fractions from aquatic humic substances in the coagulation for aluminum hydroxychloride. The larger coagulant consumption tendency was observed for the AHS's fractions coagulation of smaller apparent molecular sizes, in a range determined by $\mathrm{pH}$. Regarding the costs, the ferric chloride was the coagulant that presented smaller value for treatment (for direct filtration) of waters with high brown apparent color due the presence of AHS.

Keywords: aquatic humic substances, apparent molecular size, coagulation, color removal, aluminum hidroxychloride. 



\section{LISTA DE FIGURAS}

Figura 3.1: Principais vias propostas para a formação das substâncias húmicas no solo.... 34

Figura 3.3: Configuração de Sistemas de Filtração Direta.................................................. 42

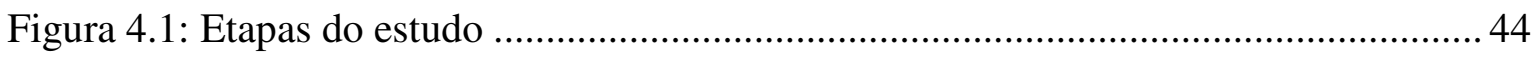

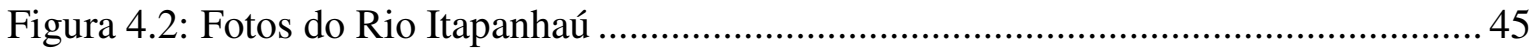

Figura 4.3: Esquema de Fracionamento de MOD, adaptado de Wei et al. (2008).............. 46

Figura 4.4: Extrator Soxhlet (a) e Rotaevaporador (b) usados ......................................... 47

Figura 4.5: Caracterização da MON.......................................................................... 48

Figura 4.6: Procedimento de Extração das Substâncias Húmicas Aquáticas ....................... 49

Figura 4.7: Coloração da Água do Rio (esquerda) e do Extrato (direita) ............................. 50

Figura 4.8: Filtração do Extrato em membrana de 0,45 4 m.................................................... 51

Figura 4.9: Sistema de Ultrafiltração por Membranas ......................................................... 51

Figura 4.10: Procedimento de Ultrafiltração ...................................................................... 52

Figura 4.11: Extratos de SHA Obtidos por Ultrafiltração.................................................. 53

Figura 4.12: Equipamento de Jarteste e filtros de laboratório usados ..................................54

Figura 5.1: Quantificação das frações da MOD do Rio Itapanhaú......................................... 62

Figura 5.2: Diagrama de Coagulação da Água de Estudo 1 - Fração de SHA menor que

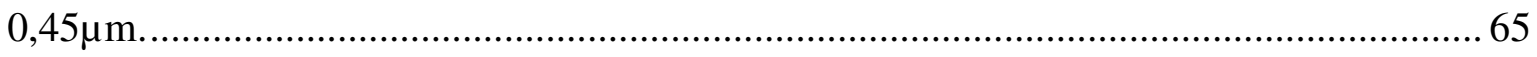

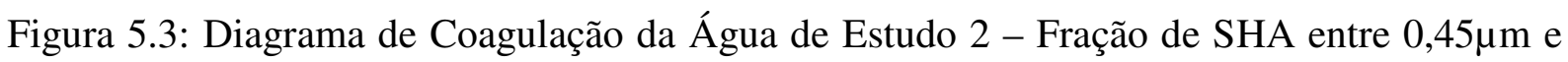
$100 \mathrm{kDa}$ 66

Figura 5.4: Diagrama de Coagulação da Água de Estudo 3 - Fração de SHA entre 100 kDa e $30 \mathrm{kDa}$.

Figura 5.5: Diagrama de Coagulação da Água de Estudo 4 - Fração de SHA menor que 30 kDa 68

Figura 5.6: Pontos obtidos, com cor aparente final indicada, para Água de Estudo 1........ 71

Figura 5.7: Pontos obtidos, com cor aparente final indicada, para Água de Estudo 2....... 72

Figura 5.8: Pontos obtidos, com cor aparente final indicada, para Água de Estudo 3........ 73

Figura 5.9: Pontos obtidos, com cor aparente final indicada, para Água de Estudo 4........ 74

Figura 5.10: Pontos escolhidos para análise de custos - Água de Estudo 1. ....................... 76

Figura 5.11: Pontos escolhidos para análise de custos - Água de Estudo 2. ....................... 77

Figura 5.12: Pontos escolhidos para análise de custos - Água de Estudo 3 ....................... 78

Figura 5.13: Pontos escolhidos para análise de custos - Água de Estudo 4 ....................... 79 

Figura A. 1: Etapas do Procedimento de Limpeza das Resinas ......................................... 90 



\section{LISTA DE TABELAS}

Tabela 4.1: Águas de Estudo e Frações de SHA ................................................................. 53

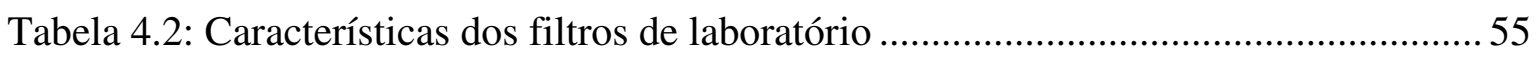

Tabela 4.3: Métodos analíticos e equipamentos usados na caracterização das águas .......... 58

Tabela 4.4: Métodos analíticos e equipamentos .................................................................5

Tabela 5.1: Caracterização físico-química da água do Rio Itapanhaú .................................. 60

Tabela 5.2: Caracterização das Águas de Estudo Preparadas .............................................. 62

Tabela 5.3: Custos com produtos químicos para tratamento da Água de Estudo 1 ............ 80

Tabela 5.4: Custos com produtos químicos para tratamento da Água de Estudo 2 ............. 81

Tabela 5.5: Custos com produtos químicos para tratamento da Água de Estudo 3 ............. 81

Tabela 5.6: Custos com produtos químicos para tratamento da Água de Estudo 4 ............. 82

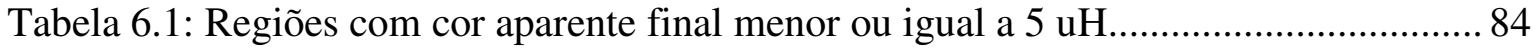

Tabela B. 1: Ensaio 1 para Água de Estudo 1...................................................................... 92

Tabela B. 2: Ensaio 2 para Água de Estudo 1................................................................... 92

Tabela B. 3Ensaio 3 para Água de Estudo 1. ….............................................................. 92

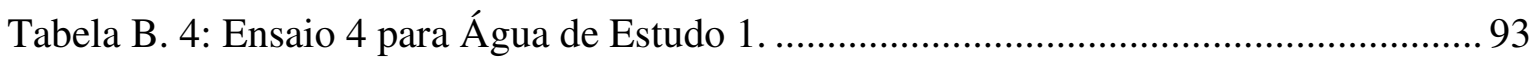

Tabela B. 5: Ensaio 5 para Água de Estudo 1................................................................ 93

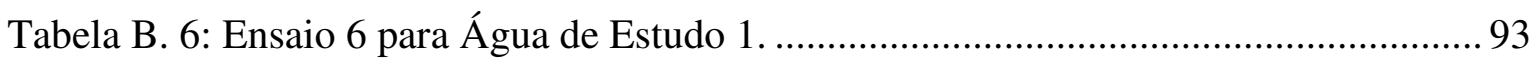

Tabela B. 7: Ensaio 7 para Água de Estudo 1................................................................... 93

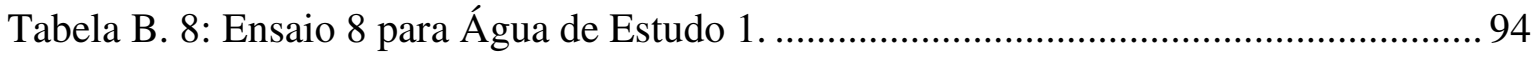

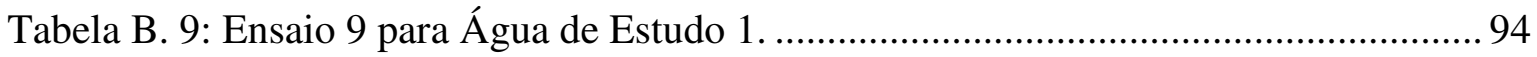

Tabela B. 10: Ensaio 10 para Água de Estudo 1............................................................... 94

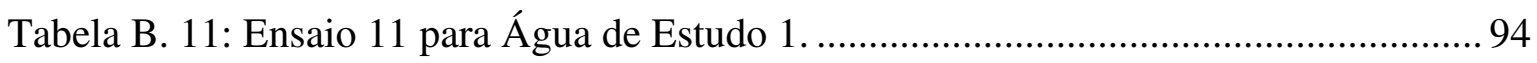

Tabela B. 12: Ensaio 6 para Água de Estudo 1................................................................ 95

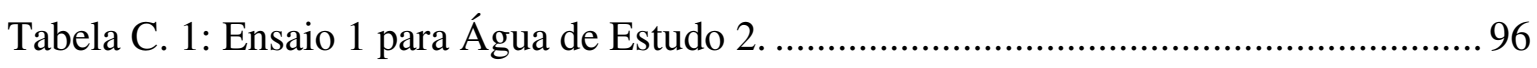

Tabela C. 2: Ensaio 2 para Água de Estudo 2 ................................................................ 96

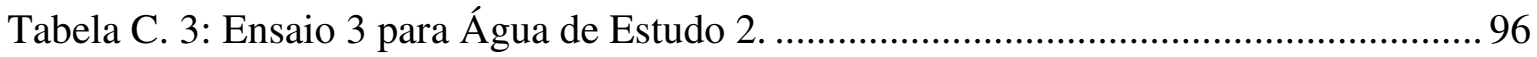

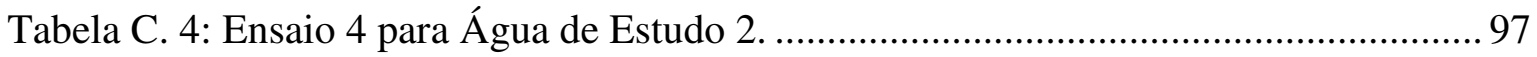

Tabela C. 5: Ensaio 5 para Água de Estudo 2 ….............................................................. 97

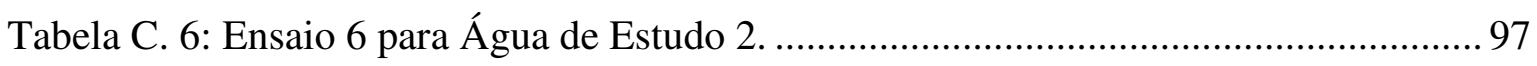

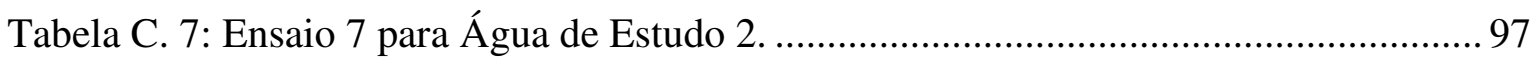

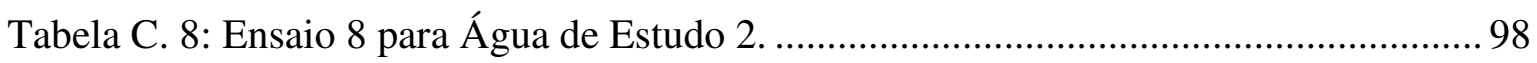



Tabela C. 9: Ensaio 9 para Água de Estudo 2. ............................................................. 98

Tabela C. 10: Ensaio 10 para Água de Estudo 2 ............................................................... 98

Tabela C. 11: Ensaio 11 para Água de Estudo 2 ............................................................ 98

Tabela C. 12: Ensaio 12 para Água de Estudo 2 ............................................................. 99

Tabela C. 13: Ensaio 13 para Água de Estudo 2. ........................................................... 99

Tabela C. 14: Ensaio 14 para Água de Estudo 2 .............................................................. 99

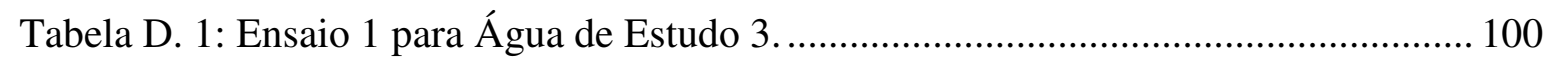

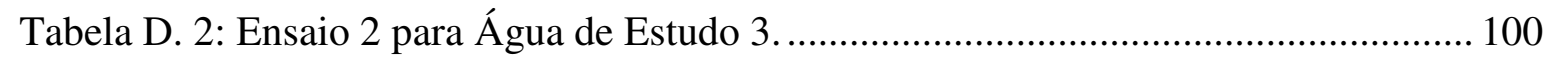

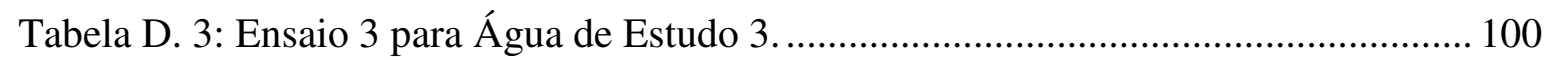

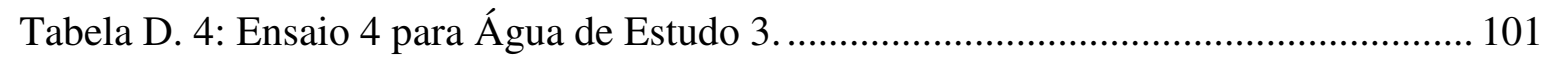

Tabela D. 5: Ensaio 5 para Água de Estudo 3 ............................................................ 101

Tabela D. 6: Ensaio 6 para Água de Estudo 3 .................................................................. 101

Tabela D. 7: Ensaio 7 para Água de Estudo 3 ................................................................... 101

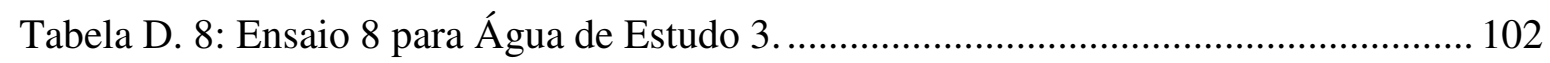

Tabela D. 9: Ensaio 9 para Água de Estudo 3 .................................................................... 102

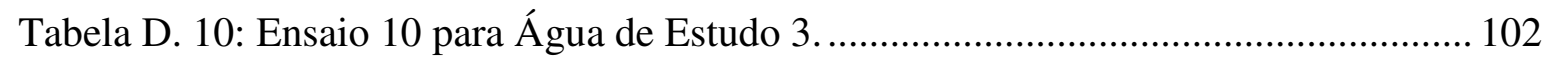

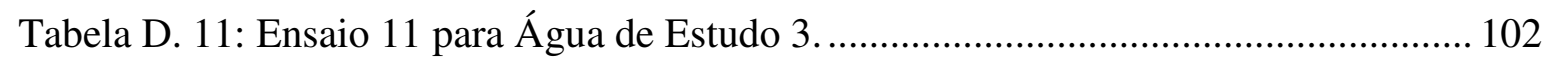

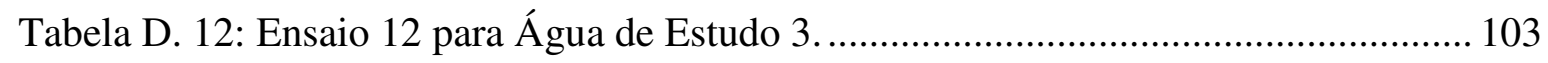

Tabela E. 1: Ensaio 1 para Água de Estudo 4. .................................................................... 104

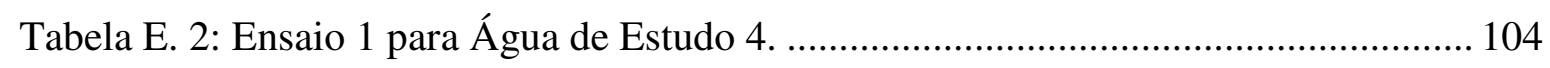

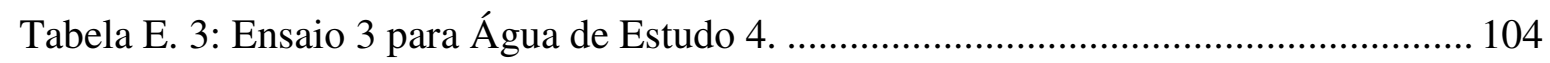

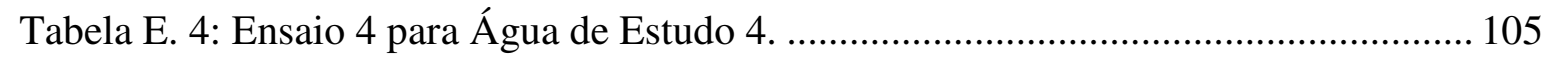

Tabela E. 5: Ensaio 5 para Água de Estudo 4. ............................................................. 105

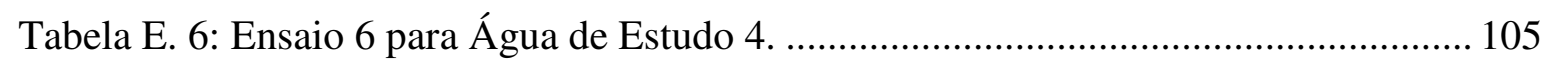

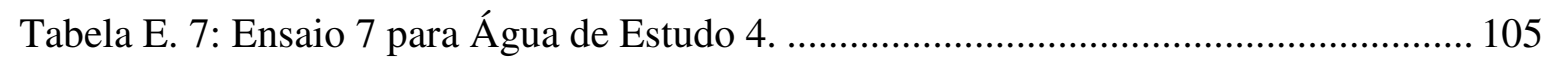

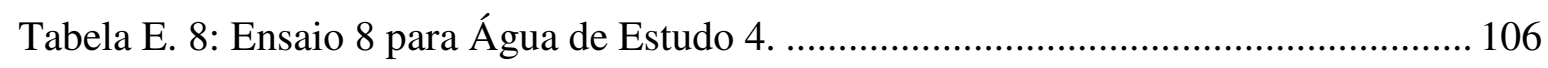

Tabela E. 9: Ensaio 9 para Água de Estudo 4. .................................................................. 106

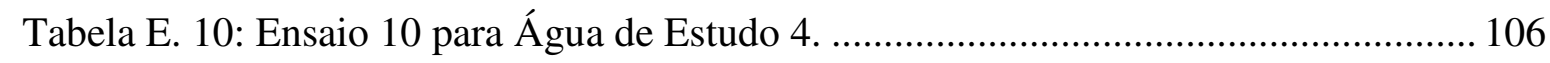

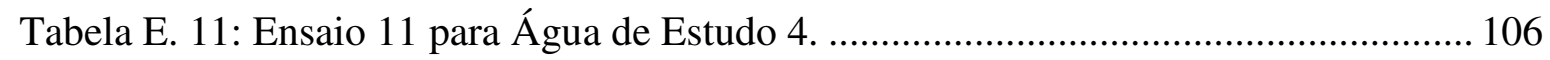

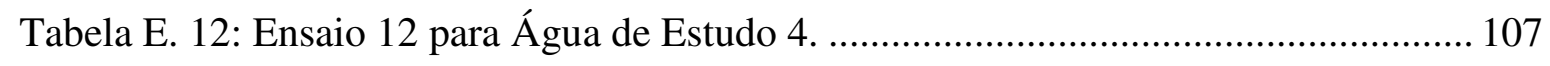

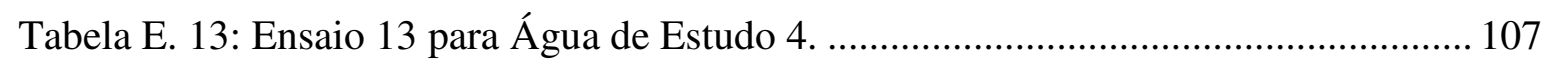

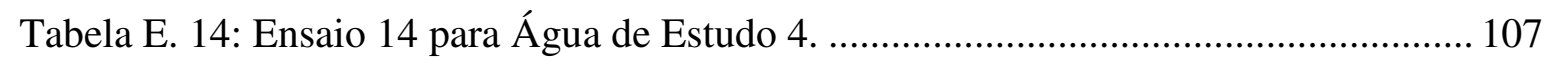

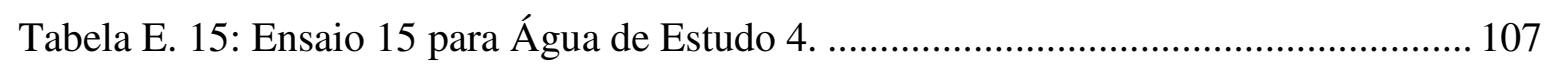



Tabela E. 16: Ensaio 16 para Água de Estudo 4.

108

Tabela E. 17: Ensaio 17 para Água de Estudo 4. 108

Tabela E. 18: Ensaio 18 para Água de Estudo 4. 108 



\section{LISTA DE ABREVIATURAS E SIGLAS}

$\begin{array}{ll}\text { AF } & \text { Ácido Fúlvico } \\ \text { COD } & \text { Carbono Orgânico Dissolvido } \\ \text { COT } & \text { Carbono Orgânico Total } \\ \text { EESC } & \text { Escola de Engenharia de São Carlos } \\ \text { ETA } & \text { Estação de Tratamento de Água } \\ \text { HPI } & \text { Hidrofílica } \\ \text { HPO } & \text { Hidrofóbica } \\ \text { HPOA } & \text { Hidrofóbica Ácida } \\ \text { HPON } & \text { Hidrofóbica Neutra } \\ \text { IHSS } & \text { International Humic Substance Society } \\ \text { MOD } & \text { Matéria Orgânica Dissolvida } \\ \text { MON } & \text { Matéria Orgânica Natural } \\ \text { SH } & \text { Substância Húmica } \\ \text { SHA } & \text { Substância Húmica Aquática } \\ \text { TPH } & \text { Transfílica } \\ \text { TPHA } & \text { Transfílica Ácida } \\ \text { TPHN } & \text { Transfílica Neutra } \\ \text { UNESP } & \text { Universidade Estadual Paulista “Júlio de Mesquita Filho” } \\ \text { USP } & \text { Universidade de São Paulo } \\ \text { UV } & \text { Ultravioleta } \\ \end{array}$





\section{LISTA DE SÍMBOLOS}

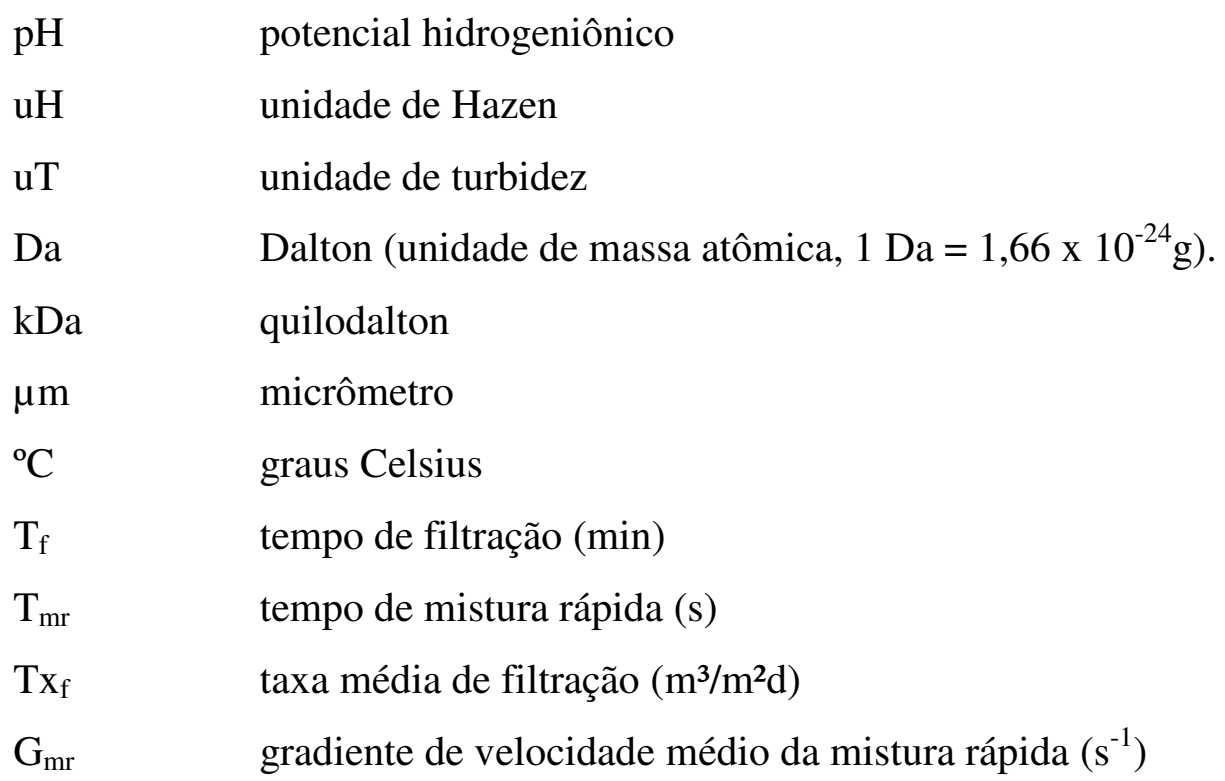





\section{SUMÁRIO}

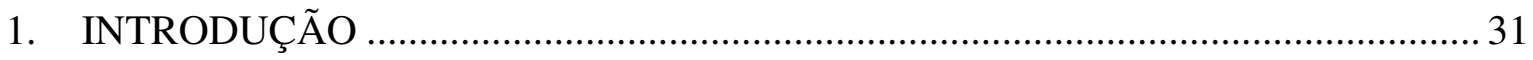

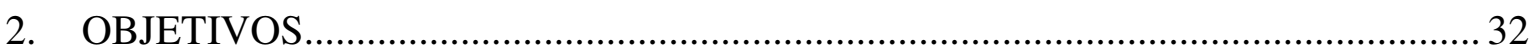

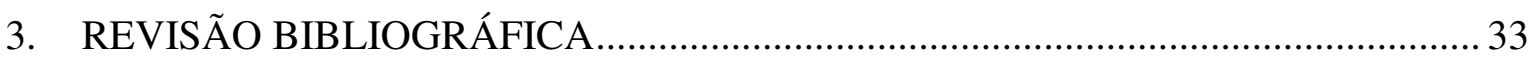

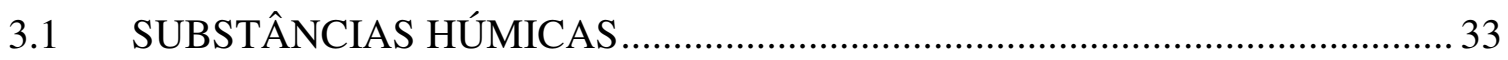

3.2 FRACIONAMENTO DE MATÉRIA ORGÂNICA DISSOLVIDA POR XAD-

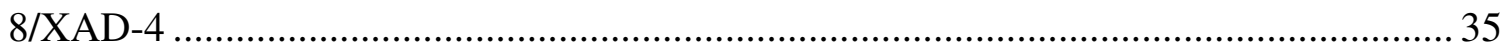

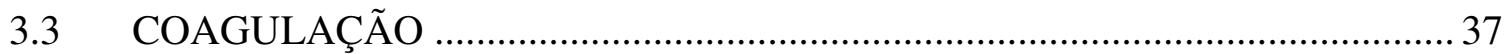

3.4 REMOÇÃO DE SUBSTÂNCIAS HÚMICAS POR COAGULAÇÃO................ 38

3.5 TAMANHO MOLECULAR APARENTE DAS SH E REMOÇÃO POR

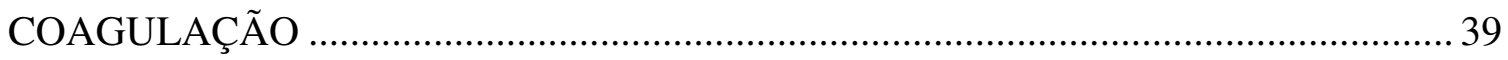

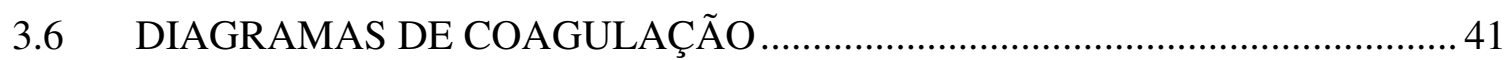

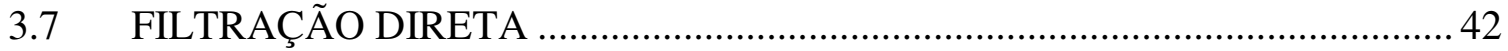

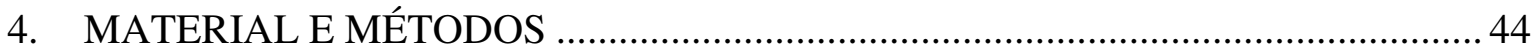

4.1 COLETA E CARACTERIZAÇÃO DA ÁGUA BRUTA ....................................... 44

4.2 EXTRAÇÃO DAS SUBSTÂNCIAS HÚMICAS AQUÁTICAS E DIÁLISE.... 48

4.3 FRACIONAMENTO DAS SUBSTÂNCIAS HÚMICAS AQUÁTICAS ............ 50

4.4 PREPARO E CARACTERIZAÇÃO DAS ÁGUAS DE ESTUDO.......................53

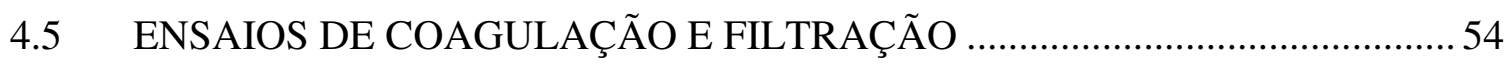

4.6 REPRODUÇÃO DAS CONDIÇÕES DE COAGULAÇÃO DE SLOBODA

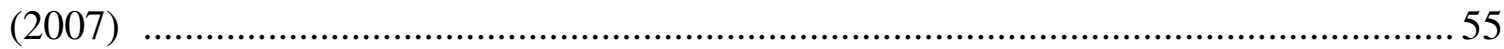

4.7 COMPARAÇÃO DE CUSTOS DOS COAGULANTES …................................ 55

4.8 EQUIPAMENTOS, PRODUTOS QUÍMICOS E MÉTODOS ANALÍTICOS... 56

5. RESULTADOS E DISCUSSÃO 60

5.1 CARACTERIZAÇÃO DA ÁGUA BRUTA E DA MATÉRIA ORGÂNICA DISSOLVIDA 60

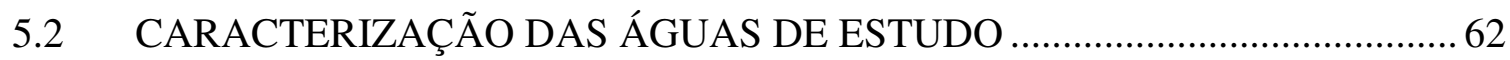

5.3 ENSAIOS DE COAGULAÇÃO E FILTRAÇÃO ............................................... 64

5.4 REPRODUÇÃO DAS CONDIÇÕES DE COAGULAÇÃO DE SLOBODA

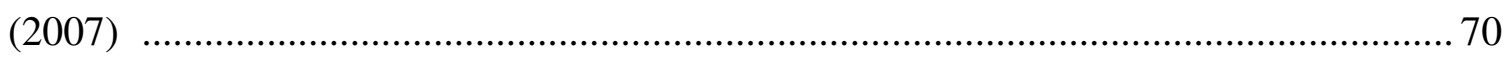

5.5 COMPARAÇÃO DE CUSTOS DOS COAGULANTES …................................. 75

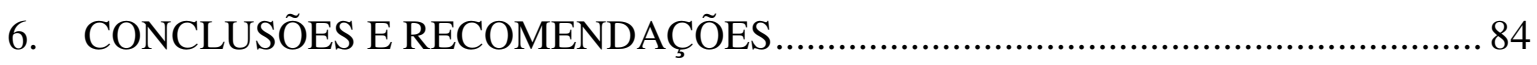





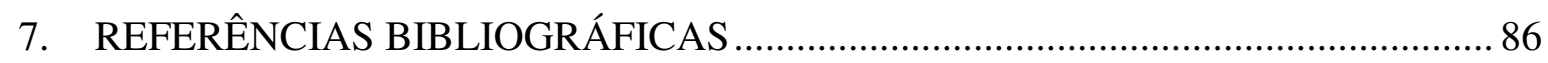

APÊNDICE A - Limpeza inicial das resinas XAD-4 e XAD-8 ….................................... 90

APÊNDICE B - Resultados dos ensaios de coagulação e filtração para construção dos diagramas da Água de Estudo 1. 92

APÊNDICE C - Resultados dos ensaios de coagulação e filtração para construção dos diagramas da Água de Estudo 2. 96

APÊNDICE D - Resultados dos ensaios de coagulação e filtração para construção dos diagramas da Água de Estudo 3. 100

APÊNDICE E - Resultados dos ensaios de coagulação e filtração para construção dos diagramas da Água de Estudo 4. 



\section{INTRODUÇÃO}

As substâncias húmicas ( $\mathrm{SH}$ ) são uma mistura complexa de compostos orgânicos naturais derivados da decomposição de restos vegetais e animais e das reações de síntese de microrganismos. Elas conferem à água uma coloração castanha, quando presentes em grandes concentrações.

Muitos mananciais usados como fonte de abastecimento apresentam elevada cor, devido à presença de SH, e baixa turbidez. Estações de Tratamento de Água que recebem águas dessas fontes têm apresentado problemas operacionais relacionados, principalmente, à coagulação e também pela tecnologia de tratamento não ser adequada à qualidade. Uma remoção ineficiente das $\mathrm{SH}$ pode ocasionar diversos problemas. O mais preocupante é relativo à saúde pública, uma vez que as $\mathrm{SH}$ podem reagir com os desinfetantes produzindo compostos que podem ser tóxicos e potencialmente cancerígenos.

As substâncias húmicas aquáticas (SHA) têm tamanho molecular aparente variado. Isso contribui para tornar diferentes as condições de coagulação no tratamento de águas com a mesma coloração devido à presença de SHA.

Sloboda (2007) estudou a influência do tamanho molecular aparente das SHA na eficiência da coagulação com sulfato de alumínio e cloreto férrico. E percebeu que, assim como ocorre com SH provenientes de turfa (Campos, 2004); a quantidade de coagulante gasta para atingir os melhores resultados de remoção de cor é maior quanto menor o tamanho molecular aparente das $\mathrm{SH}$.

Neste trabalho, estudou-se a influência do tamanho molecular aparente das SHA na coagulação por hidroxicloreto de alumínio e compararam-se os custos entre este coagulante e dois estudados anteriormente - sulfato de alumínio e cloreto férrico - para a mesma eficiência de remoção de cor devida à presença de SHA. 


\section{OBJETIVOS}

Os objetivos deste trabalho foram:

- Verificar a influência do tamanho molecular aparente de diferentes frações de substâncias húmicas aquáticas na coagulação por hidroxicloreto de alumínio;

- Obter, por meio de diagramas de coagulação, as regiões de maior eficiência de remoção de cor para águas de estudo, preparadas a partir de diferentes frações de substâncias húmicas aquáticas, com cor de 100 uH;

- Avaliar os custos para o tratamento das águas de estudo, nas regiões de melhor eficiência de remoção de cor no diagrama de coagulação, dos diferentes coagulantes: sulfato de alumínio; cloreto férrico e hidroxicloreto de alumínio. 


\section{REVISÃO BIBLIOGRÁFICA}

\subsection{SUBSTÂNCIAS HÚMICAS}

A matéria orgânica natural (MON) é composta por substâncias que podem ser agrupados como: substâncias não-húmicas - aquelas com características químicas definidas, tais como carboidratos, proteínas, lipídeos, aminoácidos e ácidos orgânicos de baixo peso molecular; e substâncias húmicas $(\mathrm{SH})$, classificadas como substâncias orgânicas biogênicas, polieletrolíticas com propriedades similares à de biocolóides, de coloração escura, de natureza heterogênea, elevada massa molecular, estrutura complexa e indefinida. (STEVENSON, 1982).

As substâncias húmicas são também citadas por Edzwald (1987) como macromoléculas ácidas, amorfas, predominantemente aromáticas e quimicamente complexas, consistindo em uma mistura complexa de compostos orgânicos naturais. São os principais componentes da MON no solo, em sedimentos e na água. Essas substâncias formam-se por reações químicas e bioquímicas de degradação e transformação de restos de plantas e animais e pela atividade de síntese de microorganismos. O principal processo é a oxidação de substratos hidrolisados monoméricos, para conduzir a polímeros macromoleculares de cor mais ou menos escura e massa molecular elevada (ROCHA; ROSA, 2003).

As quatro vias de formação das $\mathrm{SH}$, mostradas na Figura 3.1, podem ocorrer simultaneamente no solo, porém não com a mesma extensão e importância. O mecanismo 1, teoria de Maillard em 1916 apud Malcolm (1990), propõe a formação do húmus a partir da polimerização não enzimática por condensação entre aminoácidos e açúcares formados como subprodutos da atividade microbiana. Os mecanismos 2 e 3 envolvem a participação de quinonas e, no mecanismo 4, as substâncias húmicas seriam derivadas de ligninas modificadas. Na década de 20 acreditava-se que as SH seriam derivadas essencialmente de ligninas modificadas. Os mecanismos adaptados por Stevenson (1994) da condensação polimérica de polifenóis e quinonas têm sido os mais aceitos por pesquisadores e pela Sociedade Internacional de Substâncias Húmicas (IHSS). 


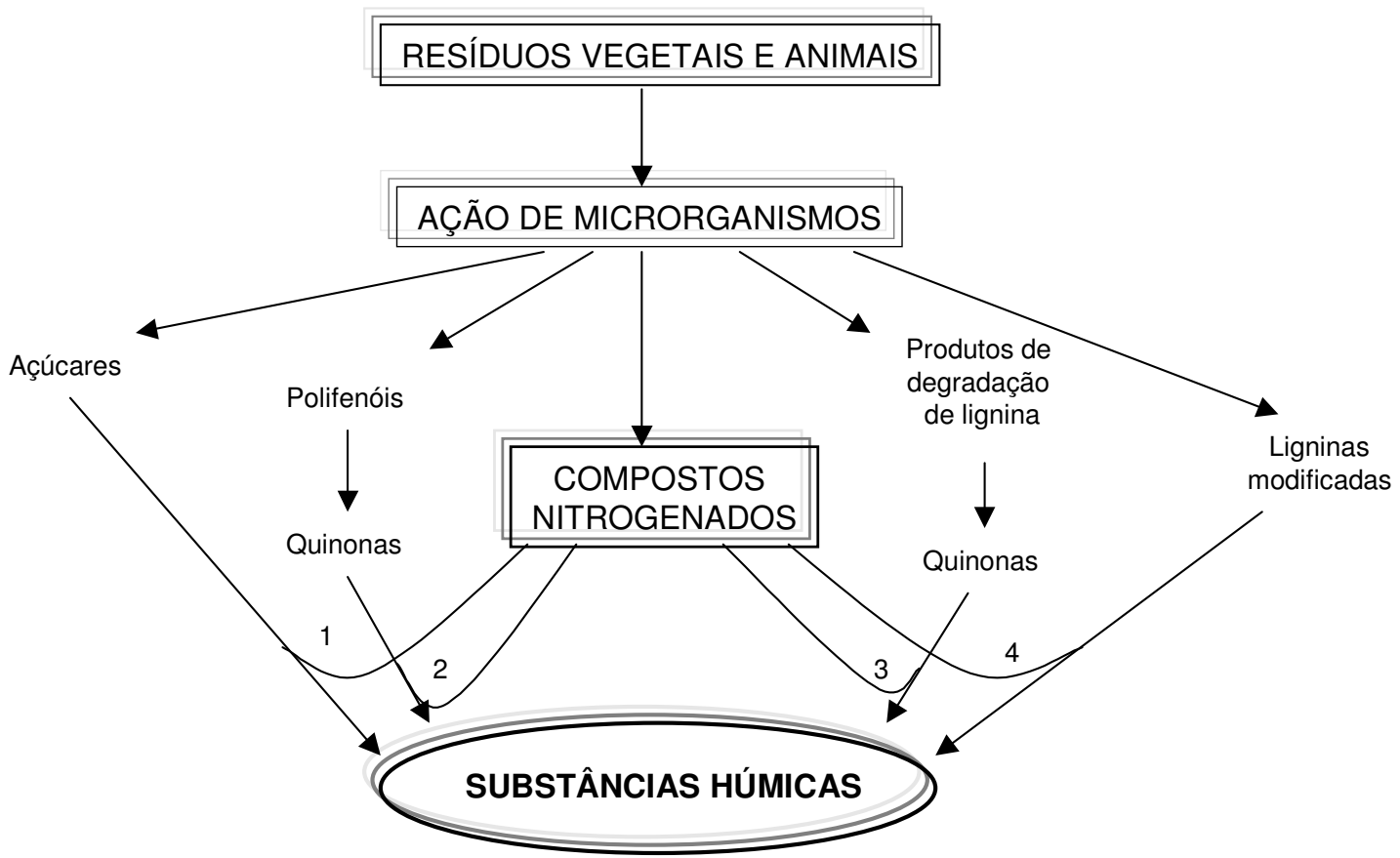

Figura 3.1: Principais vias propostas para a formação das substâncias húmicas no solo.

Fonte: Rocha; Rosa, 2003.

As principais dificuldades para definição da estrutura química e reatividade das SH derivam de sua grande heterogeneicidade química e variabilidade geográfica. A grande complexidade química das moléculas é também função das diferentes propriedades dos ecossistemas em que elas são formadas, como vegetação, clima, topografia etc. Assim, há décadas pesquisadores têm despendidos esforços na busca de modelos que descrevam a estrutura dessas substâncias. O modelo proposto por Piccolo (2001) é chamado de supramolecular. Essa teoria pode ser interpretada como sendo as $\mathrm{SH}$ formadas por pequenas e heterogêneas moléculas de várias origens, auto-organizadas em conformações supramoleculares, o que explicaria o grande tamanho molecular aparente das SH. De acordo com esse modelo, os AF seriam formados por pequenas moléculas hidrofílicas que permaneceriam dispersas em solução pela repulsão das cargas negativas originadas da dissociação da grande quantidade de grupos ácidos presentes na sua estrutura. As micelas de $\mathrm{AH}$, por outro lado, são constituídas por associações de estruturas predominantemente hidrofóbicas, e são estabilizados por ligações fracas, tais como ligações de hidrogênio e/ou interações hidrofóbicas. Estes por apresentarem menor quantidade de grupos funcionais ácidos, poderiam aproximar-se o suficiente para formar agregados de elevada massa molecular, aumentando gradualmente seu tamanho com o decréscimo do $\mathrm{pH}$, até a sua precipitação. 
As SH são componentes muito importantes no solo, modificam as propriedades físicas e químicas e melhoram sua fertilidade. Em sistemas terrestres e aquáticos as $\mathrm{SH}$ afetam a química, o ciclo e a biodisponibilidade de elementos assim como o transporte e a degradação dos compostos orgânicos xenobióticos e naturais. Sargentini Jr et al. (2001) observaram que, em águas com elevada concentração de matéria orgânica, as SH reduzem a disponibilidade de íons metálicos.

Quando presentes em altas concentrações, as SH são responsáveis pela coloração castanha natural de corpos d'água. A cor pode variar de um castanho claro amarelado ao preto, dependendo do estágio de decomposição do material, da composição e da concentração (IHSS, 2007). A cor observada é devida à absorbância da luz por essas substâncias (EDZWALD, 1987).

De acordo com a Sociedade Internacional de Substâncias Húmicas, as substâncias húmicas aquáticas (SHA) são compostas por ácidos húmicos e ácidos fúlvicos; enquanto as SH do solo apresentam, além desses dois ácidos, humina em sua composição.

Quando as SHA não são removidas eficientemente durante o tratamento da água, elas podem causar vários problemas como: servir de substrato para crescimento de microrganismos; reduzir a eficiência do processo de desinfecção; formar complexos com metais, dificultando a remoção desses; causar corrosão em tubulações; entre outros. Um dos mais preocupantes problemas é a produção de substâncias de sabor e odor desagradáveis, algumas das quais são tóxicas e potencialmente cancerígenas, quando é utilizada a préoxidação com cloro livre (DI BERNARDO; DANTAS, 2005).

\subsection{FRACIONAMENTO DE MATÉRIA ORGÂNICA DISSOLVIDA POR XAD-8/XAD-4}

A matéria orgânica dissolvida (MOD) é definida como a fração da matéria orgânica natural que passa pela membrana $0,45 \mu \mathrm{m}$. Essa parcela é a de maior interesse no tratamento de água, uma vez que a matéria orgânica particulada é facilmente removida por processos convencionais, incluindo a coagulação e filtração (EDZWALD, 1993).

O fracionamento da MOD por resinas XAD baseia-se nas diferentes capacidades de sorção das resinas sob condições ácidas ou básicas. Esse tipo de fracionamento separa a MOD 
em três grandes frações definidas operacionalmente como: hidrofóbica, transfílica e hidrofílica e é considerado um fracionamento químico.

$\mathrm{Na}$ década de 70, vários adsorventes inorgânicos foram utilizados para extração das SHA, tais como: carbono ativado, alumina, sílica gel, carbonato de cálcio etc. Porém, a taxa de recuperação é baixa devido à dificuldade de eluição e possíveis alterações químicas das SH. O uso de adsorventes orgânicos como, nylon, poliamidas e poliestirenos têm-se mostrado mais eficientes, com altas taxas de recuperação, porém podem causar algumas alterações químicas na amostra. As resinas a base de estireno de polivinilbenzeno (XAD-1, XAD-2 e XAD-4), apresentam menor facilidade de eluição das substâncias húmicas que as resinas a base de éster acrílico (XAD-7 e XAD-8). Essas são as mais hidrofílicas da série e têm maior capacidade adsorvente. As resinas XAD-1 e XAD-2 são mais utilizadas na extração de SH presentes em águas marinhas. As resinas macroporosas de éster acrílico XAD-7 e XAD-8 são mais utilizadas para a extração de SH de águas superficiais. Essas resinas apresentam área superficial elevada e em geral, a adsorção dos ácidos orgânicos é determinada pela solubilidade do soluto, $\mathrm{pH}$ da solução e a hidrofobicidade. Em baixos valores de pH os ácidos fracos são protonados e adsorvidos na resina; em $\mathrm{pH}$ elevados, os ácidos são ionizados e a desorção é favorecida. (AIKEN, 1988).

O método referenciado mundialmente para isolamento das $\mathrm{SH}$ por XAD-8 foi proposto pelo grupo de pesquisa do United States Geological Survey (THURMAN; MALCOLM, 1981). Desde então, vários pesquisadores aperfeiçoaram e testaram este método para melhorar a eficiência de recuperação e pureza da MOD, com uso das resinas XAD-8 e XAD-4 (MALCOLM; MACCARTHY, 1992; CROUÉ et al., 1999; CHANG et al., 2000; GOSLAN et al., 2002; WEI et al., 2008). A fração hidrofóbica da MOD ou fração húmica (HPO) é a parcela que é sorvida na resina XAD-8 em pH 2,0; a parcela que não é retida é denominada de fração não-húmica. A fração não-húmica pode ser fracionada em transfílica (TPH) e hidrofílica (HPI) utilizando-se a resina XAD-4. A TPH é a parcela da MOD adsorvida pela XAD-4 em pH 2,0 e a HPI é a parcela da MOD que não é adsorvida por ambas as resinas - XAD-8 e XAD-4 - em pH 2,0. Adicionalmente, as duas frações sorvidas nas XAD-8 e XAD-4 podem ser fracionadas em ácidas e neutras com o uso de diferentes solventes.

Segundo Croué et al. (1999), os ácidos hidrofóbicos (ácidos húmico e fúlvico HPOA) e os ácidos transfílicos (TPHA) representam de 50 a 90\% da MOD nas águas, enquanto que a parcela hidrofílica (HPI) representa de 20 a 30\%. Entretanto, os resultados 
apresentados por Chow et at. (2005), mostraram que a fonte da MOD das águas é o principal fator que determinará a composição da MOD nas diversas frações e que essa composição varia durante o ano. De acordo com algumas pesquisas relatadas pelos autores, em águas de rios com MOD derivada de plantas terrestres - característica observada em rios com elevada cor localizados em áreas preservadas - grande parte (cerca de $80 \%$ ) da MOD é composta pela fração HPO. Já em águas em que a MOD é derivada prioritariamente da biota aquática algas, bactérias e macrófitas - há baixa concentração de HPO (de 15\% a 30\%).

Cada sistema aquático pode ter múltiplas fontes de MOD. Variações na distribuição das frações de MOD têm sido associadas a mudanças sazonais (SHARP et al. 2006) e a fatores ambientais, que vão desde ocorrências de tempestades a foto e biodegradação da MOD (CHOW et al. 2005).

\subsection{COAGULAÇÃO}

As águas naturais podem conter uma infinidade de impurezas que precisam ser removidas durante o tratamento da água. Essas impurezas são compostas por partículas coloidais, substâncias húmicas, microrganismos e apresentam carga superficial negativa, o que impede que elas se aproximem. Assim, se nenhuma característica da água ou das próprias partículas for alterada, estas permanecerão em suspensão na água. Durante o tratamento da água, na maioria das tecnologias aplicadas atualmente; a coagulação é usada para desestabilizar as cargas negativas das partículas, fazendo com que as partículas se atraiam e formem flocos, tornando-as passíveis de remoção por sedimentação ou filtração.

A coagulação é uma importante etapa do tratamento de água, determina a qualidade final da água tratada. Se não for feita adequadamente, as impurezas não se tornarão partículas desestabilizadas capazes de serem retidas nos filtros, em sistemas de filtração direta; nem, tampouco, flocos capazes de serem removidos por sedimentação ou flotação seguida de filtração, nos de ciclo completo.

A remoção de impurezas da água bruta em estações que empregam a coagulação química em geral é feita utilizando-se sais de ferro ou de alumínio como coagulante primário e, eventualmente, polímeros. Na literatura são citados quatro mecanismos de coagulação: compressão da camada difusa, adsorção e neutralização de cargas, varredura, adsorção e formação de pontes. A definição do mecanismo predominante depende de fatores como $\mathrm{pH}$ de coagulação, dosagem do coagulante e características químicas da água bruta. Para tecnologia 
de filtração direta, o mecanismo de coagulação mais importante é o de neutralização e adsorção de cargas, pois não há necessidade de formação de flocos, somente de partículas desestabilizadas que serão retidas no meio filtrante (DI BERNARDO; DANTAS, 2005).

A coagulação depende das características da água e das impurezas nela contidas. As características da água a ser tratada são de fundamental importância para se determinar a tecnologia de tratamento e os produtos químicos a serem empregados para que se tenha maior eficiência e economia no tratamento da água. A escolha do tipo de coagulante deve levar em consideração o custo, sua eficiência na desestabilização das partículas presentes na água bruta, sua capacidade de atenuar flutuações na qualidade da água sem afetar a eficiência da coagulação, o volume de lodo produzido e sua influência sobre a duração das carreiras de filtração, sendo desejado que o coagulante reduza a perda de carga na unidade de filtração e o risco de ocorrência de transpasse (DI BERNARDO, 2003).

\subsection{REMOÇÃo DE SUBSTÂNCIAS HÚMICAS POR COAGULAÇÃo}

Dois mecanismos principais têm sido considerados na coagulação de substâncias húmicas por sulfato de alumínio. Com o pH de coagulação entre 6,0 e 8,0; onde há predomínio do precipitado de alumínio, aconteceria a adsorção do ácido húmico ao precipitado $\mathrm{Al}(\mathrm{OH})_{3(\mathrm{~s})}$. Quando o $\mathrm{pH}$ está na faixa de 4,0 e 5,5; ocorreria a neutralização de cargas dos ácidos húmicos pelas espécies hidrolisadas positivas de alumínio, que também pode ser considerada como precipitação de humato de alumínio (EDWARDS; AMIRTARAJAH, 1985; DI BERNARDO; DANTAS, 2005). Dempsey et al. (1984) relataram que o mecanismo de coagulação para remoção de ácido fúlvico (AF) por sais de alumínio também seria a adsorção do $\mathrm{AF}$ ao precipitado de alumínio $\left(\mathrm{Al}(\mathrm{OH})_{3(\mathrm{~s})}\right)$ em pH superior a 6,25 e a precipitação do AF por espécies hidrolisadas positivas de alumínio em pH abaixo de 6,0 .

Van Benschoten e Edzwald (1990a) definiram a coagulação de AF como a transformação do material dissolvido em sólido separável - um sólido separável é operacionalmente definido baseado na remoção por filtração, mesmo que não seja sedimentável. Os mesmo autores (1990b) estudaram coagulação de AF por sulfato de alumínio e hidroxicloreto de alumínio e concluíram que: a remoção por coagulação de AF em pH 7,0 é mais eficiente que em pH 5,5; mas demanda maiores dosagens de coagulante; e, 
apesar das espécies hidrolisadas dos dois coagulantes serem muito diferentes, a dosagem requerida para remoção de AF é praticamente idêntica.

Pavanelli (2001) comparou a eficiência da coagulação de substâncias húmicas de quatro coagulantes: sulfato de alumínio, cloreto férrico, hidroxicloreto de alumínio e sulfato férrico. O autor realizou ensaios de coagulação e sedimentação com água de estudo contendo ácido húmico e caulinita (cor verdadeira de $100 \mathrm{uH}$ e turbidez de 6,5 uT), construiu diagramas de coagulação com duas velocidades de sedimentação (1 e $2 \mathrm{~cm} / \mathrm{min})$ e comparou os custos dos pontos de melhor eficiência de remoção de cor. O cloreto férrico apresentou menor custo para as duas velocidades de sedimentação estudadas.

Um dos principais problemas práticos na remoção de matéria orgânica natural (MON) de águas com baixa turbidez por tratamento em ciclo completo é a incapacidade de produção de flocos sedimentáveis. A turbidez natural provê núcleos para o desenvolvimento de flocos e estes, uma vez presentes, agem como sítios de adsorção para a MON solúvel. Em águas com baixa turbidez natural, esses núcleos podem ser a cal usada para correção de $\mathrm{pH}$ e alcalinidade; adição de quantidade suficiente de cal pode ajudar a reter algumas partículas de MON (GREGOR et al., 1997). Outra solução é o uso da filtração direta para remoção de MON solúvel, porque não há necessidade de produção de flocos sedimentáveis. A tecnologia de dupla filtração é potencialmente promissora para tratar águas com MON (DI BERNARDO et al., 2004).

Vários corpos d'água usados para captação de água para abastecimento no Brasil (Açude Gavião em Fortaleza; Sistema Pedra do Cavalo em Salvador, Açude Extremoz e Jiqui, em Natal, Rio Negro em Manaus, Represa do Irai em Curitiba, Lago Bolonha em Belém, Lagoa do Peri em Florianópolis, entre outros) apresentam cor elevada, devido à presença de SH, e baixa turbidez. Segundo Dantas et al. (2007), muitas das ETAs que tratam água desses mananciais apresentam problemas operacionais, principalmente na coagulação, por contarem com tecnologias de tratamento inadequadas à qualidade da água.

\subsection{TAMANHO MOLECULAR APARENTE DAS SH E REMOÇÃO POR COAGULAÇÃO}

Thurman et al. (1982) determinaram o tamanho molecular de substâncias húmicas aquáticas (SHA) por método indireto, encontrando massa molecular correspondente, variando, principalmente, de 500 a 10.000 Da (Dalton: unidade de massa atômica, $1 \mathrm{Da}=$ 
$1,66 \times 10^{-24} \mathrm{~g}$ ). Os autores concluíram que ácidos fúlvicos aquáticos contêm substâncias de massa molecular entre 500 e $2.000 \mathrm{Da}$, enquanto os ácidos húmicos aquáticos correspondem a substâncias de massa molecular de 1.000 a mais de 10.000 Da. Os autores também determinaram que compostos de alta massa molecular (> $100 \mathrm{kDa}$ ) respondem por uma pequena fração das SHA, entre 5 e $10 \%$.

Na década de 1990, estações de tratamento de água nos Estados Unidos e no Reino Unido tiveram dificuldades operacionais relacionadas a altos teores de carbono orgânico dissolvido (COD) durante o outono e o inverno. Foi observado aumento na produção de subprodutos da desinfecção e na demanda por coagulantes. Sharp et al. (2006) notaram mudanças na composição da matéria orgânica natural (MON) ao longo de 36 meses, a fração de ácido fúlvico variou de 36\% em Setembro de 2000 para $61 \%$ em Novembro de 2003. Os autores observaram que as frações hidrofóbicas da MON, particularmente a fração de ácidos fúlvicos, foram fatores determinantes no controle da coagulação.

Resultados de Campos, Di Bernardo e Vieira (2005) mostraram que quanto menor o tamanho molecular aparente das substâncias húmicas, maiores foram as quantidades de ácidos fúlvicos; e quanto maior foi a porcentagem de ácidos fúlvicos presente na água de estudo, maior foi a dificuldade de sua remoção de cor. Assim, os autores recomendaram que as condições de coagulação de águas provenientes de fontes diferentes não sejam extrapoladas, mesmo que apresentem valores da mesma ordem de grandeza de cor verdadeira.

A presença de grupos funcionais, maior ou menor concentração de cadeias aromáticas, assim como a grande variação no tamanho molecular e na proporção de ácidos húmicos e fúlvicos podem afetar a eficiência de remoção de SH (VAN BENSCHOTEN; EZWALD, 1990b, CAMPOS et al., 2007, SLOBODA, 2007).

Campos (2004), para a água preparada com a fração de SH de turfa de maior tamanho molecular aparente $(0,45 \mu \mathrm{m}-100 \mathrm{kDa})$, detectou que foi necessária uma dosagem de $20 \mathrm{mg} \mathrm{L}$ ${ }^{1}$ de sulfato de alumínio comercial líquido $\left(7,28 \%\right.$ em massa de $\left.\mathrm{Al}_{2} \mathrm{O}_{3}\right)$ para a obtenção de valores de cor remanescente igual a $20 \mathrm{uH}$; já para a água preparada com a fração de menor massa molecular $(<30 \mathrm{kDa})$ foi utilizada uma dosagem de coagulante igual a $60 \mathrm{mg} \mathrm{L}^{-1}$. Em ambos os casos a água preparada tinha cor verdadeira inicial igual a $100 \mathrm{uH}$ e a leitura final foi realizada após coagulação, floculação e sedimentação.

Sloboda (2007) estudou a influência do tamanho molecular aparente das SHA na eficiência da coagulação com sulfato de alumínio e cloreto férrico. A partir desse trabalho, percebeu-se que, assim como ocorre com SH provenientes de turfa (CAMPOS, 2004); a 
eficiência da coagulação e a quantidade de coagulante gasta para atingir os melhores resultados de remoção de cor variam com o tamanho das moléculas.

No caso de Sloboda (2007), que trabalhou com SHA, para a água preparada com a fração de maior tamanho molecular aparente $(0,45 \mu \mathrm{m}-100 \mathrm{kDa})$ foi necessária dosagem entre 40 e $90 \mathrm{mgL}^{-1}$ de sulfato de alumínio comercial líquido e entre 26,4 e $132 \mathrm{mgL}^{-1}$ de cloreto férrico comercial líquido para a obtenção de valores de cor remanescente menores que $5 \mathrm{uH}$. Para a água preparada com a fração de menor massa molar $(<30 \mathrm{kDa})$ foi utilizada uma dosagem de coagulante superior a $110 \mathrm{mgL}^{-1}$ de sulfato de alumínio e entre 60 e $100 \mathrm{mgL}^{-1}$ de cloreto férrico para atingir a mesma eficiência. As águas de estudo da autora contavam com cor verdadeira inicial de $100 \mathrm{uH}$ e foram submetidas a coagulação e filtração. A partir desses resultados percebe-se que águas com a mesma cor verdadeira, comportaram-se de maneiras diferentes frente à coagulação; isso pode ser explicado devido aos diferentes tamanhos moleculares aparentes das SHA que estavam presentes em cada água de estudo. Quanto menores as substâncias, maiores as dosagens de coagulante necessárias para coagulação tornar- se eficiente.

\subsection{DIAGRAMAS DE COAGULAÇÃO}

Diagramas de coagulação são representações gráficas das condições de coagulação encontradas em ensaios de bancada para tratamento de água. $\mathrm{Na}$ abscissa tem-se o $\mathrm{pH}$ de coagulação - medido logo após a mistura rápida - e nas ordenadas têm-se os valores de dosagem do coagulante usado nos ensaios. Os resultados de cor ou turbidez encontrados são plotados no diagrama - como se fossem as cotas em um mapa topográfico - conforme o par de valores "pH de coagulação x dosagem de coagulante" que levaram a cada resultado. A construção de diagramas é de fundamental importância para conhecimento da água bruta a ser tratada. De acordo com Di Bernardo (2003), em razão da importância da coagulação no desempenho das unidades de filtração, o tipo de coagulante e sua dosagem necessária para promover a desestabilização das partículas devem ser definidos a partir de investigações experimentais, o diagrama de coagulação é ferramenta indispensável.

Segundo Di Bernardo e Dantas (2005), projetistas e operadores de ETAs devem conhecer os fundamentos do diagrama, isso possibilitará a escolha da tecnologia de tratamento mais apropriada e a otimização da coagulação, incorrendo em considerável economia de produtos químicos. 


\subsection{FILTRAÇÃO DIRETA}

As tecnologias de filtração direta são aquelas em que a coagulação se dá prioritariamente pelo mecanismo de adsorção e neutralização de cargas. Após a coagulação, a água segue para os filtros, que podem ser ascendentes ou descendentes; variando de acordo com o sistema adotado.

Há três sistemas de aplicação da filtração direta, conforme apresentado na Figura 3.2.

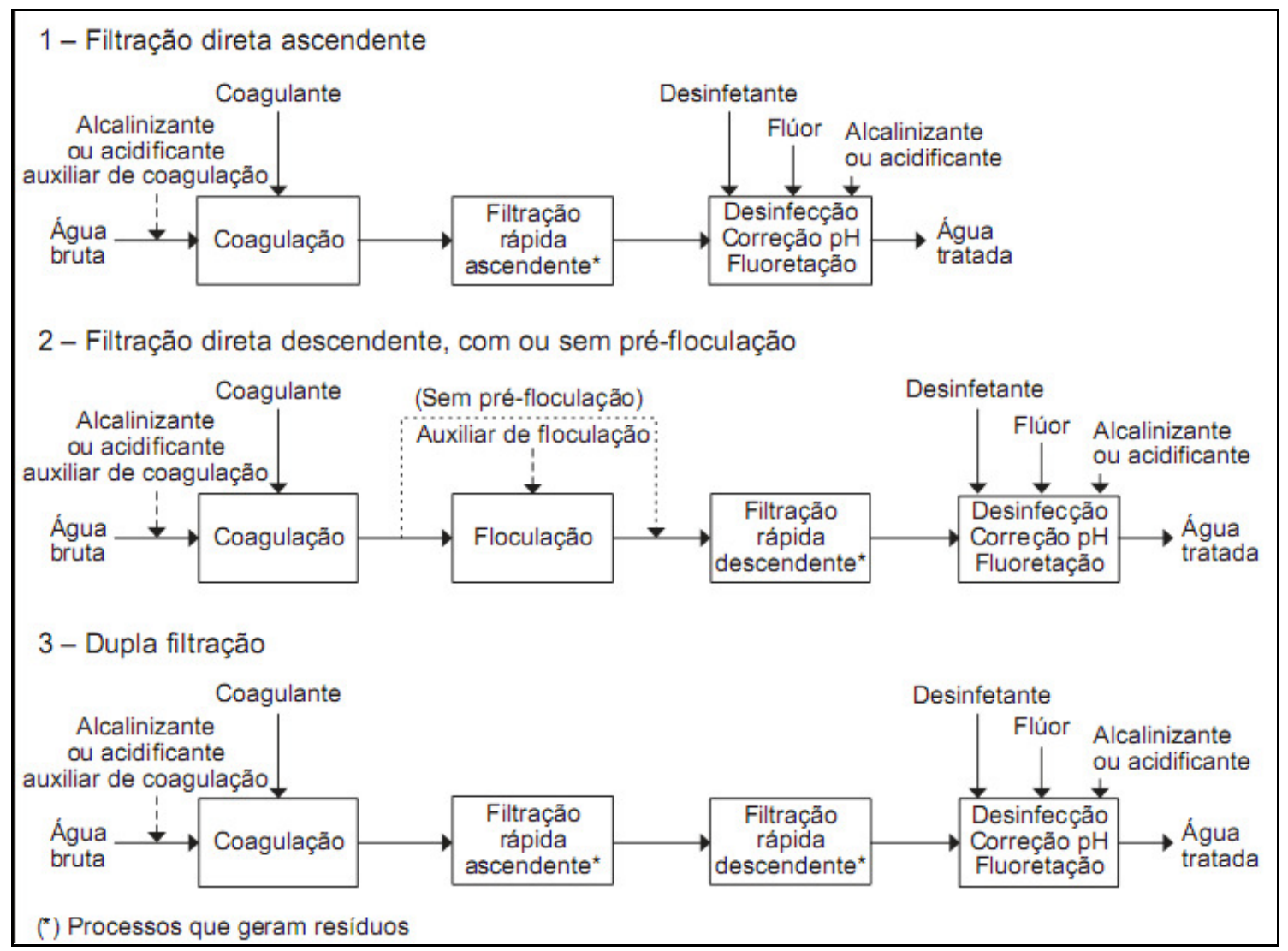

Figura 3.2: Configuração de Sistemas de Filtração Direta.

Fonte: Di Bernardo, 2003.

No Brasil, estima-se que há mais de 350 ETAs que utilizam a Filtração Direta Ascendente nos Estados de: Alagoas, Bahia, Ceará, Maranhão, Minas Gerais, Paraíba, Paraná, Pernambuco, Rio Grande do Sul, Roraima, Santa Catarina e Tocantins. Segundo Di Bernardo (2003) esta tecnologia destaca-se por:

$[\ldots]$

- Possibilitar a filtração no sentido do maior para o menor grão, resultando na utilização da altura total da camada como meio filtrante (ação de profundidade), e a redução da taxa de crescimento da perda de carga 
durante a filtração, em decorrência da remoção de uma quantidade substancial de impurezas na porção do meio filtrante de maior granulometria proporcionando, assim, carreiras de filtração com maiores durações;

- Empregar menor quantidade de coagulante por unidade de volume de água tratada, em função da não necessidade da etapa isolada de floculação (que se manifesta na própria camada suporte de pedregulho) e da busca do ponto isoelétrico na dosagem mínima, a qual, em geral, é proporcionada pelo mecanismo de coagulação de adsorção e neutralização de cargas;

- Requerer menores áreas e custos para implantação, operação e manutenção, pela eliminação das unidades de floculação e decantação e pela redução do consumo de produtos químicos, energia e mão-de-obra;

- Possibilitar a execução de descargas de fundo intermediárias com introdução de água na interface, resultando em eficiente método de remoção do material retido na camada suporte, com produção de efluentes de melhor qualidade e duração de carreiras de filtração mais prolongadas;

- Resultar em menor produção de lodo e, conseqüentemente, em menores custos de implantação de unidades de tratamento do lodo, de sua operação e manutenção e da disposição do lodo final produzido.

Assim como a Filtração Direta Ascendente, a Filtração Direta Descendente incorre em: menor consumo de coagulante por volume de água tratada; menores áreas e custos de implantação, operação e manutenção - mesmo com a implantação de unidade de floculação que é benéfica à filtração - e menor produção de lodo em relação a sistemas de Ciclo Completo. Apesar de apresentar desvantagens em relação à Filtração Direta Ascendente, a Filtração Direta Descendente tem a vantagem de não possibilitar a contaminação direta da água filtrada pela mistura com o remanescente de água de lavagem que permanece no interior da câmara do filtro - o que aumenta a segurança sanitária do tratamento -, além de permitir a adoção da operação segundo o princípio da taxa declinante e de maiores taxas de filtração.

A Dupla Filtração, apesar de requerer maiores custos de implantação, operação e manutenção quando comparada às tecnologias de Filtração Direta Ascendente e Descendente, tem vantagens como: oferecer mais segurança em relação às variações bruscas de qualidade da água bruta; dispensar o descarte de água filtrada do filtro ascendente no início da carreira de filtração; apresentar maior remoção global de microrganismos e menor risco sanitário (DI BERNARDO, 2003). 


\section{MATERIAL E MÉTODOS}

O estudo foi dividido nas etapas apresentadas na Figura 4.1 e descritas na seqüência.

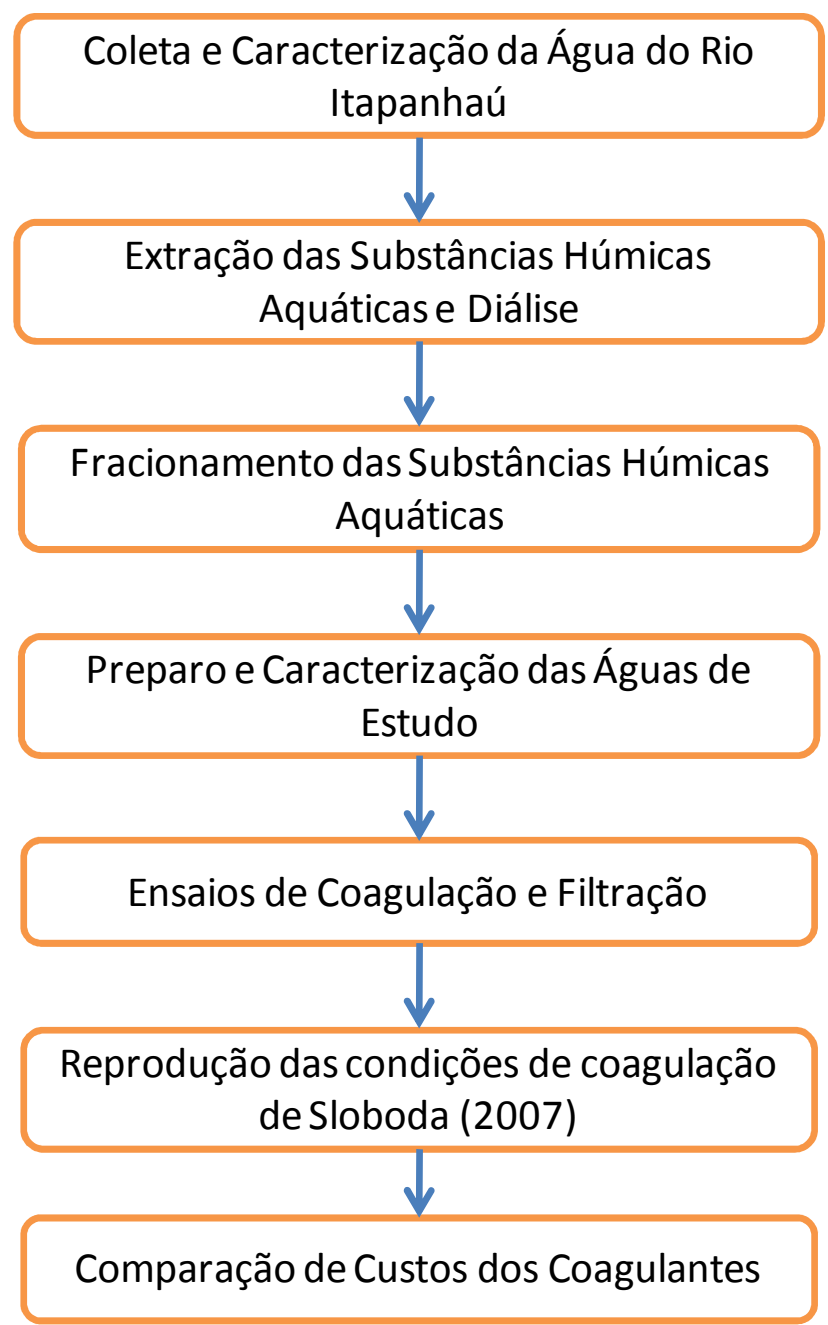

Figura 4.1: Etapas do estudo

\subsection{COLETA E CARACTERIZAÇÃO DA ÁGUA BRUTA}

A água usada para extração das substâncias húmicas aquáticas foi coletada no Rio Itapanhaú (Figura 4.2). Situado no município de Bertioga - SP, este rio é usado em pesquisas 
na Escola de Engenharia de São Carlos (EESC-USP) e UNESP de Araraquara devido ao seu alto teor de substâncias húmicas, que lhe confere cor verdadeira da ordem de $400 \mathrm{uH}$.
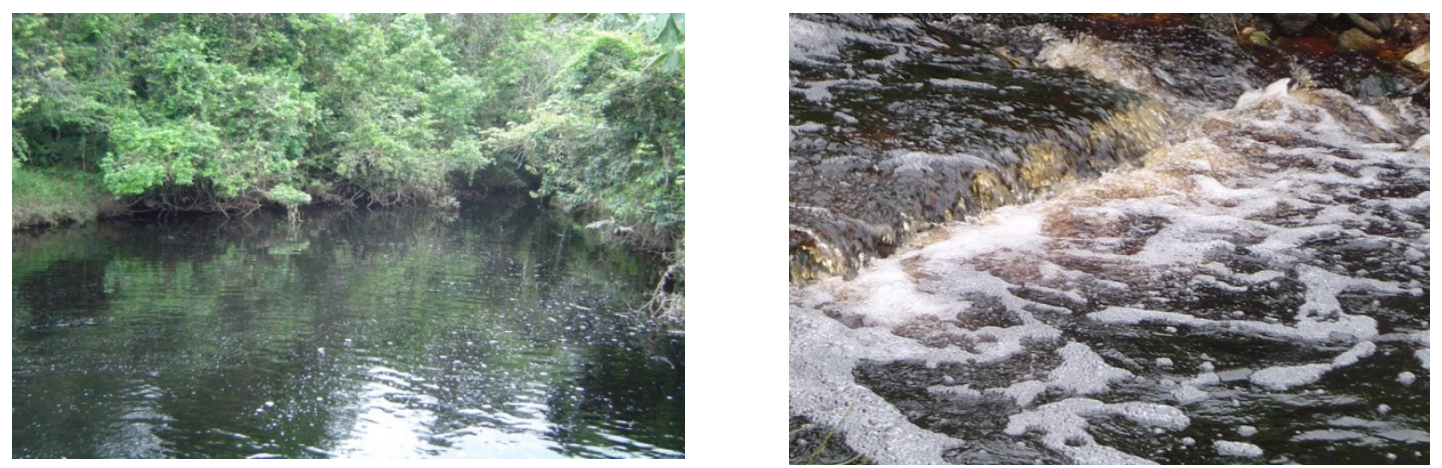

Figura 4.2: Fotos do Rio Itapanhaú

Fonte: Sloboda, 2007.

Após a coleta, acidificou-se a água com ácido clorídrico a pH 2,0, de acordo com as recomendações da Sociedade Internacional de Substâncias Húmicas (IHSS), com o propósito de impedir a precipitação de hidróxidos metálicos. Em seguida, essa foi armazenada em vasilhame de plástico. A caracterização dos parâmetros físico-químicos da água bruta foi realizada no Laboratório de Saneamento da EESC-USP.

Realizou-se também a caracterização da matéria orgânica dissolvida (MOD) no Rio Itapanhaú, conforme esquematizado na Figura 4.3 e descrito na sequência. 


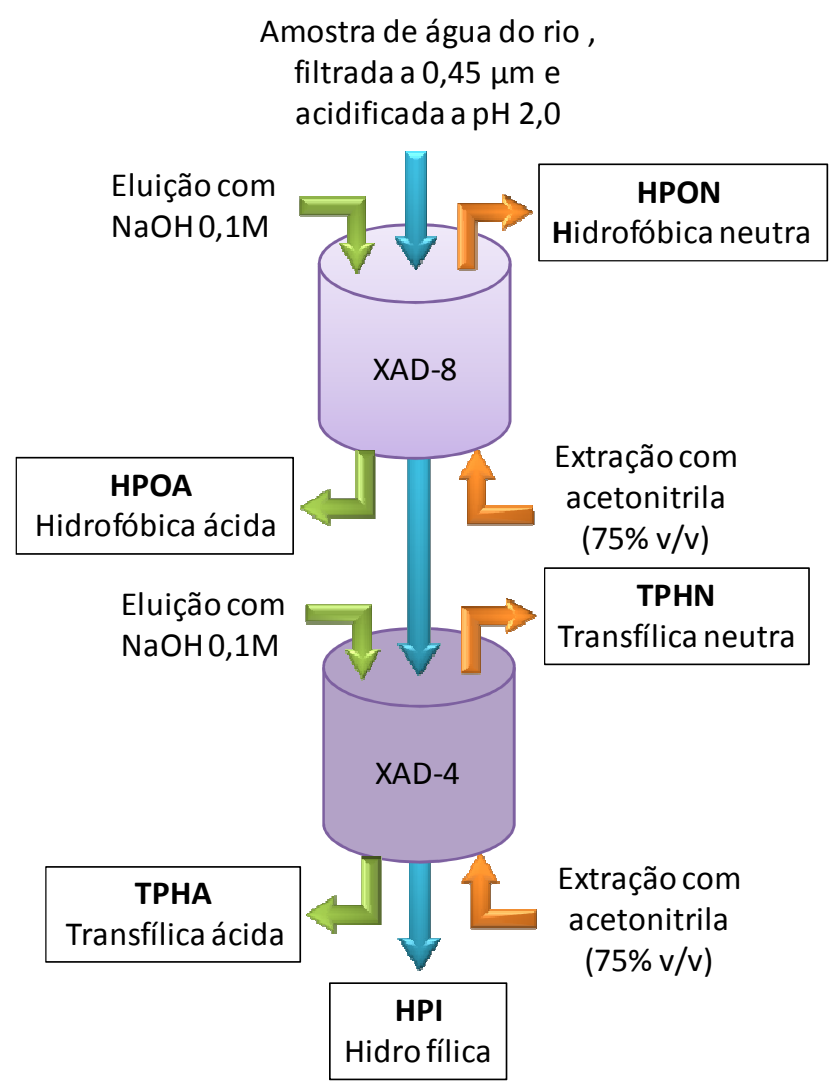

Figura 4.3: Esquema de Fracionamento de MOD, adaptado de Wei et al. (2008)

Dois litros de água do Rio Itapanhaú - filtrada em membrana $0,45 \mu \mathrm{m}$ e acidificada a pH 2,0 - foram percolados na resina macroporosa XAD-8; para adsorção da fração hidrofóbica da MOD (THURMAN; MALCOLM, 1981). Então, passou-se a mesma água pela XAD-4; tal resina adsorve a parte transfílica, de polaridade intermediária, da matéria orgânica dissolvida na água (CROUÉ et al., 1999). Após passar pelas duas resinas, a amostra de água ainda contém a fração hidrofílica da matéria orgânica dissolvida. Mediu-se o volume total da fração, coletaram-se e identificaram-se amostras como HPI.

As frações hidrofóbica e transfílica, adsorvidas respectivamente em XAD-8 e XAD-4, foram eluidas das resinas de acordo com metodologia proposta por Malcolm e MacCarthy (1992). Para eluição das frações ácidas hidrofóbica (HPOA) e transfílica (TPHA) foi usada solução $0,1 \mathrm{~mol} \mathrm{~L}^{-1}$ de $\mathrm{NaOH}$. As resinas foram lavadas com água deionizada para remoção total da base. Imediatamente após a eluição básica, neutralizaram-se os extratos com $\mathrm{HCl} 0,1$ mol $\mathrm{L}^{-1}$. Os extratos em $\mathrm{pH}$ neutro foram passados em resina de troca catiônica fortemente ácida para remoção do excesso de sais, que prejudicaria a leitura do carbono orgânico nas amostras. Ao fim dessa etapa, identificaram-se as amostras como HPOA e TPHA. 
Após a eluição com $\mathrm{NaOH}$ e lavagem com água deionizada, as resinas XAD-8 e XAD-4 foram desempacotadas, colocadas em cartucho e introduzidas no extrator Soxhlet (Figura 4.4a) para início da extração das frações hidrofóbica e transfílica neutras (HPON e TPHN). Para a extração, que foi feita em 48 horas, usou-se solução de acetonitrila $75 \%$ (v/v) e temperatura próxima a $50^{\circ} \mathrm{C}$. Passadas as 48 horas, retiraram-se as resinas e os extratos dos

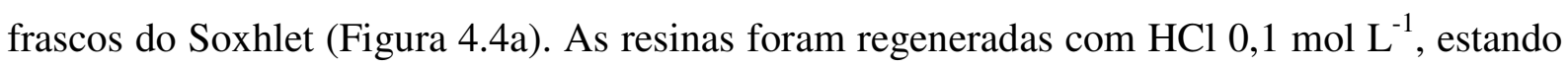
prontas para um novo ciclo. Os extratos foram colocados no rotaevaporador, a uma temperatura de $90^{\circ} \mathrm{C}$, sob vácuo, para remoção da acetonitrila (Figura 4.4b). Os extratos foram evaporados até quase secar, então se adicionou água deionizada e repetiu-se a primeira operação. Os extratos, livres de acetonitrila, foram identificados como HPON e TPHN.

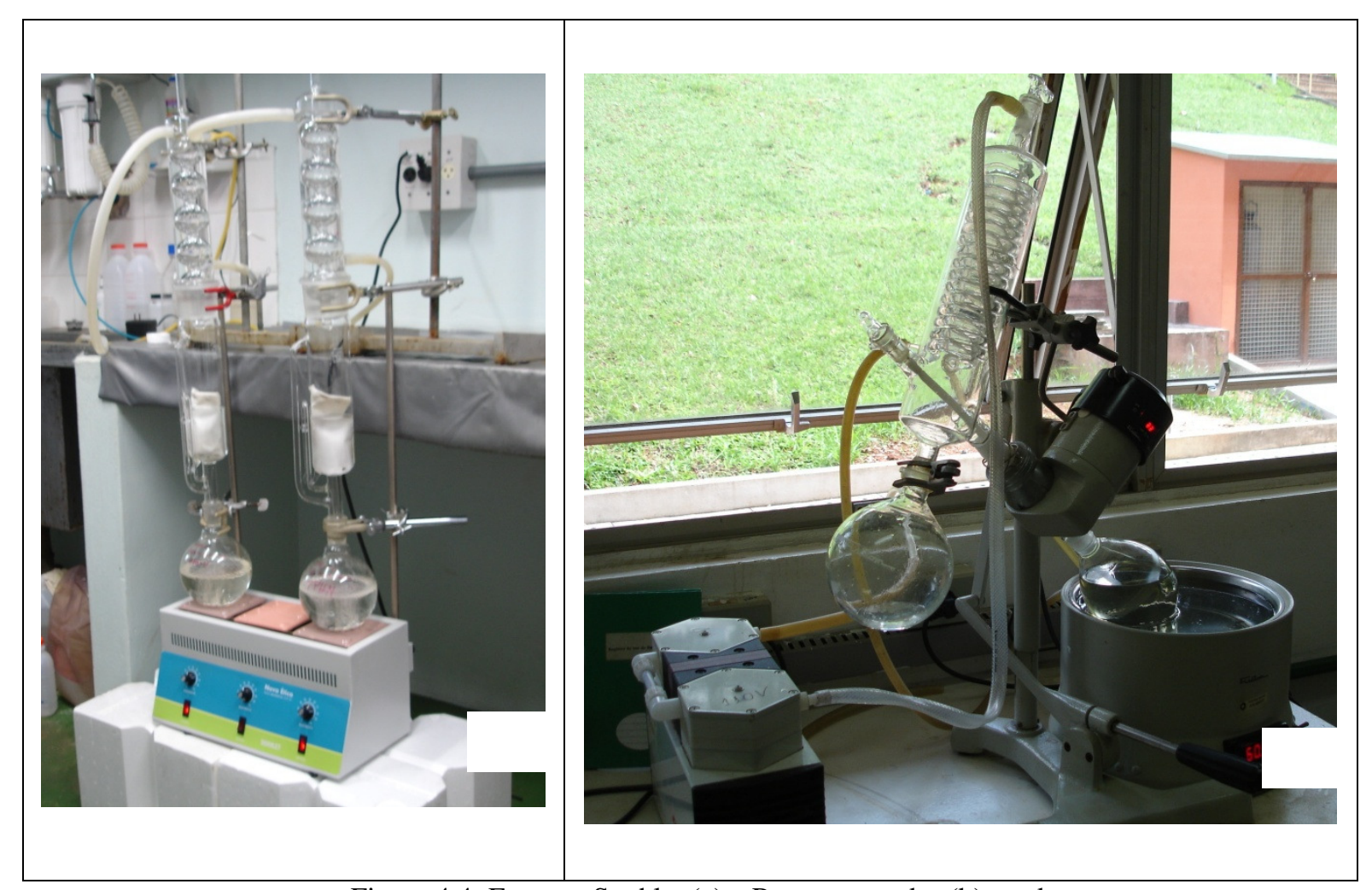

Figura 4.4: Extrator Soxhlet (a) e Rotaevaporador (b) usados

Realizou-se a leitura de COT das amostras previamente isoladas e identificadas. Um esquema detalhado de todo processo é exposto na Figura 4.5.

O procedimento de limpeza das resinas XAD-4 e XAD-8 usadas para caracterização da MOD é apresentado no Apêndice A. 


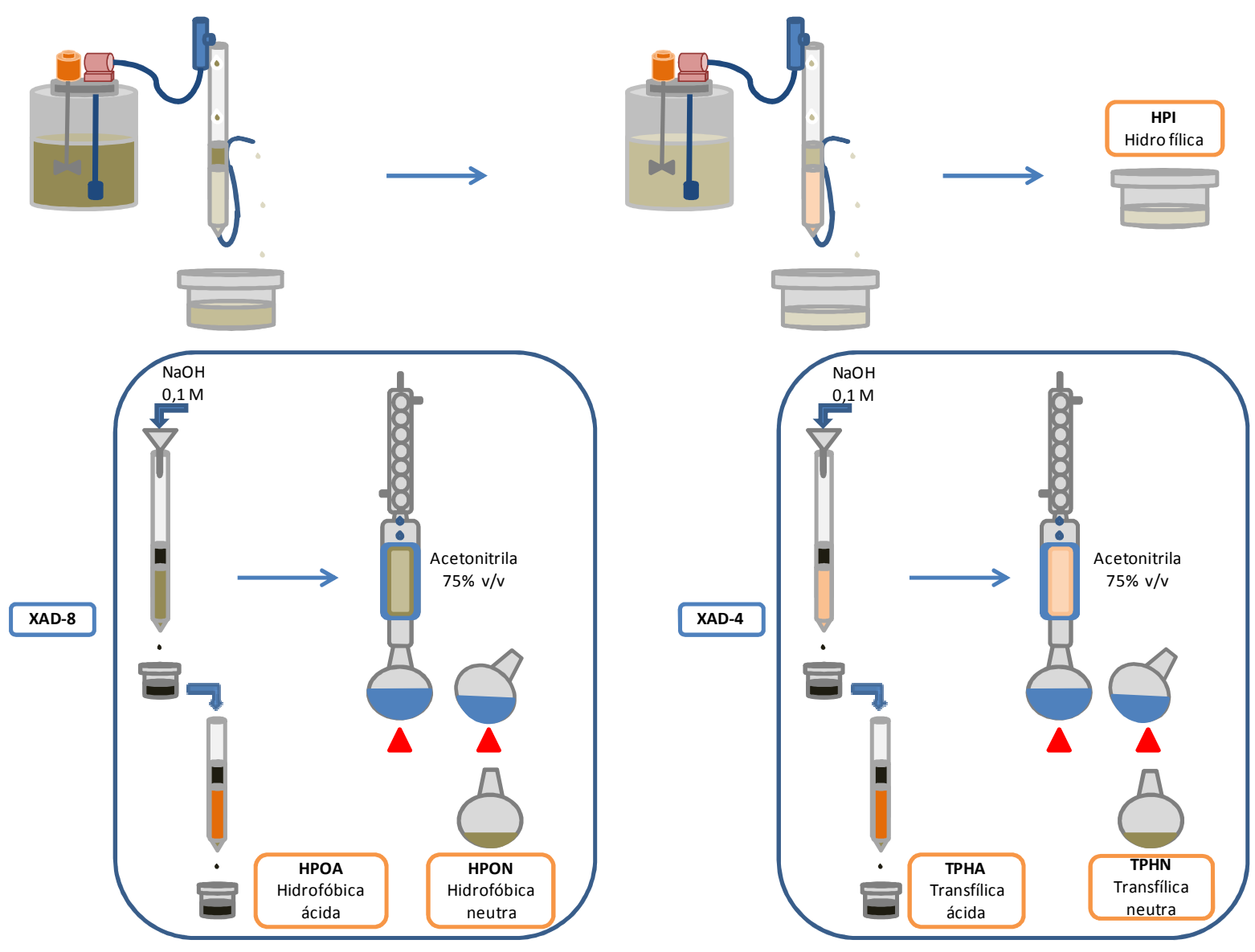

Figura 4.5: Caracterização da MON

Figura elaborada pela autora

\subsection{EXTRAÇÃO DAS SUBSTÂNCIAS HÚMICAS AQUÁTICAS E DIÁLISE}

A extração das substâncias húmicas foi realizada através do método de adsorção em resina macroporosa XAD-8, indicado pela Sociedade Internacional de Substâncias Húmicas (IHSS), desenvolvido por Thurman e Malcolm (1981). O procedimento compreende as etapas de adsorção e eluição, mostradas na Figura 4.6 e descritas a seguir:

Adsorção - a água que contém grande quantidade de substâncias húmicas foi percolada através da resina macroporosa XAD-8, a fim de reter os ácidos húmicos e fúlvicos. A resina foi alocada em um cilindro de acrílico de $31 \mathrm{~mm}$ de diâmetro, formando um leito trocador de $30 \mathrm{~cm}$ de altura. $\mathrm{O}$ acompanhamento para identificação da saturação da resina foi feito por meio de medida da absorvância a $254 \mathrm{~nm}$ da água após a passagem pela resina. Quando o efluente da resina de extração atingia uma absorvância igual ou maior a $50 \%$ do valor da absorvância inicial da água, finalizava-se o ciclo de extração e dava-se início a 
eluição. Cada ciclo de adsorção durava, em média, 48 horas e permitia a percolação de aproximadamente 20 litros de água bruta.

Eluição - a regeneração da resina foi realizada com solução de hidróxido de sódio $(\mathrm{NaOH})$ a $0,1 \mathrm{~mol} \mathrm{~L}^{-1}$ e o percolado, líquido de cor escura altamente básico - $\mathrm{pH}$ da ordem de 13, denominado extrato de substâncias húmicas. Após passar pela resina aproximadamente 400 mL de solução de $\mathrm{NaOH}$, iniciou-se sua lavagem com água deionizada, para remoção da base. Em seguida, foi feita a lavagem com metanol e posterior enxágüe com água deionizada até a remoção do metanol (Thurman e Malcolm, 1981). Após o procedimento de lavagem, a resina foi empacotada - recolocada na coluna de acrílico -, estando, então, pronta para um novo ciclo de extração. $\mathrm{O}$ extrato foi armazenado em recipiente plástico, a $4^{\circ} \mathrm{C}$.

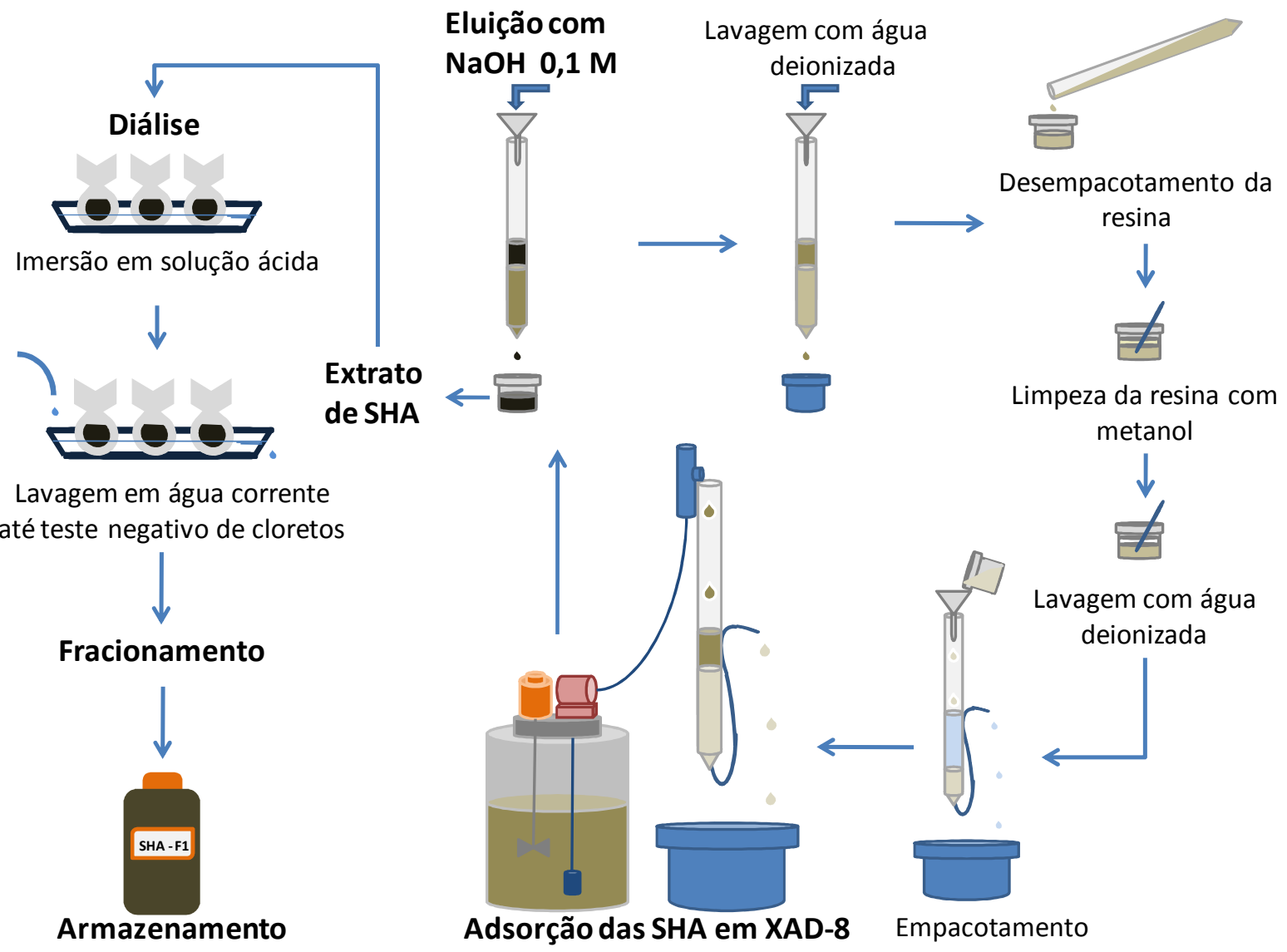

Figura 4.6: Procedimento de Extração das Substâncias Húmicas Aquáticas

Figura elaborada pela autora

A Diálise foi realizada com o intuito de reduzir o pH do extrato de SHA até que ficasse próximo ao da água do rio usado como fonte de SHA e com ausência de cloretos. O 
extrato de SHA foi envolto por papel celofane e imerso em recipiente contendo solução de ácido clorídrico $(\mathrm{HCl}) \mathrm{com} \mathrm{pH}$ próximo a 2,5. Após a redução do $\mathrm{pH}$ do extrato (entre 6,0 e 7,0 ), as embalagens de extrato foram lavadas com água corrente, proveniente do poço artesiano do Campus da USP de São Carlos, até teste negativo de cloretos.

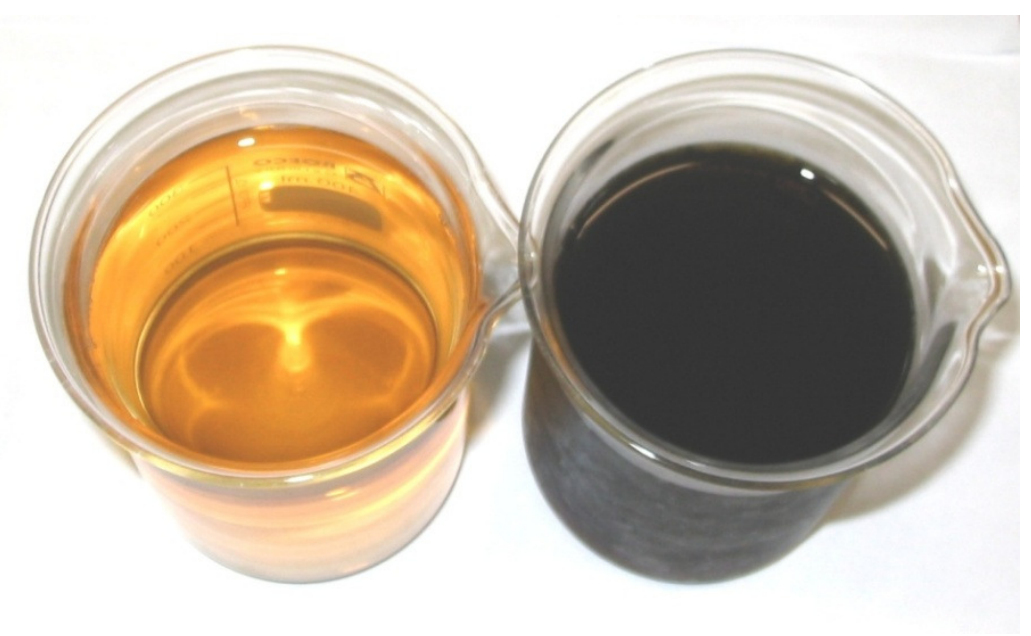

Figura 4.7: Coloração da Água do Rio (esquerda) e do Extrato (direita)

A extração das SHA foi a fase que demandou mais tempo. Neste estudo, a cada 2 dias realizava-se a eluição das duas colunas de resina XAD-8 utilizadas, o rendimento era entre 400 e $600 \mathrm{~mL}$ de extrato por 40 litros de água bruta. Gastou-se para realização dos ensaios cerca de 40 litros do referido extrato. Em trabalhos futuros que pretendam extrair SHA em grande volume, é interessante que se considere o tempo desta etapa no planejamento inicial.

\subsection{FRACIONAMENTO DAS SUBSTÂNCIAS HÚMICAS AQUÁTICAS}

O extrato de SHA foi filtrado em membrana de $0,45 \mu \mathrm{m}$, com auxílio de um sistema de filtração a vácuo (Figura 4.8). Antes do início da filtração, a membrana filtrou $200 \mathrm{~mL}$ de água deionizada. Cada membrana foi usada para filtrar até $800 \mathrm{~mL}$ de extrato. 


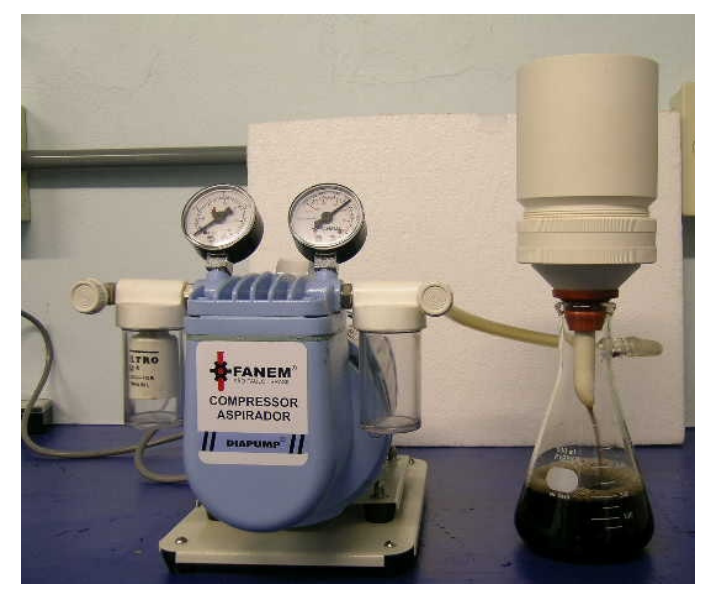

Figura 4.8: Filtração do Extrato em membrana de $0,45 \mu \mathrm{m}$

Fonte: Campos, 2004

Após a filtração, fracionou-se o extrato usando membranas de ultrafiltração. O sistema de fracionamento era composto por duas membranas de polietersulfonato em paralelo com fluxo tangencial, Vivaflow 50 - fabricadas pela Vivascience (Figura 4.9).

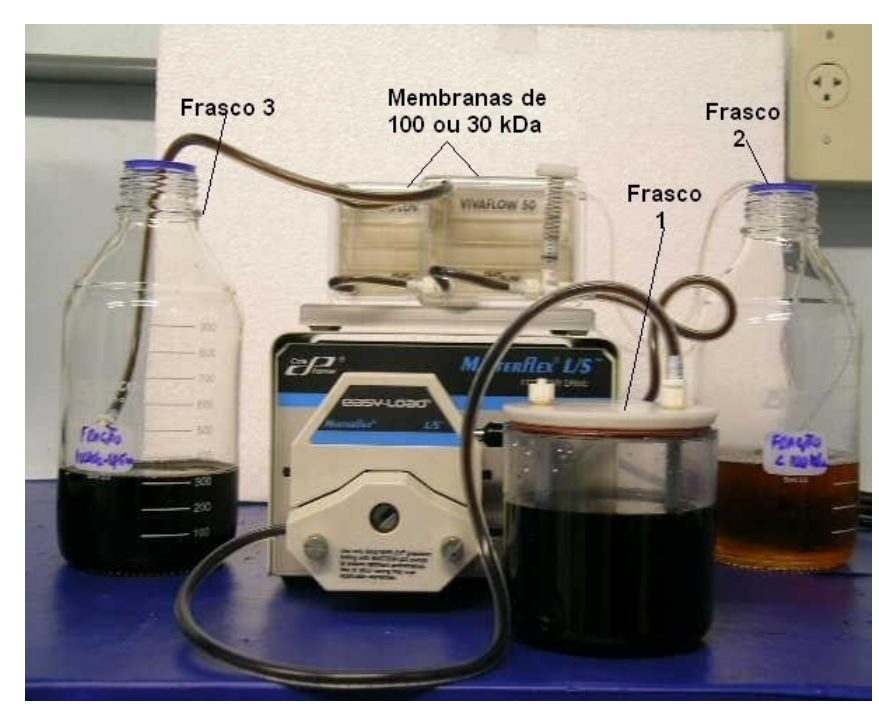

Figura 4.9: Sistema de Ultrafiltração por Membranas

Fonte: Campos, 2004

Utilizaram-se membranas de 100 e $30 \mathrm{kDa}$, para obtenção das frações testadas: $\mathbf{F}_{\mathbf{1}}$ menor que $0,45 \mu \mathrm{m}$ (fração que não necessita ultrafiltração), $\mathbf{F}_{\mathbf{2}}$ - entre $0,45 \mu \mathrm{m}$ e $100 \mathrm{kDa}, \mathbf{F}_{\mathbf{3}}$ - entre $100 \mathrm{kDa}$ e $30 \mathrm{kDa}, \mathbf{F}_{\mathbf{4}}$ - menor que $30 \mathrm{kDa}$. As membranas foram usadas para filtrar 
até 12 L de extrato; pois, de acordo com Campos (2004), até esse volume não há diferenças significativas nas características do extrato filtrado.

Para o fracionamento por ultrafiltração, adotou-se o método de concentração por recirculação do extrato retido na membrana, para obtenção de maior volume de amostra fracionada (Duarte et al., 2001).

O procedimento de ultrafiltração seguiu os seguintes passos:

Passo 1: $\mathrm{O}$ extrato filtrado na membrana de 0,45 $\mu \mathrm{m}$ (frasco R1) passou pelas membranas de $100 \mathrm{kDa}$, no frasco R2 foi coletado extrato de SHA com peso molecular menor que 100 kDa (Figura 4.10a). Depois de passados 90\% do volume inicial (Buffle et al., 1978), a recirculação não foi mais realizada e houve a coleta da fração $\mathbf{F}_{2}$, no frasco R3 (Figura 4.10b).

Passo 2: O extrato com massa molecular menor que $100 \mathrm{kDa}$ foi colocado no frasco $\mathrm{R} 1$ e passou pelas membranas de $30 \mathrm{kDa}$. Nesta etapa, o frasco R2 coletou extrato com SHA de massa molecular menor que $30 \mathrm{kDa}$ (Fração $\mathbf{F}_{\mathbf{4}}$ ). Como no passo anterior, depois de filtrados $90 \%$ do volume inicial contido em R1; a recirculação foi encerrada e a fração $\mathbf{F}_{\mathbf{3}}$ foi coletada no frasco R3.

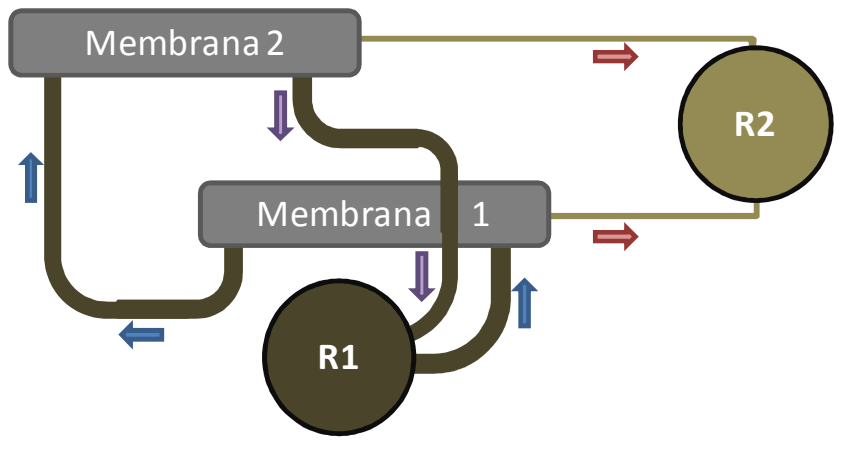

Figura 4.10 a: Concentração da Amostra

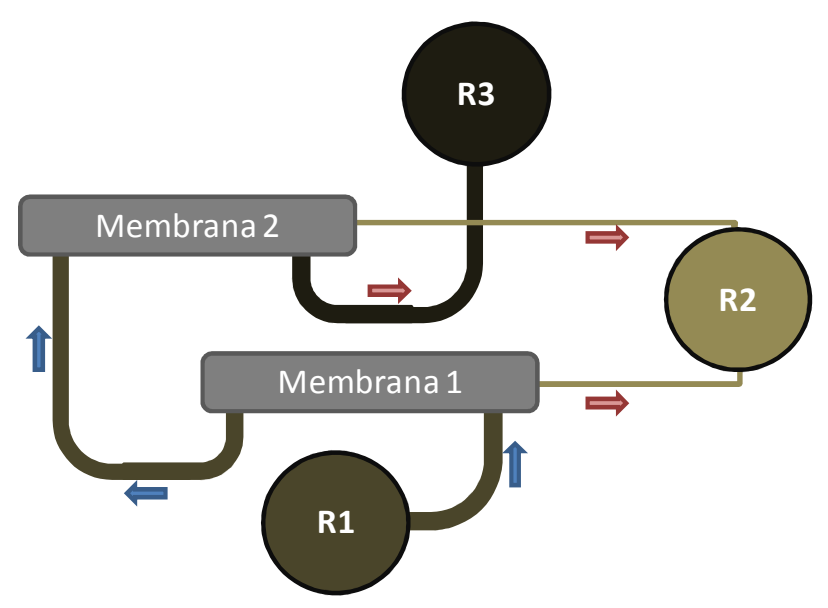

Figura 4.10 b: Coleta da Fração Intermediária

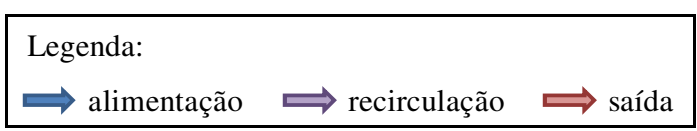

Figura 4.10: Procedimento de Ultrafiltração

Figura elaborada pela autora

Os extratos de cada uma das quatro frações apresentam diferentes intensidades de cor, como exposto na Figura 4.11. 


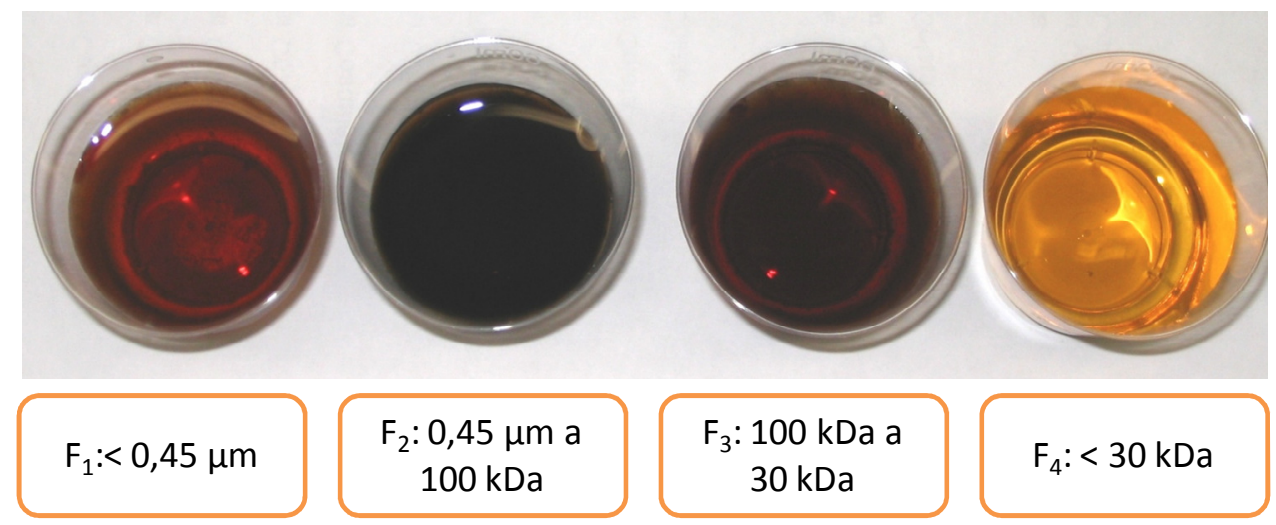

Figura 4.11: Extratos de SHA Obtidos por Ultrafiltração.

\subsection{PREPARO E CARACTERIZAÇÃO DAS ÁGUAS DE ESTUDO}

Prepararam-se quatro águas de estudo com cor verdadeira de $100 \mathrm{uH}$, turbidez de $5 \mathrm{uT}$, $\mathrm{pH}$ 6,0 e temperatura de $20^{\circ} \mathrm{C}$. O extrato da fração de SHA correspondente à água que se pretendia preparar (Tabela 4.1) e uma suspensão de caulinita - para conferir turbidez - foram adicionados a cerca de 200 litros de água do poço artesiano do Campus da EESC-USP.

A suspensão de caulinita foi preparada para evitar erros na adição de argila à água, conforme sugerido por Di Bernardo (2004). Adiocionou-se $1 \mathrm{~kg}$ de caulinita a 50 litros de água, agitou-se por duas horas. Depois da agitação, a suspensão ficou em repouso por 10 horas. O sobrenadante foi coletado e usado como suspensão estoque.

Tabela 4.1: Águas de Estudo e Frações de SHA

\begin{tabular}{ll}
\hline \hline Água de Estudo & Fração usada no preparo \\
\hline \hline Água 1 & $\mathbf{F}_{\mathbf{1}}$ : menor que $0,45 \mu \mathrm{m}$ \\
Água 2 & $\mathbf{F}_{\mathbf{2}}$ : entre $0,45 \mu \mathrm{m}$ e $100 \mathrm{kDa}$ \\
Água 3 & $\mathbf{F}_{\mathbf{3}}$ : entre $100 \mathrm{kDa}$ e $30 \mathrm{kDa}$ \\
Água 4 & $\mathbf{F}_{\mathbf{4}}$ : menor que $30 \mathrm{kDa}$ \\
\hline \hline
\end{tabular}

A caracterização das águas de estudo foi realizada no Laboratório de Saneamento da EESC-USP. Os parâmetros analisados foram os mesmos usados na caracterização da água bruta do Rio Itapanhaú. 


\subsection{ENSAIOS DE COAGULAÇÃO E FILTRAÇÃO}

Realizaram-se ensaios de coagulação e filtração em jarteste com filtros de laboratório acoplados, como apresentado na Figura 4.12.

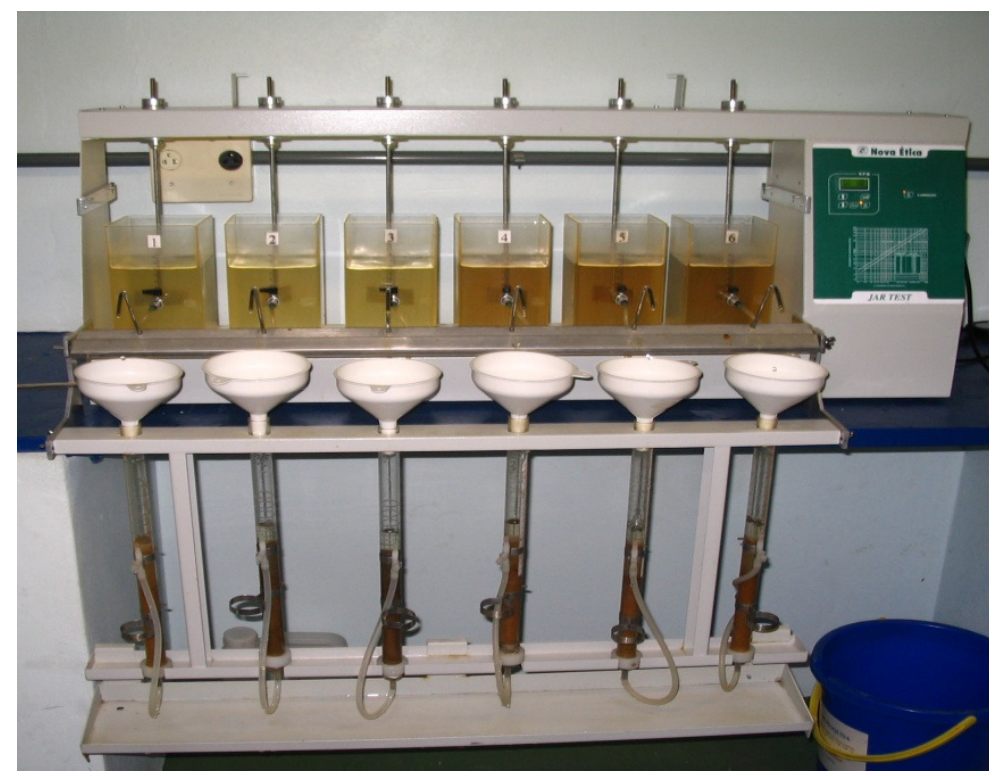

Figura 4.12: Equipamento de Jarteste e filtros de laboratório usados

Foram confeccionados diagramas de coagulação para cada uma das quatro águas de estudo. Para construção dos diagramas, realizaram-se ensaios em jarteste variando-se a dosagem do coagulante Hidroxicloreto de Alumínio e o pH de coagulação - por meio da adição de soluções de hidróxido de sódio ou ácido clorídrico. Os parâmetros medidos durante os ensaios foram: cor aparente e turbidez após a filtração e pH de coagulação em todos os pontos.

Os ensaios foram feitos sob as mesmas condições adotadas por Sloboda (2007), uma vez que se pretendia realizar comparação com os resultados obtidos pela autora. Tais condições foram:

- Tempo de Mistura Rápida $\left(\mathrm{T}_{\mathrm{mr}}\right): 30 \mathrm{~s}$;

- Gradiente de Velocidade Médio da Mistura Rápida $\left(\mathrm{G}_{\mathrm{mr}}\right): 1.000 \mathrm{~s}^{-1}$;

- Taxa Média de Filtração $\left(\mathrm{Tx}_{\mathrm{f}}\right): 50$ a 70 m²/m²d;

- Tempo de Filtração $\left(\mathrm{T}_{\mathrm{f}}\right): 20 \mathrm{~min}$. 
Os filtros de laboratório também apresentavam as mesmas características dos utilizados na pesquisa citada, apresentadas na Tabela 4.2.

Tabela 4.2: Características dos filtros de laboratório

\begin{tabular}{ll}
\hline \hline Diâmetro nominal dos filtros & $25 \mathrm{~mm}$ \\
\hline Diâmetro interno dos filtros & $19 \mathrm{~mm}$ \\
\hline Espessura do meio filtrante & $15 \mathrm{~cm}$ \\
\hline Altura total dos filtros & $40 \mathrm{~cm}$ \\
\hline Tamanho dos grãos & 0,30 e $0,59 \mathrm{~mm}$ \\
\hline \hline
\end{tabular}

\subsection{REPRODUÇÃO DAS CONDIÇÕES DE COAGULAÇÃO DE SLOBODA (2007)}

Tentou-se reproduzir as condições de coagulação de Sloboda (2007) com o intuito de usar os diagramas da autora para comparar os custos entre os três coagulantes estudados hidroxicloreto de alumínio, sulfato de alumínio e cloreto férrico - na remoção de cor das diferentes águas testadas.

Neste trabalho, a reprodução foi feita com as quatro águas de estudo para os dois coagulantes: sulfato de alumínio e cloreto férrico, usados por Sloboda (2007). Para isso, foram escolhidos pontos nas regiões que apresentaram cor final menor ou igual a $5 \mathrm{uH}$ obtidos pela autora para os dois coagulantes e verificou-se se os resultados obtidos foram compatíveis com aqueles obtidos no estudo anterior.

O procedimento experimental para reprodução das condições de coagulação de Sloboda (2007) foi o mesmo descrito na seção anterior.

\subsection{COMPARAÇÃO DE CUSTOS DOS COAGULANTES}

Os pontos de menor consumo de coagulante e alcalinizante foram escolhidos nas regiões de cor final menor ou igual a $5 \mathrm{uH}$ dos diagramas construídos a partir dos ensaios realizados com hidroxicloreto de alumínio, sulfato de alumínio e cloreto férrico para cada uma das águas de estudo. 
Foi feita a cotação dos coagulantes, alcalinizante e acidificante usados. O valor gasto foi calculado para cada um dos pontos escolhidos e a comparação dos custos foi feita a partir desses dados, levando-se em conta somente os gastos estimados com produtos químicos para o tratamento da água.

\subsection{EQUIPAMENTOS, PRODUTOS QUÍMICOS E MÉTODOS ANALÍTICOS}

As análises de caracterização da água do Rio Itapanhaú e das águas de estudo foram realizadas no Laboratório de Saneamento da EESC-USP, de acordo com as metodologias descritas no Standards Methods for the Examination of Water \& Wastewater (2005) e apresentadas 
Tabela 4.3. Durante o preparo das águas de estudo foram medidos os seguintes parâmetros: pH, cor verdadeira e aparente, turbidez e temperatura. 
Tabela 4.3: Métodos analíticos e equipamentos usados na caracterização das águas

\begin{tabular}{|c|c|c|}
\hline Parâmetro & Método & Equipamento para leitura \\
\hline Absorbância em 254 nm & Espectrofotométrico & Espectofotômetro \\
\hline Condutividade Elétrica ( $\mu \mathrm{s} / \mathrm{cm})$ & Potenciométrico & Condutivímetro de bancada \\
\hline Cor Verdadeira (uH) & Espectrofotométrico & Espectofotômetro \\
\hline Cor Aparente (uH) & Espectrofotométrico & Espectofotômetro \\
\hline $\mathrm{pH}$ & Potenciométrico & Potenciômetro de bancada \\
\hline Turbidez (uT) & Nefelométrico & Turbidímetro de bancada \\
\hline Alcalinidade Total (mg/L $\left.\mathrm{CaCO}_{3}\right)$ & Titulométrico & Potenciômetro de bancada \\
\hline Dureza Total (mg/L $\left.\mathrm{CaCO}_{3}\right)$ & EDTA Titulométrico & - \\
\hline Sulfatos (mg/L) & Turbidimétrico & Espectofotômetro \\
\hline Nitrogênio Nitrato (mg/L) & Espectrofotométrico & Espectofotômetro UV visível \\
\hline Nitrogênio Nitrito (mg/L) & Espectrofotométrico & Espectofotômetro \\
\hline Sólidos Totais (mg/L) & Gravimétrico & Balança analítica \\
\hline Sólidos Totais Suspensos (mg/L) & Gravimétrico & Balança analítica \\
\hline Sólidos Totais Dissolvidos (mg/L) & Gravimétrico & Balança analítica \\
\hline Sódio (mg/L) & Fotometria de Chama & Fotômetro de Chama \\
\hline Potássio (mg/L) & Fotometria de Chama & Fotômetro de Chama \\
\hline Carbono Orgânico Total (mg/L) & Espectrofotométrico & TOC Analyser 5000 A \\
\hline Carbono Orgânico Dissolvido (mg/L) & Espectrofotométrico & TOC Analyser 5000 A \\
\hline Zinco (mg/L) & Espectrofotométrico & Espectofotômetro de Absorção Atômica \\
\hline Chumbo (mg/L) & Espectrofotométrico & Espectofotômetro de Absorção Atômica \\
\hline Cádmio (mg/L) & Espectrofotométrico & Espectofotômetro de Absorção Atômica \\
\hline Níquel (mg/L) & Espectrofotométrico & Espectofotômetro de Absorção Atômica \\
\hline Ferro $(\mathrm{mg} / \mathrm{L})$ & Espectrofotométrico & Espectofotômetro de Absorção Atômica \\
\hline Manganês (mg/L) & Espectrofotométrico & Espectofotômetro de Absorção Atômica \\
\hline Cobre $(\mathrm{mg} / \mathrm{L})$ & Espectrofotométrico & Espectofotômetro de Absorção Atômica \\
\hline Cromo (mg/L) & Espectrofotométrico & Espectofotômetro de Absorção Atômica \\
\hline
\end{tabular}


Os testes de coagulação foram executados em reatores estáticos de bancada, Jarteste, da marca Nova Ética. Este equipamento possui 6 jarros com capacidade de 2 litros cada e eixos de paletas com rotação programável entre 20 e 600 rpm. Durante os ensaios de jarteste foram utilizados ácido, base e os coagulantes a seguir:

- Ácido clorídrico - $\mathrm{HCl}$ : produto comercial líquido com 36,5\% de $\mathrm{HCl}(\mathrm{m} / \mathrm{m})$;

- Hidróxido de sódio - $\mathrm{NaOH}$ : produto comercial, base anidra;

- Hidroxicloreto de alumínio - $\mathrm{Al}_{\mathrm{n}}(\mathrm{OH})_{\mathrm{m}} \mathrm{Cl}_{3 \mathrm{n}-\mathrm{m}}$ : produto comercial líquido com $10 \%$ de $\mathrm{Al}_{2} \mathrm{O}_{3}(\mathrm{~m} / \mathrm{m})$;

- Sulfato de alumínio - $\mathrm{Al}_{2}\left(\mathrm{SO}_{4}\right)_{3} \quad x \quad 14 \mathrm{H}_{2} \mathrm{O}$ : produto comercial líquido com $7,28 \%$ de $\mathrm{Al}_{2} \mathrm{O}_{3}(\mathrm{~m} / \mathrm{m})$;

- Cloreto férrico - $\mathrm{FeCl}_{3} \times 6 \mathrm{H}_{2} \mathrm{O}$ : produto comercial líquido com $38 \%$ de $\mathrm{FeCl}_{3}$ $x 6 \mathrm{H}_{2} \mathrm{O}(\mathrm{m} / \mathrm{m})$;

Nestes ensaios, os métodos analíticos e equipamentos que foram usados para análise dos parâmetros de interesse, encontram-se na Tabela 4.4.

Tabela 4.4: Métodos analíticos e equipamentos

\begin{tabular}{lll}
\hline \hline Parâmetro & Método & Equipamento \\
\hline \hline Turbidez $(\mathrm{uT})$ & Nefelométrico & Turbidímetro de bancada \\
\hline Cor verdadeira $(\mathrm{uH})$ & Espectrofotométrico & Espectrofotômetro \\
\hline Cor aparente $(\mathrm{uH})$ & Espectrofotométrico & Espectrofotômetro \\
\hline $\mathrm{pH}$ & Potenciométrico & Potenciômetro de bancada \\
\hline Temperatura $\left({ }^{0} \mathrm{C}\right)$ & Leitura direta & Termômetro de mercúrio \\
\hline \hline
\end{tabular}




\section{RESULTADOS E DISCUSSÃO}

\subsection{CARACTERIZAÇÃo DA ÁGUA BRUTA E DA MATÉRIA ORGÂNICA DISSOLVIDA}

Na Tabela 5.1, apresentam-se os resultados da caracterização.

Tabela 5.1: Caracterização físico-química da água do Rio Itapanhaú

\begin{tabular}{|c|c|c|c|}
\hline Parâmetros & Valores & Parâmetros & Valores \\
\hline Absorbância em 254 nm & 1,664 & Carbono Orgânico Dissolvido (mg/L) & 25,68 \\
\hline Condutividade Elétrica $(\mu \mathrm{s} / \mathrm{cm})$ & 80,7 & Zinco - amostra não digerida (mg/L) & ND \\
\hline Cor Verdadeira (uH) & 386 & Zinco - amostra digerida (mg/L) & ND \\
\hline Cor Aparente (uH) & 438 & Chumbo - amostra não digerida (mg/L) & ND \\
\hline $\mathrm{pH}$ & 5,76 & Chumbo - amostra digerida (mg/L) & ND \\
\hline Turbidez (uT) & 2,9 & Cádmio - amostra não digerida (mg/L) & ND \\
\hline Alcalinidade Total (mg/L CaCO 3 ) & 7,0 & Cádmio - amostra digerida (mg/L) & ND \\
\hline Dureza Total (mg/L CaCO 3$)$ & 14,0 & Níquel - amostra não digerida (mg/L) & ND \\
\hline Sulfatos (mg/L) & ND & Níquel - amostra digerida (mg/L) & ND \\
\hline Nitrogênio Nitrato (mg/L) & 0,050 & Ferro - amostra não digerida (mg/L) & 1,63 \\
\hline Nitrogênio Nitrito (mg/L) & 0,0032 & Ferro - amostra digerida (mg/L) & 6,78 \\
\hline Sólidos Totais (mg/L) & 161,0 & $\begin{array}{l}\text { Manganês - amostra não digerida } \\
(\mathrm{mg} / \mathrm{L})\end{array}$ & 0,04 \\
\hline Sólidos Totais Suspensos (mg/L) & 42,0 & Manganês - amostra digerida (mg/L) & 0,09 \\
\hline Sólidos Totais Dissolvidos (mg/L) & 119,0 & Cobre - amostra não digerida (mg/L) & 0,01 \\
\hline Sódio (mg/L) & 6,6 & Cobre - amostra digerida (mg/L) & 0,03 \\
\hline Potássio (mg/L) & 0,9 & Cromo - amostra não digerida (mg/L) & ND \\
\hline Carbono Orgânico Total (mg/L) & 34,00 & Cromo - amostra digerida (mg/L) & ND \\
\hline
\end{tabular}


Conforme observado na Tabela 5.1, a água do Rio Itapanhaú apresenta cor verdadeira de 368 uH e concentração de Carbono Orgânico Total igual a $34 \mathrm{mg} \mathrm{L}^{-1}$, valores elevados que mostram a grande concentração de substâncias húmicas aquáticas nesta água.

Foram encontradas dificuldades durante os ensaios para caracterização da matéria orgânica dissolvida presente na água e na compilação de resultados. Esperava-se que o balanço de massa (relação entre as massas de entrada e saídas das espécies isoladas de MOD) fechasse, mas não foi o que ocorreu: a massa inicial - calculada multiplicando o volume de água percolada nas resinas XAD pela concentração de COT da água do rio - foi menor que o somatório das massas das frações isoladas. Algumas hipóteses podem ser levantadas acerca do tema: a acetonitrila pode ter interferido nos resultados de COT, os solventes usados podem ter carreado alguma impureza presente nas resinas ou ainda a limpeza inicial das resinas pode ter sido ineficaz ou inadequada para o tipo de análise realizada.

Contudo, se considerarmos somente a relação das massas de cada uma das frações de MOD isoladas - como é apresentado em diversos trabalhos publicados, nos quais não há citação do balanço de massas: Chow et al. (2005), Croué et al. (1999) - tem-se o gráfico apresentado na

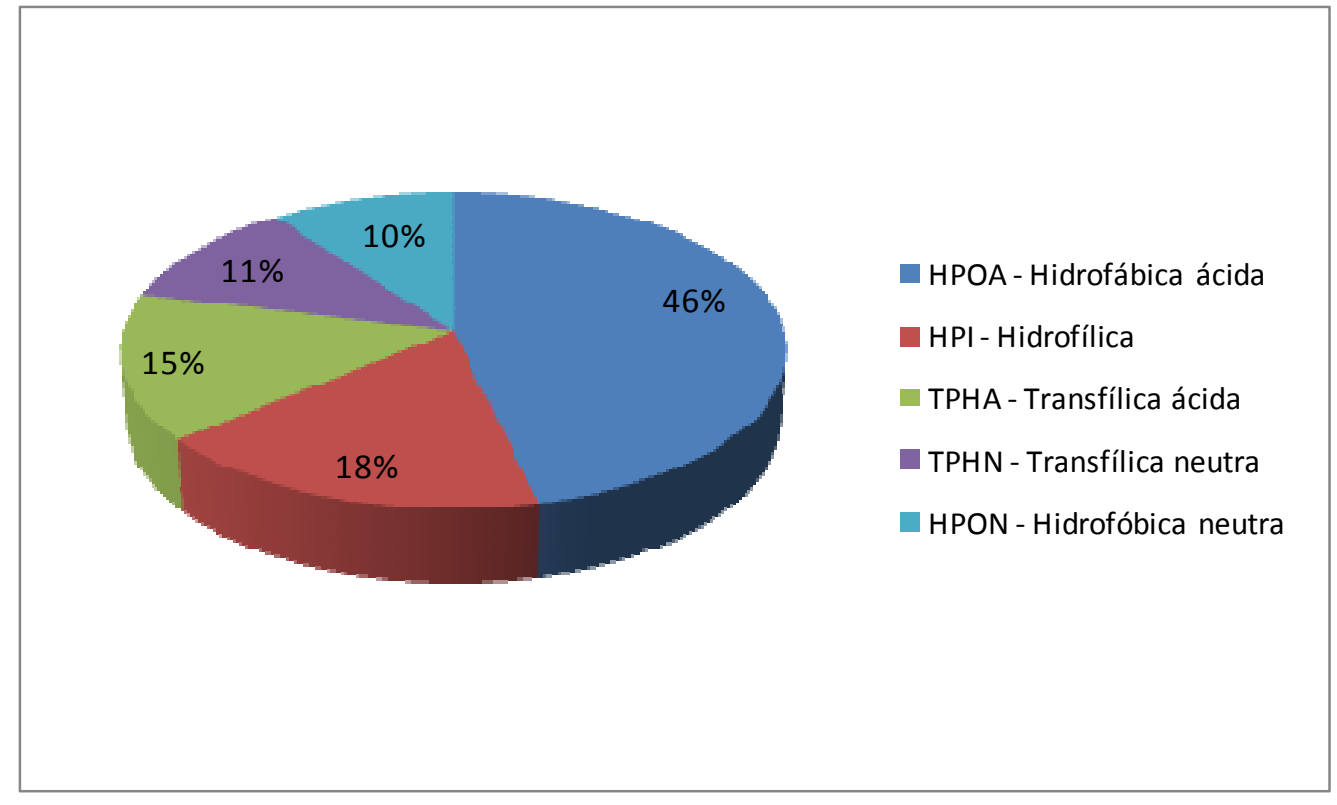

Figura 5.1. Este mostra que a maior proporção de MOD da água do Rio Itapanhaú é representada pela fração ácida hidrofóbica (HPOA), obtida pela extração com $\mathrm{NaOH}$ das SHA adsorvidas em XAD-8. Isso justifica o uso da metodologia de Thurman e Malcolm (1981) para obtenção de SHA da água do Rio Itapanhaú, pois há indícios de que tal fração (HPOA) é a que está presente em maior concentração nesta água. 


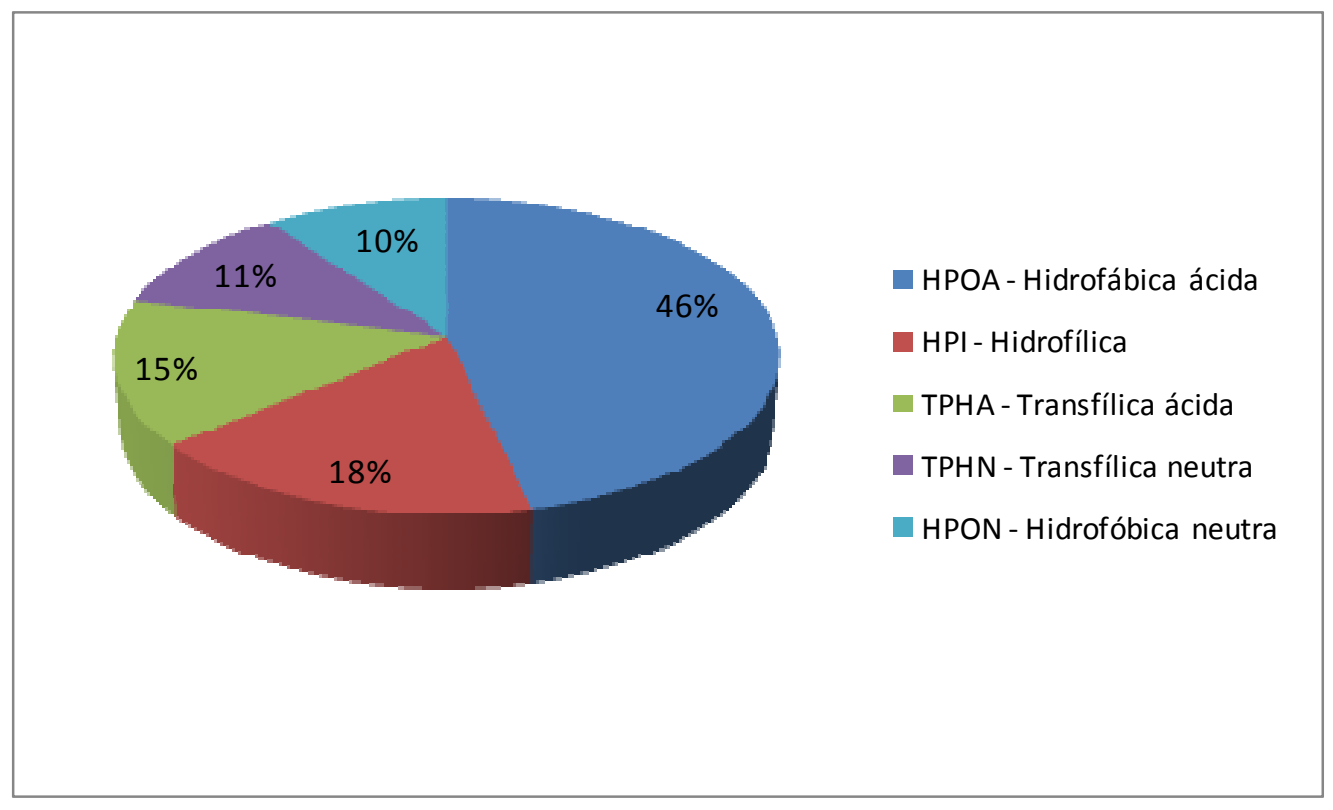

Figura 5.1: Quantificação das frações da MOD do Rio Itapanhaú

\subsection{CARACTERIZAÇÃO DAS ÁGUAS DE ESTUDO}

No mesmo laboratório, realizaram-se as análises de caracterização das águas de estudo preparadas. Os resultados são apresentados na Tabela 5.2.

Tabela 5.2: Caracterização das Águas de Estudo Preparadas

\begin{tabular}{|c|c|c|c|c|}
\hline \multirow{2}{*}{ Parâmetros } & \multicolumn{4}{|c|}{ Valores } \\
\hline & Água 1 & Água 2 & Água 3 & Água 4 \\
\hline Absorbância em $254 \mathrm{~nm}$ & 0,369 & 0,250 & 0,337 & 0,473 \\
\hline Condutividade Elétrica $(\mu \mathrm{S} / \mathrm{cm})$ & 73,9 & 71,8 & 81,7 & 81,0 \\
\hline Cor Verdadeira $(\mathrm{uH})$ & 100 & 100 & 103 & 105 \\
\hline Cor Aparente (uH) & 136 & 115 & 127 & 140 \\
\hline $\mathrm{pH}$ & 6,23 & 6,29 & 6,18 & 6,42 \\
\hline Turbidez (uT) & 5,9 & 5,3 & 5,0 & 5,2 \\
\hline Alcalinidade Total $\left(\mathrm{mg} / \mathrm{L} \mathrm{CaCO}_{3}\right)$ & 9,0 & 6,0 & 9,0 & 9,0 \\
\hline Dureza Total $\left(\mathrm{mg} / \mathrm{L} \mathrm{CaCO}{ }_{3}\right)$ & 20,0 & 20,0 & 22,0 & 23,0 \\
\hline Sulfatos $(\mathrm{mg} / \mathrm{L})$ & ND & ND & ND & ND \\
\hline Nitrogênio Nitrato $(\mathrm{mg} / \mathrm{L})$ & 0,029 & 0,114 & ND & ND \\
\hline Nitrogênio Nitrito (mg/L) & ND & ND & ND & ND \\
\hline Sólidos Totais (mg/L) & 127,0 & 101,0 & 276,0 & 320,0 \\
\hline Sólidos Totais Suspensos (mg/L) & 34,0 & 20,0 & 32,0 & 38,0 \\
\hline Sólidos Totais Dissolvidos (mg/L) & 93,0 & 81,0 & 244,0 & 382,0 \\
\hline Sódio $(\mathrm{mg} / \mathrm{L})$ & 2,0 & 1,7 & 1,8 & 2,4 \\
\hline Potássio (mg/L) & 4,0 & 4,1 & 3,9 & 4,3 \\
\hline
\end{tabular}

62 
Carbono Orgânico Total (mg/L)

Carbono Orgânico Dissolvido (mg/L)

Zinco - amostra não digerida $(\mathrm{mg} / \mathrm{L})$

Zinco - amostra digerida (mg/L)

Chumbo - amostra não digerida (mg/L)

Chumbo - amostra digerida (mg/L)

Cádmio - amostra não digerida (mg/L)

Cádmio - amostra digerida (mg/L)

Níquel - amostra não digerida (mg/L)

Níquel - amostra digerida (mg/L)

Ferro - amostra não digerida $(\mathrm{mg} / \mathrm{L})$

Ferro - amostra digerida (mg/L)

Manganês - amostra não digerida $(\mathrm{mg} / \mathrm{L})$

Manganês - amostra digerida (mg/L)

Cobre - amostra não digerida $(\mathrm{mg} / \mathrm{L})$

Cobre - amostra digerida (mg/L)

Cromo - amostra não digerida (mg/L)

Cromo - amostra digerida $(\mathrm{mg} / \mathrm{L})$

\begin{tabular}{cccc}
7,891 & 5,436 & 10,540 & 15,910 \\
6,475 & 4,878 & 7,770 & 14,570 \\
0,126 & 0,049 & ND & ND \\
0,196 & 0,084 & 0,056 & 0,087 \\
0,01 & 0,01 & ND & ND \\
0,22 & 0,15 & ND & ND \\
ND & ND & ND & ND \\
0,022 & 0,013 & 0,015 & 0,045 \\
0,016 & 0,017 & ND & ND \\
0,057 & 0,042 & 0,025 & 0,037 \\
0,031 & 0,028 & ND & ND \\
0,223 & 0,203 & ND & ND \\
ND & ND & ND & 0,001 \\
0,002 & 0,001 & ND & 0,008 \\
0,081 & 0,029 & 0,039 & 0,065 \\
0,098 & 0,043 & 0,042 & 0,070 \\
ND & ND & ND & ND \\
0,019 & 0,008 & ND & ND \\
\hline
\end{tabular}

Como pode ser observado na Tabela 5.2; as quatro águas de estudo, mesmo tendo Cor Verdadeira próxima a $100 \mathrm{uH}$, apresentaram diferentes valores de COT, COD e Absorbância em $254 \mathrm{~nm}$. Analisando-se as Águas de Estudo 2, 3 e 4; nota-se que há uma tendência crescente nos valores desses parâmetros, conforme a redução do tamanho molecular aparente das SHAs usadas no preparo da água. Contudo, a Água de Estudo 1 apresenta valores intermediários de COT, COD e Absorbância em 254 nm; o que indica que a fração usada no preparo da água é uma mistura de SHA de variados tamanhos moleculares aparentes. O mesmo comportamento foi observado por De Julio (2005), para águas de estudo preparadas com frações SH de turfa de tamanho molecular aparente variado. Outros parâmetros que apresentaram tendência semelhante foram os Sólidos Totais, Suspensos e Dissolvidos.

Os resultados da caracterização das águas de estudo do presente trabalho leva-nos a concordar com De Julio (2005), que relatou que Cor Verdadeira é um parâmetro simplista para caracterização de águas. É válida, ainda, a recomendação de que sejam incluídas análises de COT e Absorbância em 254 nm tendo em vista uma caracterização mais completa de águas pré-tratamento. 


\subsection{ENSAIOS DE COAGULAÇÃO E FILTRAÇÃO}

Os resultados dos ensaios de coagulação e filtração foram compilados em Diagramas de Coagulação apresentados a seguir, nas Figuras 5.2 a 5.5. 


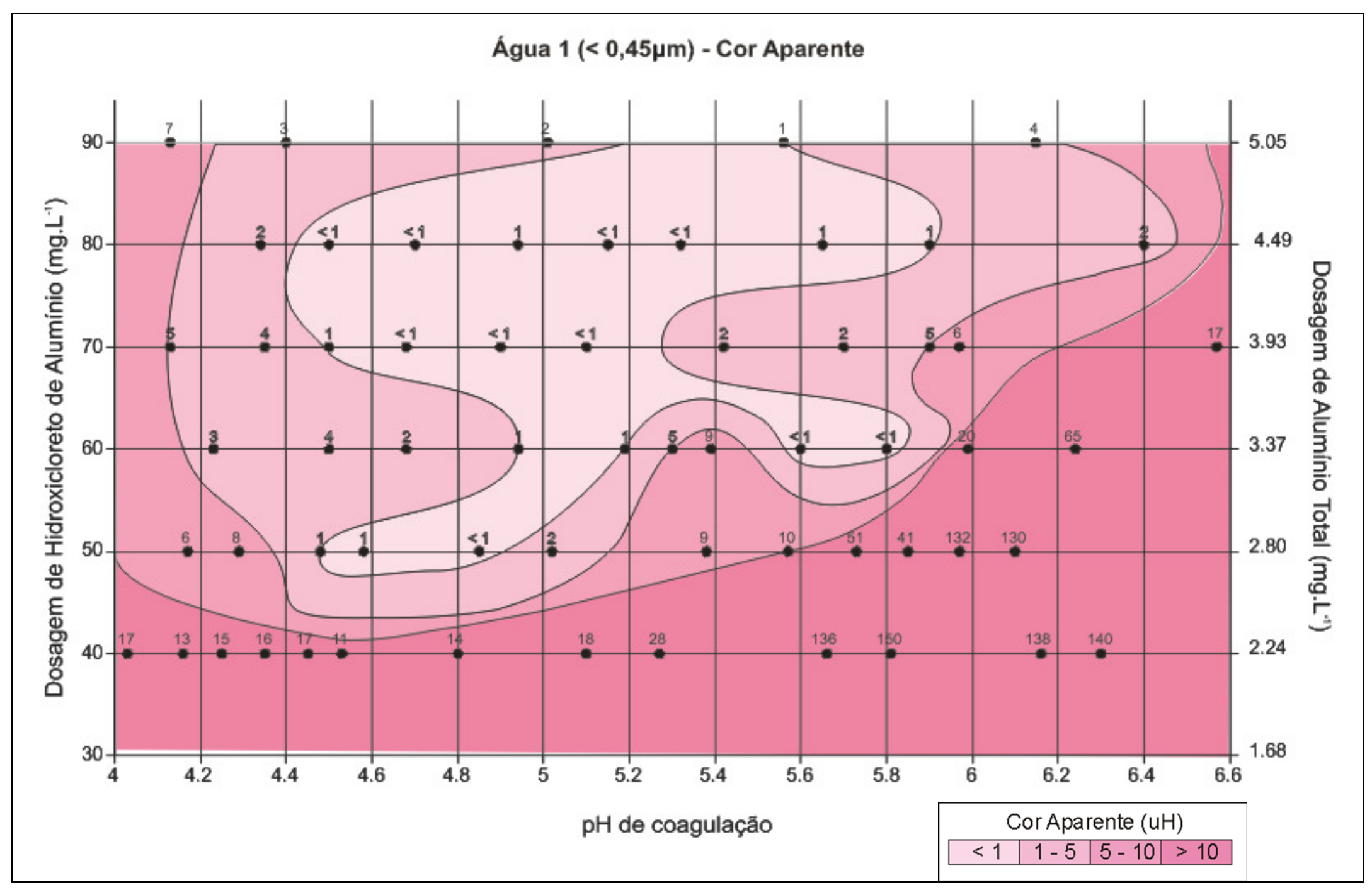

Figura 5.2: Diagrama de Coagulação da Água de Estudo 1 - Fração de SHA menor que $0,45 \mu$ m. 


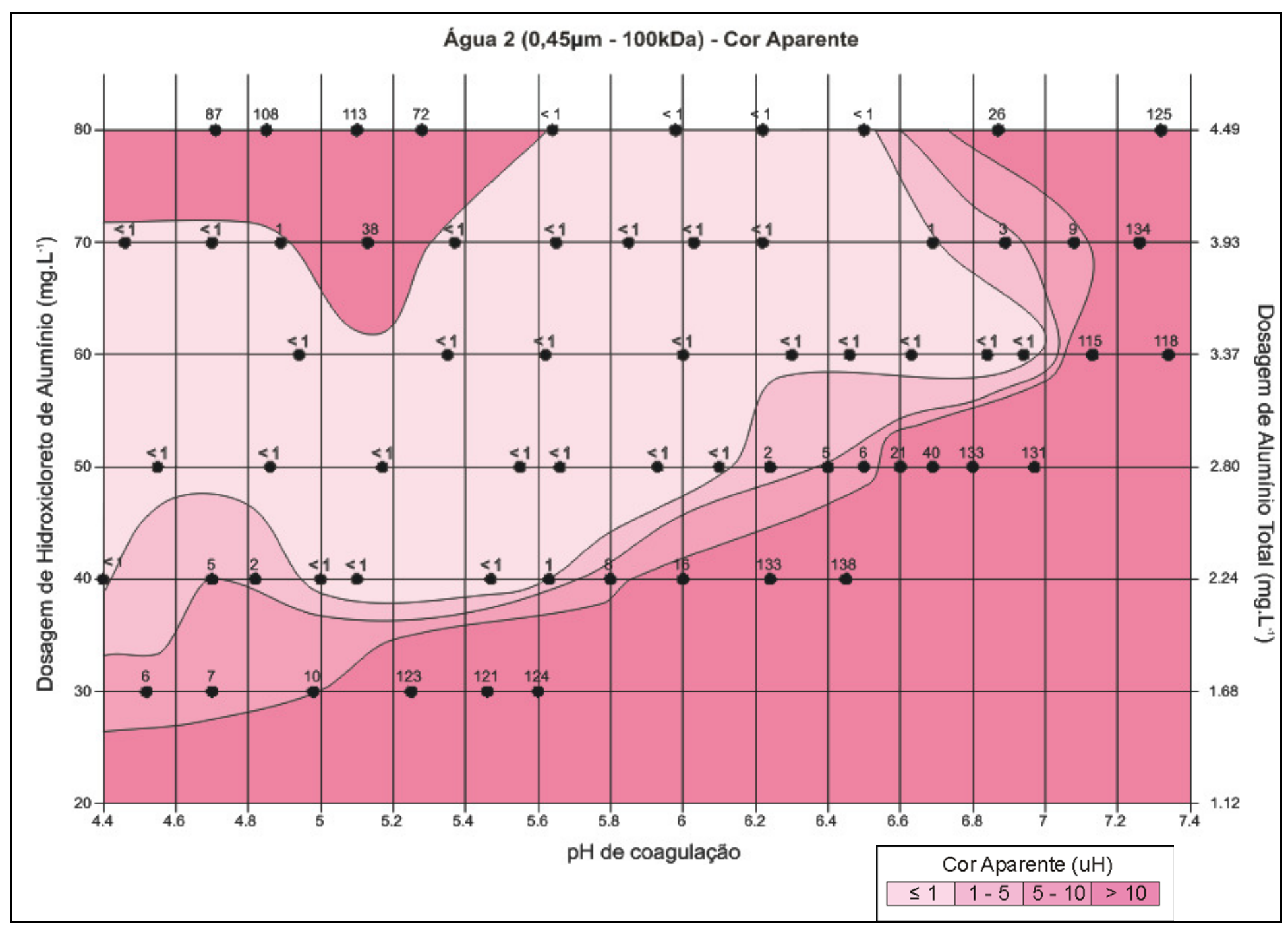

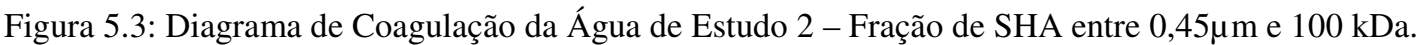




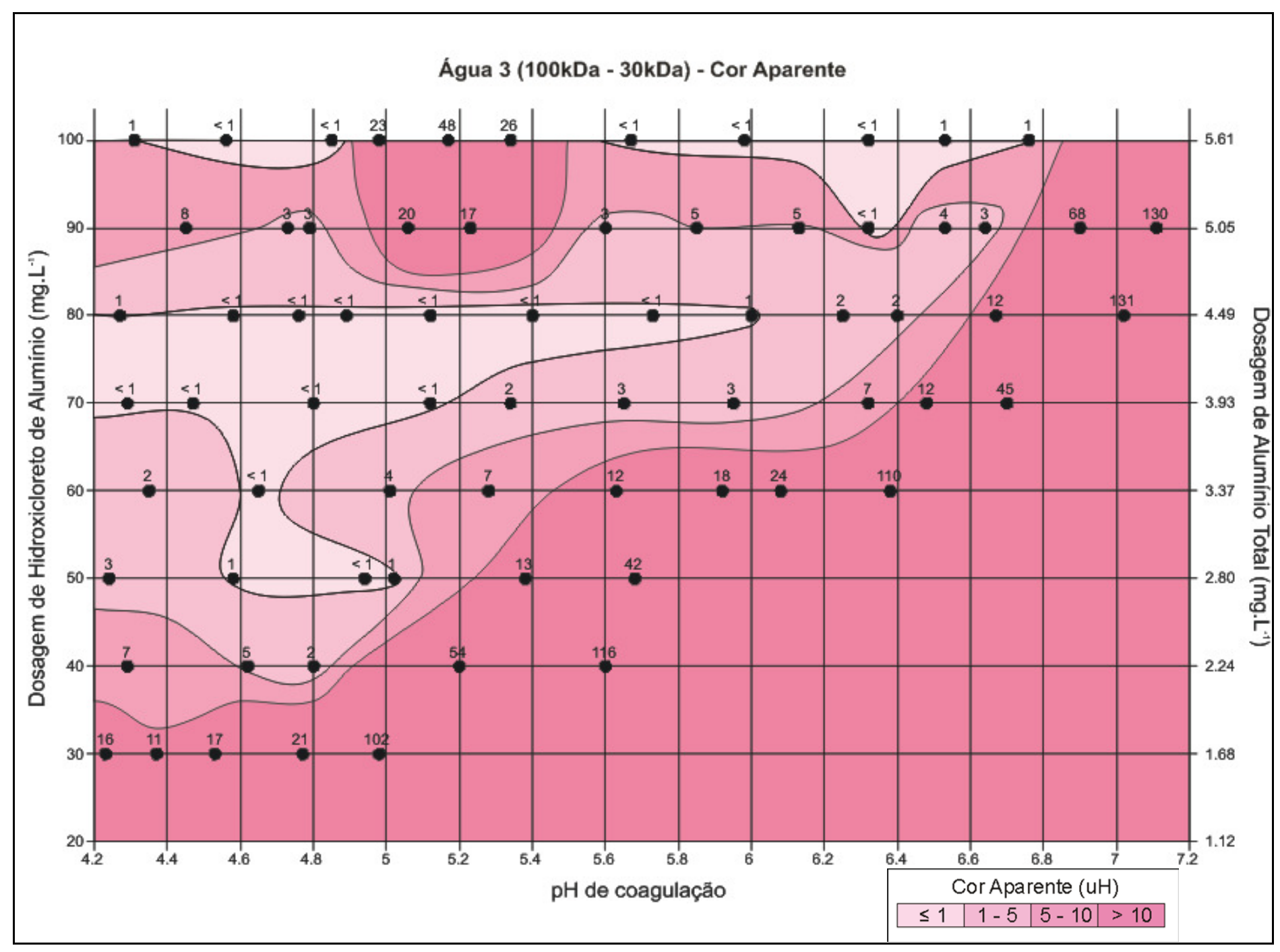

Figura 5.4: Diagrama de Coagulação da Água de Estudo 3 - Fração de SHA entre 100 kDa e 30 kDa. 


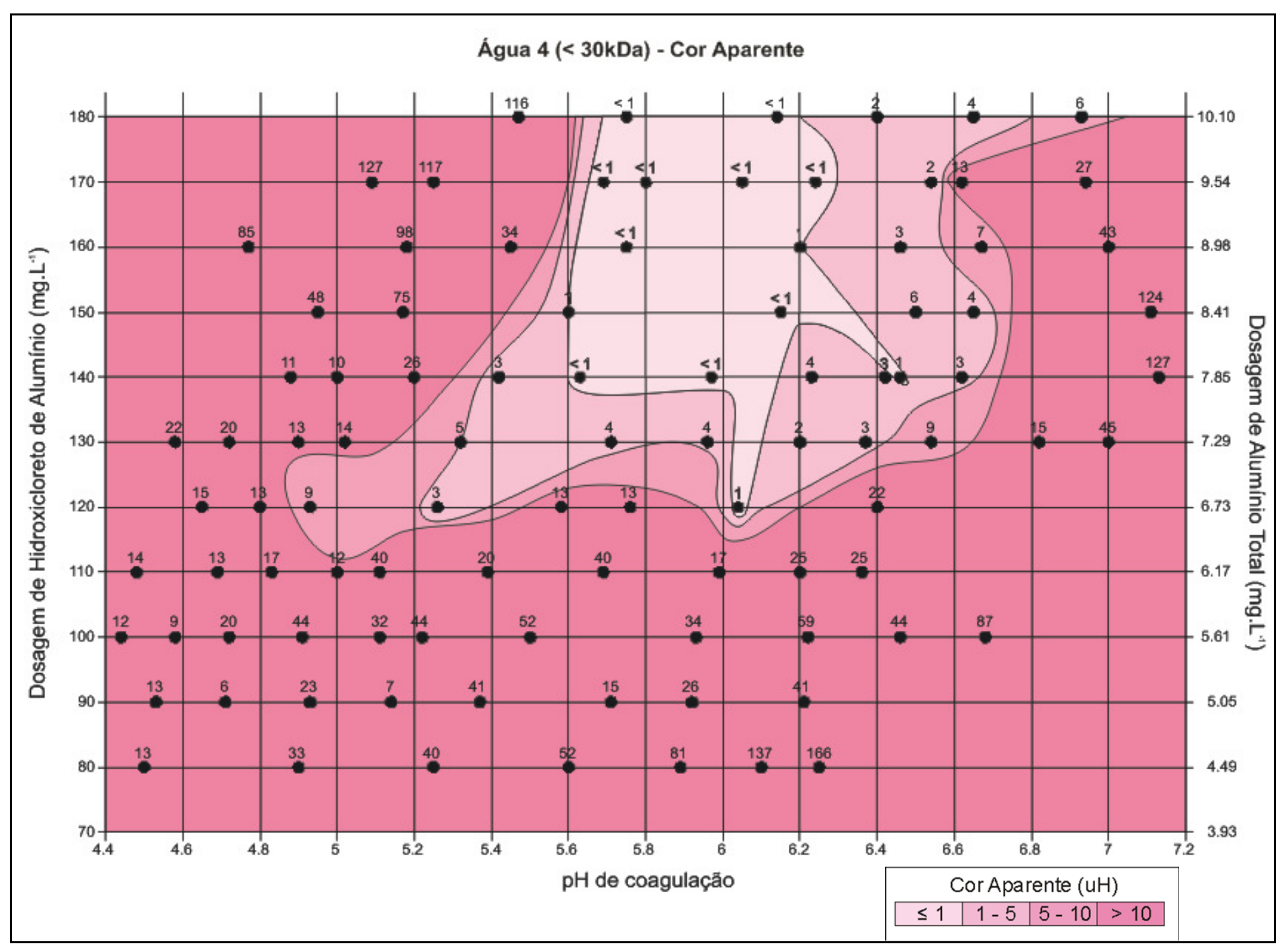

Figura 5.5: Diagrama de Coagulação da Água de Estudo 4 - Fração de SHA menor que 30 kDa 
A Água de Estudo 1, que foi preparada com extrato de SHA de tamanho molecular aparente $<0,45 \mu \mathrm{m}$, apresentou uma ampla região de cor aparente final menor que $5 \mathrm{uH}$ no diagrama de coagulação. Testaram-se dosagens de 30 a $90 \mathrm{mg} \mathrm{L}^{-1} \mathrm{com} \mathrm{pH}$ de coagulação variando entre 4,0 e 6,6, limites em que pode-se demarcar as condições de coagulação mais favoráveis para a remoção de cor. Como se pode observar na Figura 5.2, os pontos com resultados de cor aparente da água filtrada menor ou igual a $5 \mathrm{uH}$ foram obtidos com dosagens de hidroxicloreto de alumínio comercial a partir de $50 \mathrm{mg} \mathrm{L}^{-1}$ e $\mathrm{pH}$ de coagulação entre 4,2 e 6,4 .

A Água de Estudo 2 foi preparada a partir do extrato da fração de SHA com tamanho molecular aparente entre $100 \mathrm{kDa}$ e $0,45 \mu \mathrm{m}$. Os ensaios realizados com essa água (Figura 5.3) apresentaram grande facilidade na obtenção de pontos com baixa cor aparente da água filtrada. Pontos com dosagens de coagulante a partir de $40 \mathrm{mg} \mathrm{L}^{-1}$ e com $\mathrm{pH}$ de coagulação abaixo de 7,0 apresentaram resultados de cor aparente final menores ou iguais a $5 \mathrm{uH}$. Sendo que, para dosagens maiores que $70 \mathrm{mg} \mathrm{L}^{-1}$ e pH abaixo de 5,6, percebe-se uma região em que a remoção de cor não se mostrou eficiente.

Para a Água de Estudo 3, preparada com fração de SHA de tamanho molecular aparente entre 30 e $100 \mathrm{kDa}$, a região do diagrama de coagulação (Figura 5.4) com cor aparente final menor ou igual a $5 \mathrm{uH}$ foi menor em relação à da Água de Estudo 2. Os pontos que apresentaram resultados de cor aparente da água filtrada menores ou iguais a $5 \mathrm{uH}$ foram os de dosagens entre 40 e $90 \mathrm{mg} \mathrm{L}^{-1}$ de hidroxicloreto de alumínio e pH entre 4,2 e 6,5. Outras duas regiões de resultados semelhantes aparentemente iniciam-se em dosagens superiores a $100 \mathrm{mg} \mathrm{L}^{-1}$ com intervalos de $\mathrm{pH}$ entre 4,3 e 4,8 e entre 5,6 e 6,8 .

A Água de Estudo 4 foi a que apresentou maior dificuldade para obtenção de pontos com cor aparente da água filtrada menor ou igual a $5 \mathrm{uH}$. Esta água foi preparada com extrato da menor fração de SHA estudada, de tamanho molecular aparente menor que $30 \mathrm{kDa}$. O diagrama de coagulação obtido para a Água de Estudo 4, que pode ser visto na Figura 5.5, apresentou pontos de cor aparente final menor ou igual a $5 \mathrm{uH}$ a partir da dosagem de $120 \mathrm{mg}$ $\mathrm{L}^{-1}$ de hidroxicloreto de alumínio, com faixa de $\mathrm{pH}$ entre 5,3 e 6,7.

Fazendo-se uma leitura dos resultados encontrados para as quatro águas de estudo; vêse que, para a água preparada com a fração de menor tamanho molecular aparente, houve necessidade de maiores concentrações de coagulante para remoção de cor por coagulação seguida de filtração. E mesmo entre as três águas com fração de SHA com maiores tamanhos moleculares aparentes ocorreram variações nas regiões "dosagem x pH" que apresentaram cor aparente final baixa. Esses resultados mostram a influência do tamanho molecular aparente 
das SHA nas condições de coagulação com hidroxicloreto de alumínio, como já observado em trabalhos anteriores com outros coagulantes (Sloboda, 2007; Campos, 2004).

Nota-se, também, que quanto menor o tamanho molecular aparente das SHA, mais restrita é a região de cor aparente final baixa e maiores são as concentrações de hidroxicloreto de alumínio requeridas; o que demonstra a maior dificuldade na remoção das menores frações de SHA por coagulação seguida de filtração. O que pode explicar esse comportamento é que quanto menor o tamanho molecular aparente da fração de SHA, maior a concentração de ácidos fúlvicos e menor e de ácidos húmicos. Os ácidos fúlvicos têm grande teor de grupos com cargas negativas, o que requer maior quantidade de coagulante para desestabilizá-las.

\subsection{REPRODUÇÃO DAS CONDIÇÕES DE COAGULAÇÃO DE SLOBODA (2007)}

Com as quatro águas de estudo, reproduziram-se as condições de coagulação de Sloboda (2007).

As Figuras 5.6 a 5.9 mostram os pontos encontrados para coagulação com sulfato de alumínio e cloreto férrico. Os pontos encontrados foram sobrepostos aos Diagramas de Coagulação da autora, para se verificar se as condições de coagulação foram realmente reproduzidas para as águas preparadas. 


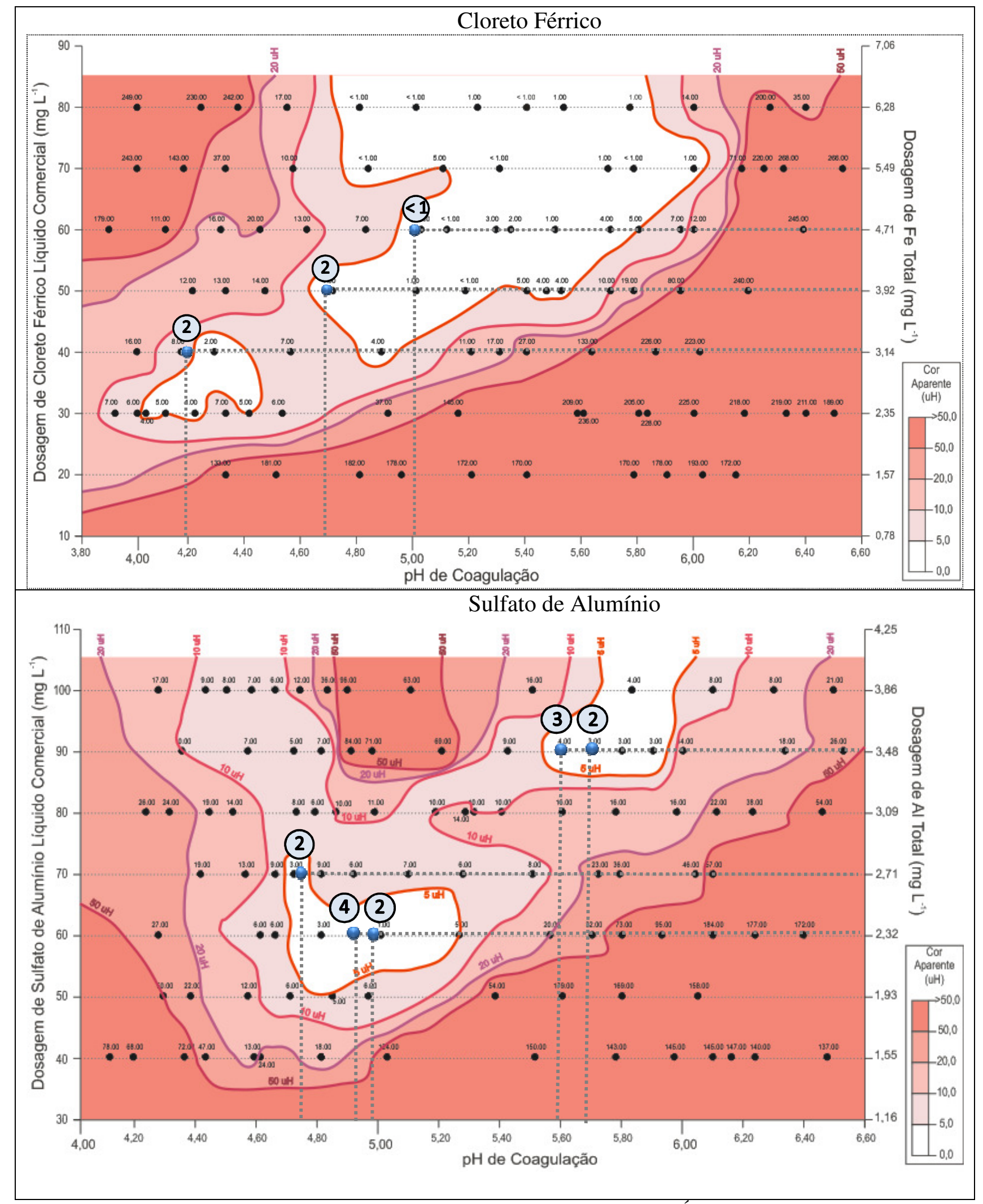

Figura 5.6: Pontos obtidos, com cor aparente final indicada, para Água de Estudo 1. 


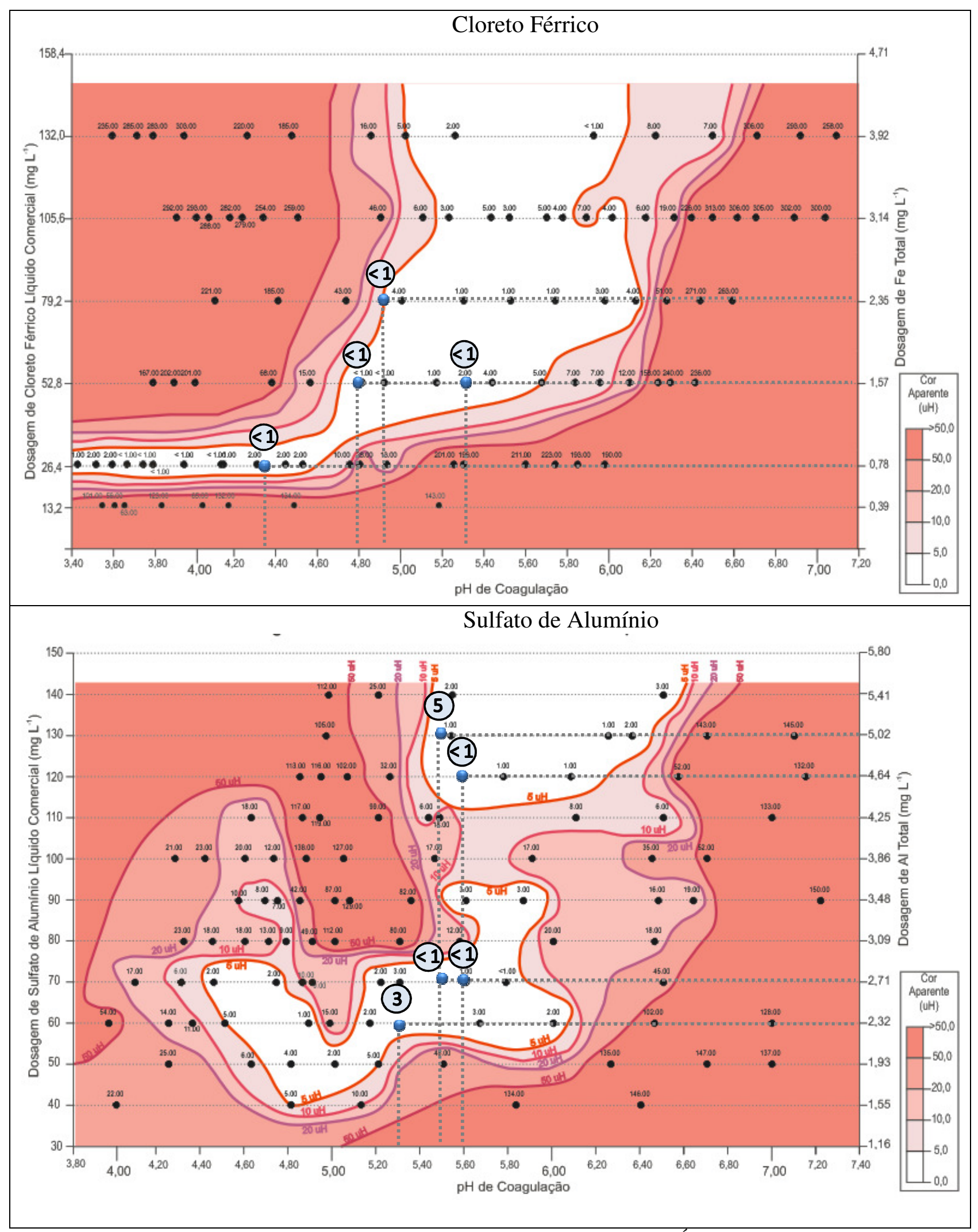

Figura 5.7: Pontos obtidos, com cor aparente final indicada, para Água de Estudo 2. 


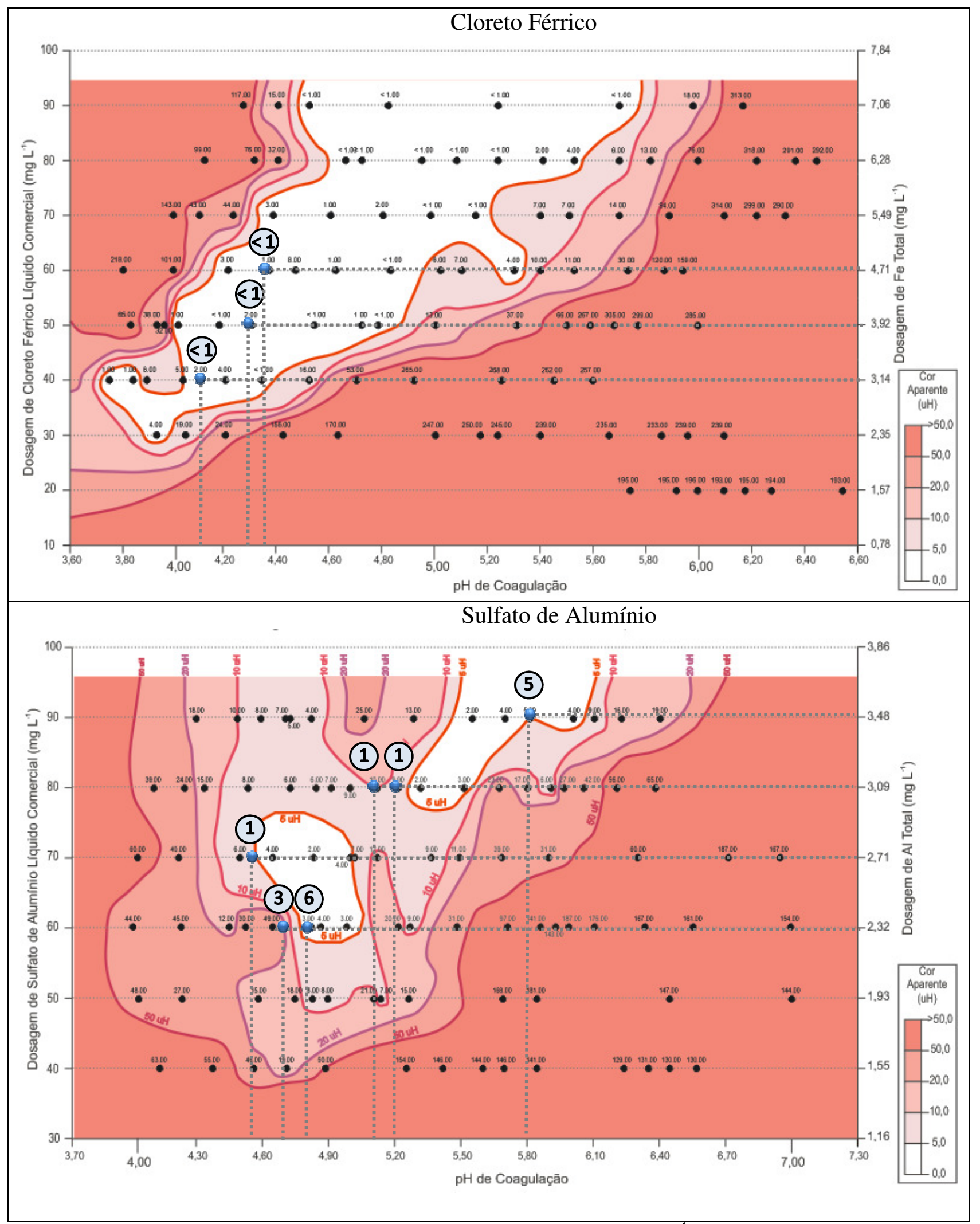

Figura 5.8: Pontos obtidos, com cor aparente final indicada, para Água de Estudo 3. 


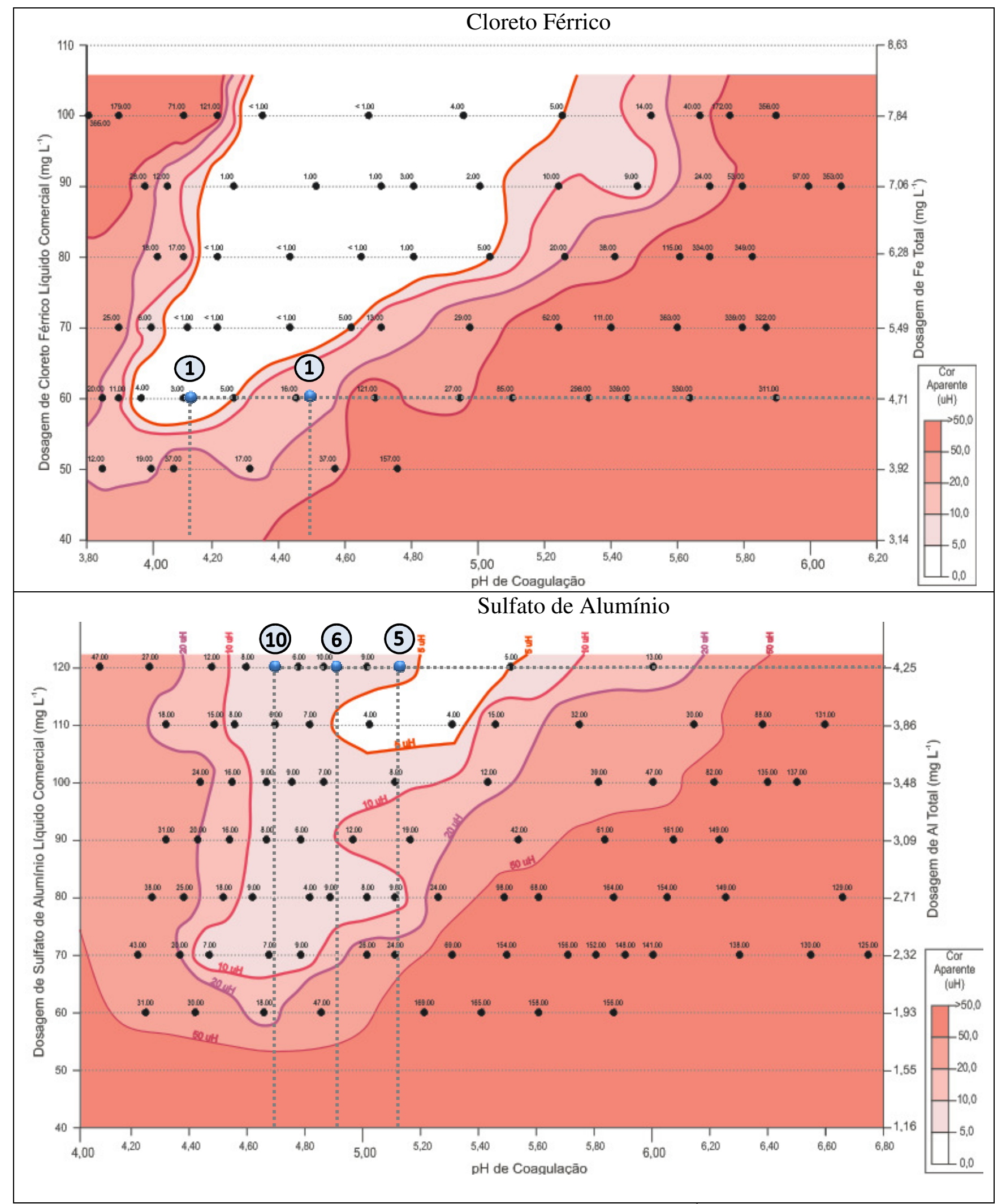

Figura 5.9: Pontos obtidos, com cor aparente final indicada, para Água de Estudo 4. 
Como se pode verificar, a maioria dos pontos obtidos nas mesmas faixas de $\mathrm{pH}$ e dosagem de coagulantes apresentaram valores de cor aparente da água filtrada semelhantes aos encontrados por Sloboda (2007). Sendo assim, podemos considerar as condições de coagulação encontradas pela autora como válidas para as quatro águas de estudo usadas no presente trabalho.

\subsection{COMPARAÇÃO DE CUSTOS DOS COAGULANTES}

Considerando os Diagramas de Coagulação de Sloboda e os obtidos no presente trabalho, fez-se a comparação dos custos com produtos químicos entre os três coagulantes usados.

Os pontos usados para comparação de custos foram aqueles que apresentaram menor consumo de coagulantes e alcalinizante, dentro da faixa de cor aparente final menor ou igual a $5 \mathrm{uH}$ e também aqueles que apresentaram menor valor de cor aparente da água filtrada, para cada uma das quatro águas estudadas. Nas Figuras 5.10 a 5.13 são apresentados os diagramas de coagulação das águas estudadas com os três coagulantes. Foram selecionados dois pontos em cada diagrama:

- Ponto A: ponto "dosagem de coagulante x pH de coagulação" que resultou na menor cor aparente da água filtrada; nos casos pontos com o mesmo valor de cor aparente, foi escolhido aquele com as menores dosagens de produtos químicos;

- Ponto B: ponto "dosagem de coagulante x pH de coagulação" que resultou em cor aparente menor ou igual a $5 \mathrm{uH}$, com as menores dosagens de produtos químicos. 


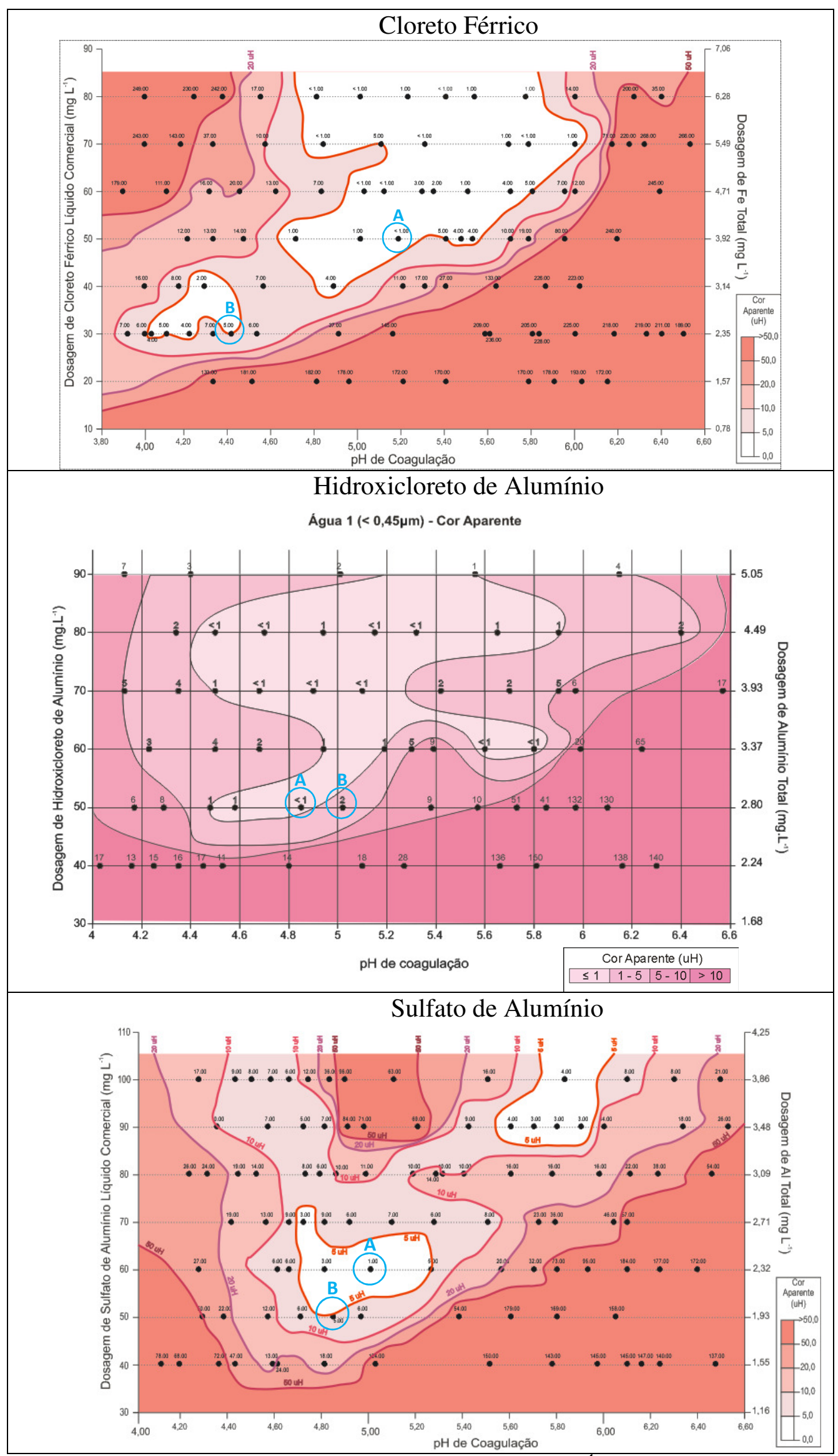

Figura 5.10: Pontos escolhidos para análise de custos - Água de Estudo 1. 


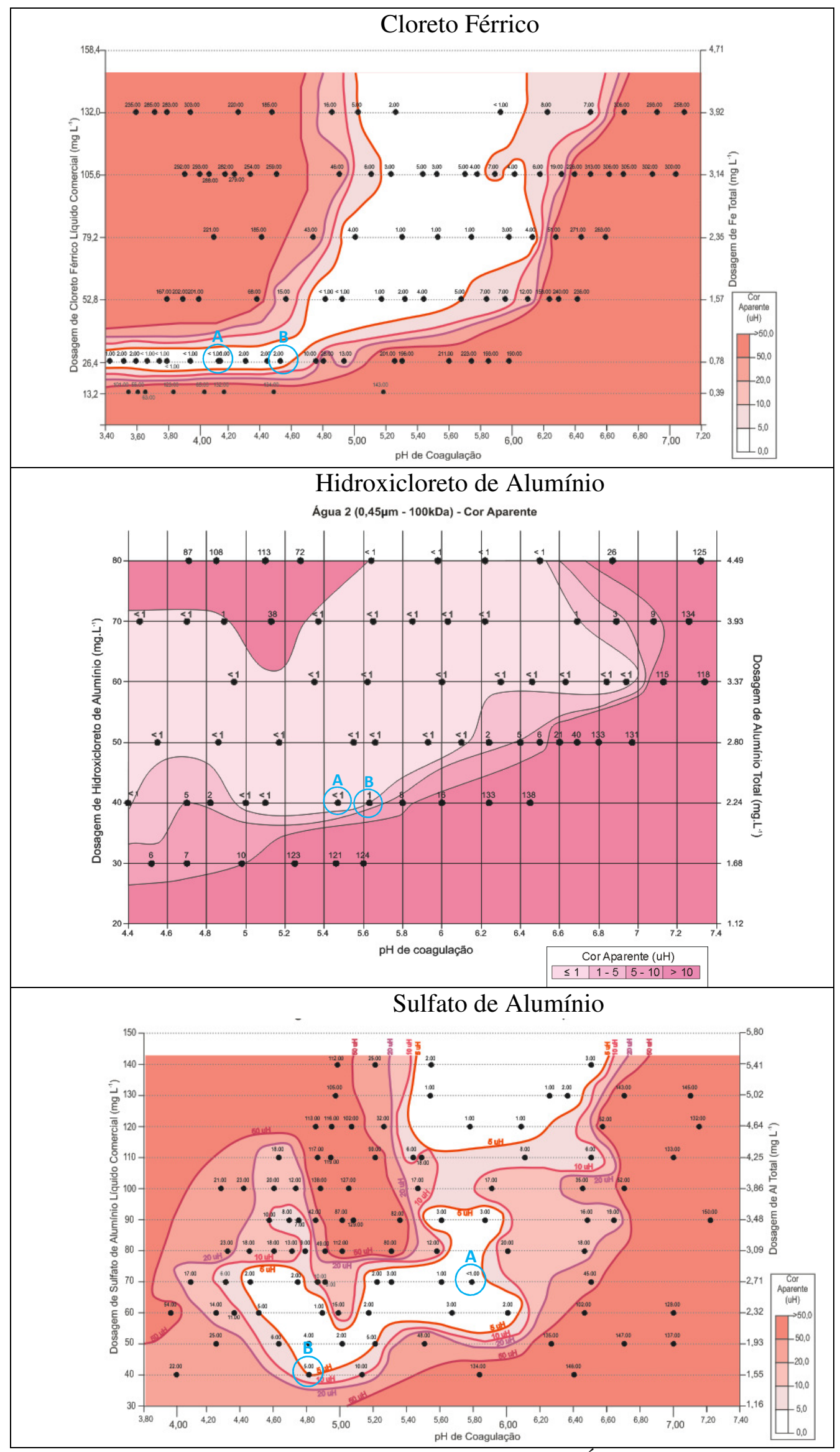

Figura 5.11: Pontos escolhidos para análise de custos - Água de Estudo 2. 


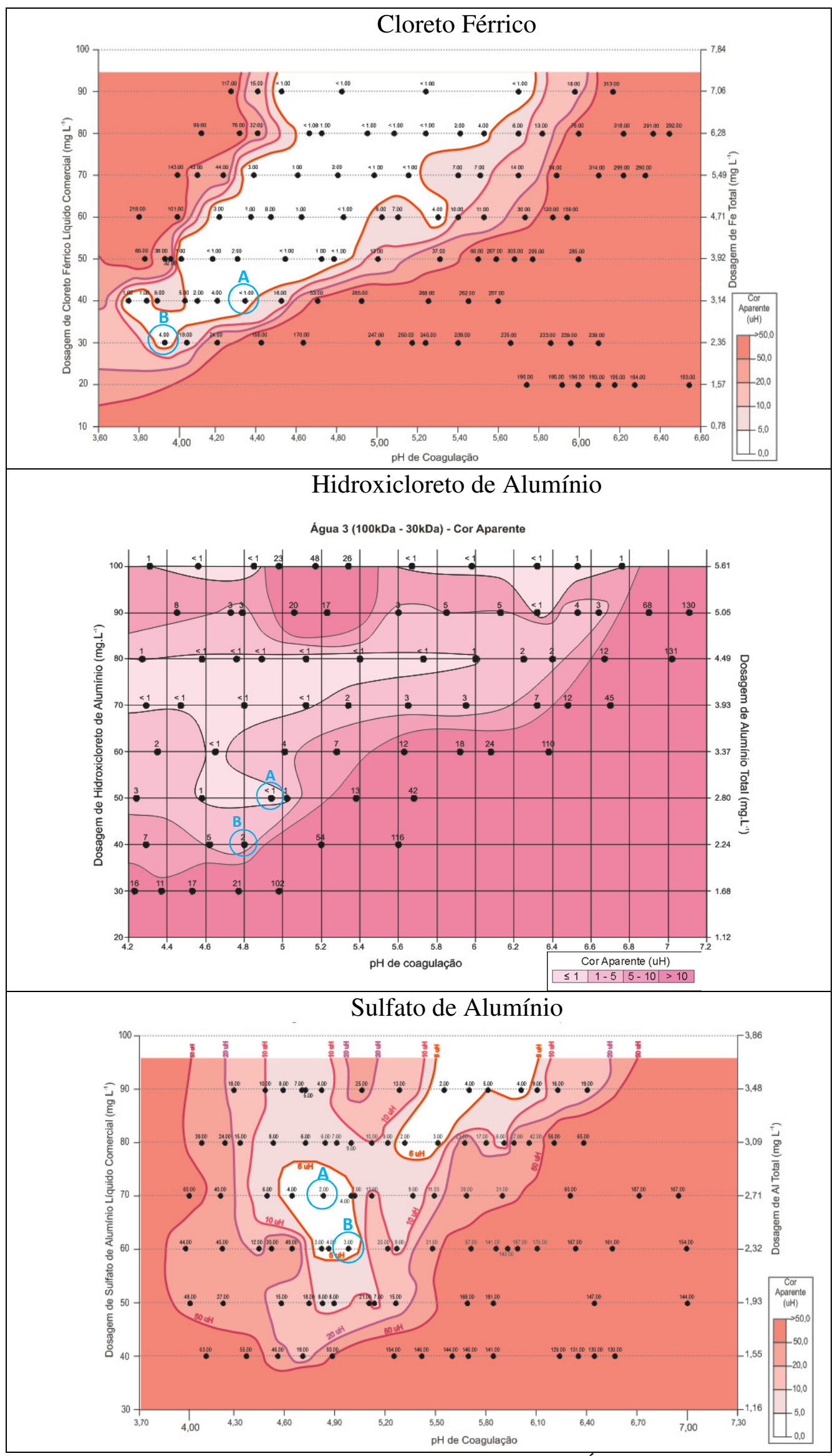

Figura 5.12: Pontos escolhidos para análise de custos - Água de Estudo 3 


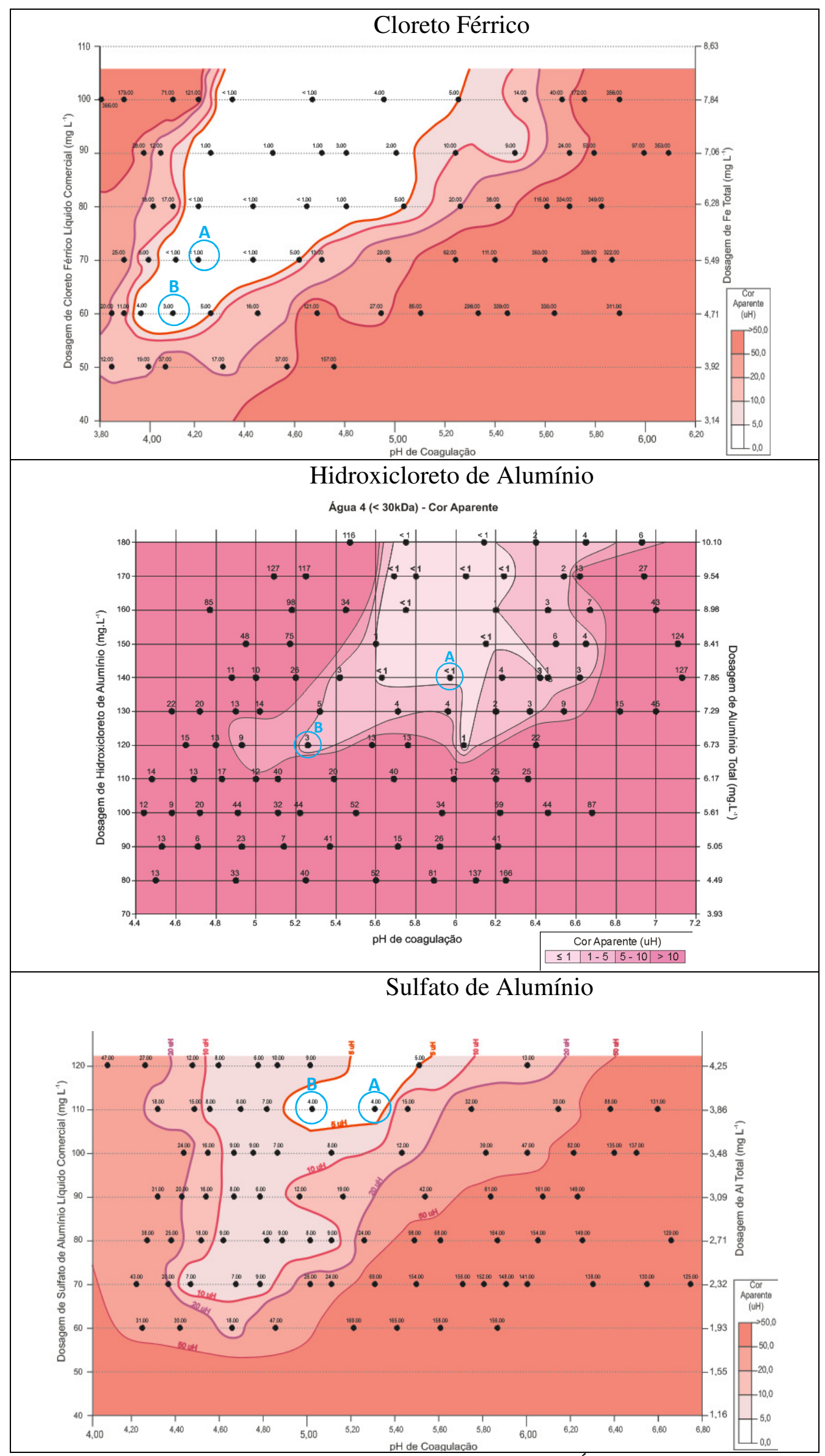

Figura 5.13: Pontos escolhidos para análise de custos - Água de Estudo 4 
Selecionados os pontos em cada diagrama de coagulação, realizou-se o cálculo dos custos com produtos químicos para tratamento por filtração direta das quatro águas de estudo. Os valores encontrados estão dispostos nas Tabelas 5.3 a 5.6.

Os seguintes preços ${ }^{1}$ foram considerados nos cálculos:

- Sulfato de alumínio: produto comercial líquido com 7,28\% de $\mathrm{Al}_{2} \mathrm{O}_{3}(\mathrm{~m} / \mathrm{m}) ; \mathrm{R} \$$ $450,00 / \mathrm{t}$

- Cloreto férrico: produto comercial líquido $38 \%$ de $\mathrm{FeCl}_{3} x \quad 6 \quad \mathrm{H}_{2} \mathrm{O}(\mathrm{m} / \mathrm{m}) ; \mathrm{R} \$$ $750,00 / t$

- Hidroxicloreto de alumínio: produto comercial líquido: $10 \%$ de $\mathrm{Al}_{2} \mathrm{O}_{3}(\mathrm{~m} / \mathrm{m}) ; \mathrm{R} \$$ $885,00 /$;

- Ácido clorídrico: produto comercial com $32 \%(\mathrm{~m} / \mathrm{m}) ; \mathrm{R} \$ 580,00 / \mathrm{t}$;

- Hidróxido de sódio: produto comercial base anidra; $\mathrm{R} \$ 700,00 / \mathrm{t}$.

Tabela 5.3: Custos com produtos químicos para tratamento da Água de Estudo 1

\begin{tabular}{|c|c|c|c|c|c|c|c|c|}
\hline \multirow{2}{*}{\multicolumn{2}{|c|}{$\begin{array}{l}\text { ÁGUA DE } \\
\text { ESTUDO } 1 \\
(\text { SHA }<0,45 \mu \mathrm{m})\end{array}$}} & \multicolumn{3}{|c|}{ Dosagem de Produtos Químicos (mg/L) } & \multirow{2}{*}{$\begin{array}{l}\begin{array}{l}\text { Água } \\
\text { coagulada }\end{array} \\
\text { pH coagulação }\end{array}$} & \multicolumn{2}{|c|}{ Água Filtrada } & \multirow{2}{*}{$\begin{array}{l}\text { Custo } \\
\text { Total } \\
\left(\mathrm{R} \$ / 1000 \mathrm{~m}^{3}\right)\end{array}$} \\
\hline & & Coagulante & $\begin{array}{l}\text { Ácido } \\
\text { Clorídrico }\end{array}$ & $\begin{array}{l}\text { Hidróxido } \\
\text { de Sódio }\end{array}$ & & $\begin{array}{l}\text { Turbidez } \\
\text { (uT) }\end{array}$ & $\begin{array}{l}\text { Cor Apar. } \\
(\mathrm{uH})\end{array}$ & \\
\hline \multirow{2}{*}{$\begin{array}{l}\text { Cloreto } \\
\text { Férrico }\end{array}$} & A & 50 & 0,00 & 8,40 & 5,18 & 0,46 & $<1$ & 43,38 \\
\hline & B & 30 & $\mathbf{0 , 8 7}$ & $\mathbf{0 , 0 0}$ & 4,40 & $\mathbf{0 , 4 0}$ & 5 & 22,94 \\
\hline \multirow{2}{*}{$\begin{array}{l}\text { Hidroxicloreto } \\
\text { de Alumínio }\end{array}$} & A & 50 & 9,27 & 0,00 & 4,85 & 0,49 & $<1$ & 48,89 \\
\hline & B & 50 & 8,11 & 0,00 & 5,02 & 0,53 & 2 & 48,31 \\
\hline \multirow{2}{*}{$\begin{array}{l}\text { Sulfato de } \\
\text { Alumínio }\end{array}$} & A & 60 & 0,00 & 0,00 & 5,00 & 0,40 & 1 & 27,00 \\
\hline & B & 50 & 4,34 & 0,00 & 4,84 & 0,38 & 5 & 24,68 \\
\hline
\end{tabular}

Para a Água de Estudo 1, o menor custo com produtos químicos foi obtido para o ponto $\mathrm{B}$, com o coagulante cloreto férrico. Para o tratamento com sulfato de alumínio, os custos de ambos os pontos foram próximos; com valor um pouco superior ao menor obtido nos ensaios com cloreto férrico. Já o hidroxicloreto de alumínio foi o coagulante que

\footnotetext{
${ }^{1}$ A cotação dos produtos químicos foi feita junto a fornecedores do interior do Estado de São Paulo, no início de 2009. 
apresentou maior custo para o tratamento proposto para Água 1, com valores próximos ao dobro do menor custo calculado para os pontos obtidos nos ensaios com esta água.

Tabela 5.4: Custos com produtos químicos para tratamento da Água de Estudo 2

\begin{tabular}{|c|c|c|c|c|c|c|c|c|}
\hline \multirow{2}{*}{\multicolumn{2}{|c|}{$\begin{array}{l}\text { ÁGUA DE } \\
\text { ESTUDO } 2 \\
\text { (SHA entre } 0,45 \\
\mu \mathrm{m} \text { e } 100 \mathrm{kDa})\end{array}$}} & \multicolumn{3}{|c|}{ Dosagem de Produtos Químicos (mg/L) } & \multirow{2}{*}{$\begin{array}{l}\begin{array}{l}\text { Água } \\
\text { coagulada }\end{array} \\
\text { pH coagulação }\end{array}$} & \multicolumn{2}{|c|}{ Água Filtrada } & \multirow{2}{*}{$\begin{array}{l}\text { Custo } \\
\text { Total } \\
\left(\mathrm{R} \$ / 1000 \mathrm{~m}^{3}\right)\end{array}$} \\
\hline & & Coagulante & $\begin{array}{l}\text { Ácido } \\
\text { Clorídrico }\end{array}$ & $\begin{array}{l}\text { Hidróxido } \\
\text { de Sódio }\end{array}$ & & $\begin{array}{l}\text { Turbidez } \\
\text { (uT) }\end{array}$ & $\begin{array}{l}\text { Cor Apar. } \\
\text { (uH) }\end{array}$ & \\
\hline \multirow{2}{*}{$\begin{array}{l}\text { Cloreto } \\
\text { Férrico }\end{array}$} & A & 26,4 & 4,06 & 0,00 & 4,13 & 0,43 & $<1$ & 21,83 \\
\hline & B & 26,4 & 2,03 & 0,00 & 4,52 & 0,38 & 2 & 20,82 \\
\hline \multirow{2}{*}{$\begin{array}{l}\text { Hidroxicloreto } \\
\text { de Alumínio }\end{array}$} & A & 40 & 2,32 & 0,00 & 5,47 & 0,59 & $<1$ & 36,56 \\
\hline & B & 40 & 1,16 & 0,00 & 5,63 & 0,57 & 1 & 35,98 \\
\hline \multirow{2}{*}{$\begin{array}{l}\text { Sulfato de } \\
\text { Alumínio }\end{array}$} & A & 70 & 0,00 & 8,75 & 5,60 & 0,42 & $<1$ & 37,63 \\
\hline & B & 40 & $\mathbf{0 , 0 0}$ & $\mathbf{0 , 0 0}$ & 4,80 & 0,45 & 5 & 18,00 \\
\hline
\end{tabular}

Nos ensaios com a Água de Estudo 2, o menor custo com produtos químicos foi obtido no ensaio com sulfato de alumínio, ponto B. O cloreto férrico apresentou custo próximo a esse para ambos os pontos estudados. E para esta água, o hidroxicloreto de alumínio também foi a opção mais cara.

Tabela 5.5: Custos com produtos químicos para tratamento da Água de Estudo 3

\begin{tabular}{|c|c|c|c|c|c|c|c|c|}
\hline \multirow{2}{*}{\multicolumn{2}{|c|}{$\begin{array}{l}\text { ÁGUA DE } \\
\text { ESTUDO } 3 \\
\text { (SHA entre } 100 \mathrm{e} \\
30 \mathrm{kDa})\end{array}$}} & \multicolumn{3}{|c|}{ Dosagem de Produtos Químicos (mg/L) } & \multirow{2}{*}{$\begin{array}{l}\begin{array}{l}\text { Água } \\
\text { coagulada }\end{array} \\
\text { pH coagulação }\end{array}$} & \multicolumn{2}{|c|}{ Água Filtrada } & \multirow{2}{*}{$\begin{array}{l}\text { Custo } \\
\text { Total } \\
\left(\mathrm{R} \$ / 1000 \mathrm{~m}^{3}\right.\end{array}$} \\
\hline & & Coagulante & $\begin{array}{l}\text { Ácido } \\
\text { Clorídrico }\end{array}$ & $\begin{array}{l}\text { Hidróxido } \\
\text { de Sódio }\end{array}$ & & $\begin{array}{l}\text { Turbidez } \\
\text { (uT) }\end{array}$ & $\begin{array}{l}\text { Cor Apar. } \\
\text { (uH) }\end{array}$ & \\
\hline \multirow{2}{*}{$\begin{array}{l}\text { Cloreto } \\
\text { Férrico }\end{array}$} & A & 40 & 0,41 & 0,00 & 4,34 & 0,48 & $<1$ & 30,20 \\
\hline & B & 30 & 10,43 & $\mathbf{0 , 0 0}$ & 3,94 & $\mathbf{0 , 8 0}$ & 4 & 27,72 \\
\hline \multirow{2}{*}{$\begin{array}{l}\text { Hidroxicloreto } \\
\text { de Alumínio }\end{array}$} & A & 50 & 4,63 & 0,00 & 4,94 & 0,67 & $<1$ & 46,57 \\
\hline & $\mathrm{B}$ & 40 & 5,21 & 0,00 & 4,80 & 0,60 & 2 & 38,01 \\
\hline \multirow{2}{*}{$\begin{array}{l}\text { Sulfato de } \\
\text { Alumínio }\end{array}$} & A & 70 & 2,90 & 0,00 & 4,81 & 0,52 & 2 & 32,95 \\
\hline & $\mathrm{B}$ & 60 & 2,90 & 0,00 & 4,96 & 0,48 & 3 & 28,45 \\
\hline
\end{tabular}


Para a Água de Estudo 3, o menor custo com produtos químicos foi obtido para o com o coagulante cloreto férrico, ponto B; assim como observado para a Água de Estudo 1. O sulfato de alumínio apresentou custo intermediário. O hidroxicloreto de alumínio foi o coagulante que apresentou maior custo.

Tabela 5.6: Custos com produtos químicos para tratamento da Água de Estudo 4

\begin{tabular}{|c|c|c|c|c|c|c|c|c|}
\hline \multirow{2}{*}{\multicolumn{2}{|c|}{$\begin{array}{l}\text { ÁGUA DE } \\
\text { ESTUDO } 4 \\
(\text { SHA < } 30 \text { kDa })\end{array}$}} & \multicolumn{3}{|c|}{ Dosagem de Produtos Químicos (mg/L) } & \multirow{2}{*}{$\begin{array}{l}\begin{array}{l}\text { Água } \\
\text { coagulada }\end{array} \\
\text { pH coagulação }\end{array}$} & \multicolumn{2}{|c|}{ Água Filtrada } & \multirow{2}{*}{$\begin{array}{l}\text { Custo } \\
\text { Total } \\
\left(\mathrm{R} \$ / 1000 \mathrm{~m}^{3}\right)\end{array}$} \\
\hline & & Coagulante & $\begin{array}{l}\text { Ácido } \\
\text { Clorídrico }\end{array}$ & $\begin{array}{l}\text { Hidróxido } \\
\text { de Sódio }\end{array}$ & & $\begin{array}{l}\text { Turbidez } \\
\text { (uT) }\end{array}$ & $\begin{array}{l}\text { Cor Apar. } \\
\text { (uH) }\end{array}$ & \\
\hline \multirow{2}{*}{$\begin{array}{l}\text { Cloreto } \\
\text { Férrico }\end{array}$} & A & 70 & 0,00 & 8,00 & 4,11 & 0,48 & $<1$ & 58,10 \\
\hline & B & 60 & $\mathbf{0 , 0 0}$ & 5,00 & 4,10 & 0,63 & 3 & 48,50 \\
\hline \multirow{2}{*}{$\begin{array}{l}\text { Hidroxicloreto } \\
\text { de Alumínio }\end{array}$} & $\mathrm{A}$ & 140 & 0,00 & 6,00 & 5,63 & 0,51 & $<1$ & 128,10 \\
\hline & B & 120 & 0,00 & 2,00 & 5,26 & 0,66 & 3 & 107,60 \\
\hline \multirow{2}{*}{$\begin{array}{l}\text { Sulfato de } \\
\text { Alumínio }\end{array}$} & A & 110 & 13,03 & 0,00 & 5,30 & 0,56 & 4 & 56,03 \\
\hline & $\mathrm{B}$ & 110 & 10,72 & 0,00 & 5,01 & 0,52 & 4 & 54,87 \\
\hline
\end{tabular}

Para a Água de Estudo 4, novamente observou-se menor custo com produtos químicos usando o cloreto férrico como coagulante e o maior, o hidroxicloreto de alumínio.

Como se pode observar; para todas as águas de estudo, os pontos obtidos nos ensaios com hidroxicloreto de alumínio apresentaram os maiores custos com produtos químicos para o tratamento proposto. Apesar disso, este coagulante demonstrou maior facilidade de remoção de SHA quando comparado com os outros dois estudados por Sloboda (2007), com regiões amplas de cor aparente da água filtrada menor que a máxima permitida pela Portaria 518/2004 do Ministério da Saúde - $15 \mathrm{uH}$ - para todas as águas estudadas. Com isso, o hidróxido de alumínio pode ser uma alternativa interessante para tratamento de águas com elevada cor aparente e baixa turbidez, por sua maior flexibilidade operacional. Assim, cabe às empresas operadoras de estações de tratamento de água avaliar o custo-benefício do uso do coagulante hidróxido de alumínio.

Para três das quatro águas preparadas com frações de diferentes tamanhos moleculares aparentes de SHA, o cloreto férrico foi o coagulante que apresentou menores custos com 
produtos químicos para tratamento por coagulação e filtração direta. Sendo que os custos obtidos para os ensaios com sulfato de alumínio mantiveram-se próximos àqueles. 


\section{CONCLUSÕES E RECOMENDAÇÕES}

As conclusões deste trabalho foram:

- Pode-se afirmar que há influência do tamanho molecular aparente de diferentes frações de substâncias húmicas aquáticas na coagulação por hidroxicloreto de alumínio. A tendência observada é que quanto menor o tamanho molecular aparente da fração de SHA, maiores as concentrações requeridas do coagulante dentro de determinada faixa de $\mathrm{pH}$ - para redução da cor aparente a valores menores ou iguais a $5 \mathrm{uH}$;

- Para as águas estudadas, as regiões “dosagem x pH” nas quais se obtiveram pontos com cor aparente final da água filtrada menor ou igual a $5 \mathrm{uH}$ variaram conforme apresentado na Tabela 6.1;

Tabela 6.1: Regiões com cor aparente final menor ou igual a $5 \mathrm{uH}$

\begin{tabular}{lll}
\hline \hline Água de Estudo & $\begin{array}{l}\text { Faixa de dosagem de } \\
\text { hidroxicloreto de alumínio } \\
\left(\mathrm{mg} \mathrm{L}^{-1}\right)\end{array}$ & $\begin{array}{l}\text { Faixa de } \mathrm{pH} \\
\text { de coagulação }\end{array}$ \\
\hline Água 1 & 50 a 90 & 4,1 a 6,4 \\
\hline Água 2 & 40 a 80 & 4,4 a 7,0 \\
\hline & 40 a 90 & 4,2 a 6,7 \\
Água 3 & 90 a 100 & 5,6 a 6,8 \\
\hline Água 4 & 100 & 4,3 a 4,9 \\
\hline \hline
\end{tabular}

- Entre os coagulantes estudados: sulfato de alumínio; cloreto férrico e hidroxicloreto de alumínio; para águas com elevada cor verdadeira - devida a presença de SHA de tamanhos moleculares aparentes variados - e baixa turbidez, o cloreto férrico apresentou menor custo de tratamento na maioria dos casos, considerando somente os custos com produtos químicos e tratamento por filtração direta. 
A partir dos resultados do presente trabalho, sugere-se:

- Uso de outros parâmetros, tais como: absorbância em 254 nm e Carbono Orgânico Total, na caracterização inicial de água bruta com elevada cor aparente. E estudo de correlação entre estes parâmetros de qualidade da água e o tamanho molecular aparente das substâncias húmicas aquáticas, para se prever a concentração aproximada de coagulante necessária para realização do jarteste;

- A confecção de Diagramas de Coagulação para identificar as regiões "dosagem x pH” em que há condições mais favoráveis de coagulação para remoção de cor de águas com elevados teores de SHA;

- Novos testes para desenvolvimento e aprimoramento da metodologia proposta para caracterização de matéria orgânica dissolvida em água com elevada cor verdadeira, a fim de se certificar se é possível a realização de balanço de massas por meio dessa e de se identificar a composição da MOD em águas com tais características;

- Otimização do Gradiente de Mistura Rápida e do Tempo de Mistura Rápida para cada fração de SHA. 


\section{REFERÊNCIAS BIBLIOGRÁFICAS}

AIKEN, G. R. A critical evaluation of the use of macroporous resins for the isolation of aquatic humic substances. In: FRIMMEL, F. H.; CHRISTMAN, R. F. Humic substances and their role in the environment. New York: John Wiley, 15-32, 1988.

BUFLE, J.; DELADOEY, P.; HAERDI, W. The use of ultra filtration for the separation and fractionation of organic ligands in fresh waters. Analytica Chimica Acta, v. 101, p. 339-357, 1978.

CAMPOS S. X.; DI BERNARDO L.; VIEIRA E. M. Influência das características das substâncias húmicas na eficiência da coagulação com sulfato de alumínio. Eng. Sanitária e Ambiental Vol.10 - No 3 - jul/set 2005, 194-199, 2005.

CAMPOS, S. X. et al. Color Removal by Coagulation Flocculation and Sedimentation from Water Containing Humic Substances with Different Apparent Molecular Sizes. Journal of Water Supply: Research and Technology (AQUA). 56 (5), 327-33, 2007.

CAMPOS, S. X. Influência de diferentes características das substâncias húmicas na coagulação, floculação e sedimentação no tratamento de água. Tese (Doutorado) - Escola de Engenharia de São Carlos, Universidade de São Paulo, São Carlos - SP, 2004.

CHANG, C. et al. Characterization and isolation of natural organic matter from a eutrophic reservoir. . Journal of Water Supply and Technology - AQUA. 49(5), 269-280, 2000.

CHOW, A. T.; GAO, S.; DAHIGREN, R. A. Physical and chemical fractionation of dissolved organic matter and trihalomethane precursors: A review. Journal of Water Supply and Technology - AQUA. 54(8), 475-503, 2005.

CROUE, J. P. et al. Natural organic matter : structural characteristics and reactive properties. In : Singer, P. C. (ed). Formation and Control of Disinfection By-products in Drinking Water. American Water Works Association, Denver, Colorado, pp. 65-94, 1999.

DANTAS, A.D.B. et al. Influência da massa molar de substâncias húmicas aquáticas na coagulação com sulfato de alumínio. Anais do $24^{\circ}$ Congresso Brasileiro de Engenharia Sanitária e Ambiental, Belo Horizonte - MG, 2007.

DE JULIO, M. Efeito da massa molecular das substâncias húmicas na eficiência da coagulação com o reagente de Fenton, floculação e flotação de águas de mesma cor verdadeira. Tese (Doutorado) - Escola de Engenharia de São Carlos, Universidade de São Paulo, São Carlos - SP, 2005.

DEMPSEY, B. A.; GANHO, R. M.; O'MELIA, C. R. The coagulation of humic substances by means of aluminum salts. Journal. AWWA. Vol. 76, p.141-150, 1984. 
DI BERNARDO, A. S. Desempenho de sistemas de dupla filtração no tratamento de água com turbidez elevada. Tese (Doutorado). Escola de Engenharia de São Carlos, Universidade de São Paulo, São Carlos - SP, 2004.

DI BERNARDO, L. (Coord.). Tratamento de água para abastecimento por filtração direta. Rio de Janeiro: ABES, RiMa, 2003. 498 p.

DI BERNARDO, L. et al. Recent developments on two-stage filtration for water treatment. Proceedings of the $9^{\text {th }}$ World Filtration Congress, New Orleans, 2004.

DI BERNARDO, L.; DANTAS, A. D. B. Métodos e técnicas de tratamento de água. $2^{\mathrm{a}}$ ed. São Carlos: RiMa, 2005.

DUARTE, M. B. O.; SANTOS, E. P. H.; DUARTE, A. P. Comparison between diafiltration and concentration operation modes for the determination of permeation coefficients of humic substances through ultrafiltration membranes. Analytica Chimica Acta, v. 442, p. 155-164, 2001.

EDWARDS, G. A.; AMIRTHARAJAH, A. Removing color caused by humic acids. Journal JAWWA, 77(3), 50-57, 1985.

EDZWALD, J. K. Coagulation-sedimentation-filtration process for removing organic substances from drinking water. In: BERGER, B. B. (Ed.) Control of organics substances in water and wastewater. New Jersey: Noyes Data Corporation. p. 26-64, 1987.

EDZWALD. J. K. Coagulation in drinking water: Particles, organics and coagulants. Wat. Environ. Res. 27(11), 21-35, 1993.

GOSLAN, E. H. et al. Seasonal variations in the disinfection by-product precursor profile of a reservoir water. Journal of Water Supply and Technology - AQUA. 51(8), 475-482, 2002.

GREGOR, J. E.; NOKES C. J.; FENTON E. Optimizing natural organic matter removal from low turbidity waters by controlled ph adjustment of aluminium coagulation. Water Research. 31 (12), 2949-2958, 1997.

INTERNATIONAL HUMIC SUBSTANCES SOCIETY. What are humic substances? In: www.ihss.gatech.edu, postado em Dezembro de 2007. Acesso em Fevereiro de 2008.

MALCOLM, R.L. The uniqueness of humic substances in each of soil, stream and marine environments. Analytica Chimica Acta, 232: 19-30, 1990.

MALCOLM, R. L. ; MACCARTHY, P. Quantitative evaluation of XAD-8 and XAD-4 resins used in Tandem for removing organic solutes from water. Environmental International, 18:597-607, 1992. 
PAVANELLI, G. Eficiência de diferentes tipos de coagulantes na coagulação, floculação e sedimentação de água com turbidez elevada e cor verdadeira baixa. Dissertação (Mestrado) Escola de Engenharia de São Carlos, Universidade de São Paulo, São Carlos - SP, 2001.

PICCOLO, A. The supramolecular structures of humic substances. Soil Science, 166: 810832, 2001.

ROCHA J. C.; ROSA, A. H. Substâncias húmicas aquáticas: interações com espécies metálicas. São Paulo: Editora UNESP, 2003. 120 p.

SARGENTINI JR, E. et al. Substâncias húmicas aquáticas: fracionamento molecular e caracterização de rearranjos internos após a complexação com íons metálicos. Química Nova, Vol. 24, No. 3, 339-344, 2001.

SHARP, E. L.; PARSONS, S. A.; JEFFERSON, B. Seasonal variations in natural organic matter and its impact on coagulation in water treatment. Science of the Total Environment. 363, $183-194,2006$.

SLOBODA, E. Influência do tamanho molecular aparente das substâncias húmicas aquáticas na eficiência da coagulação com sulfato de alumínio e cloreto férrico. Dissertação (Mestrado) Instituto de Química de São Carlos, Universidade de São Paulo, São Carlos - SP, 2007.

STANDARDS METHODS FOR THE EXAMINATION OF WATER \& WASTEWATER 21st. ed. - Washington: American Public Health Association, 2005.

STEVENSON, F. J. Extraction, fractionation, and general chemical composition of soil organic matter. In: STEVENSON, F. J. Humus Chemistry: genesis, composition and reaction. New York: John Wiley, 26-53, 1982.

STEVENSON, F. J. Humus Chemistry: genesis, composition and reaction. 2. ed. New York: John Wiley, 1994.

THURMAN, E, M.; MALCOLM. R. L. Preparative isolation of aquatic substances. Environmental Science Technology, v. 15, p. 463-466, 1981.

THURMAN, E. M. et al. Molecular size of aquatic humic substances. Organic Geochemistry, 4, 27-35, 1982.

VAN BENSCHOTEN J. E., EDZWALD J. K. Chemical aspects of coagulation using aluminum salts - I . Hydrolytic reactions of alum and polyaluminum chloride. Water Research. 24, 1519-1526, 1990a.

VAN BENSCHOTEN J. E., EDZWALD J. K. Chemical aspects of coagulation using aluminum salts - II. Coagulation of fulvic acid using alum and polyaluminum chloride. Water Research. 24, 1527-1535, $1990 \mathrm{~b}$. 
WEI, L. et al. Removal and transformation of dissolved organic matter in secondary effluent during granular activated carbon treatment. Journal of Zhejiang Univ. Sci. 9 (7): 994-1003, 2008 . 


\section{APÊNDICE A - Limpeza inicial das resinas XAD-4 e XAD-8}

Antes de iniciar o procedimento de adsorção nas resinas, foi realizada uma limpeza para remoção de possíveis contaminantes presentes. A metodologia de limpeza usada foi baseada na proposta por Thurman e Malcolm (1981) e modificada por Wei et al. (2008), apresentada na Figura A. 1 e descrita a seguir.

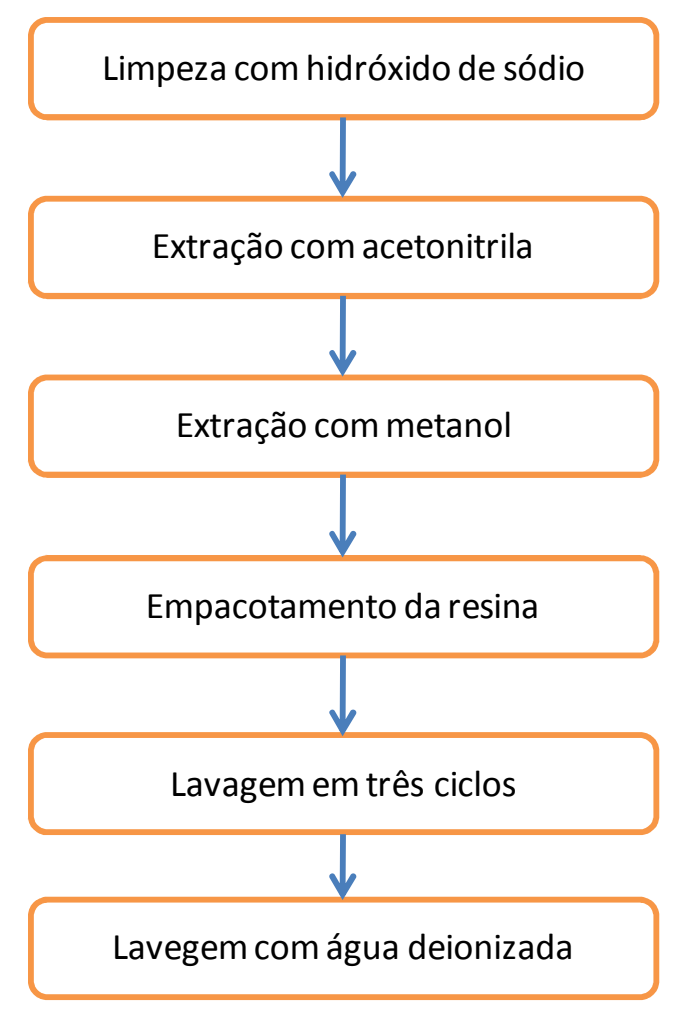

Figura A. 1: Etapas do Procedimento de Limpeza das Resinas

Limpeza com hidróxido de sódio

Imersão da resina em solução $0,1 \mathrm{M}$ de $\mathrm{NaOH}$ por 24 horas, sob agitação.

\section{Extração com acetonitrila}

Nesta etapa, colocou-se a resina em extrator Soxhlet com acetonitrila PA (3/4 do volume do balão) como solvente. A extração foi feita por 8 horas, a temperatura de aproximadamente $50^{\circ} \mathrm{C}$. 


\section{Extração com metanol}

Após a extração com acetonitrila, trocou-se o solvente; introduzindo-se metanol no balão do extrator Soxhlet. A extração com metanol durou 16 horas e foi feita a uma temperatura de aproximadamente $65^{\circ} \mathrm{C}$.

\section{Empacotamento da resina}

Retirou-se a resina do extrator Soxhlet, retirando-a do cartucho usado na extração, e fez-se a transferência de seu volume para a coluna de adsorção. Para a caracterização, usou-se aproximadamente $50 \mathrm{~mL}$ de cada uma das resinas.

\section{Lavagem em três ciclos}

Nesta etapa foram percolados pela resina, em três ciclos:

- $300 \mathrm{~mL}$ de solução $0,1 \mathrm{M}$ de $\mathrm{NaOH}$ (6 vezes o volume da resina);

- 600 mL de água deionizada;

- $300 \mathrm{~mL}$ de solução $0,1 \mathrm{M}$ de $\mathrm{HCl}$ (6 vezes o volume da resina).

\section{Lavagem com água deionizada}

Após os três ciclos de base/água/ácido, iniciou-se a lavagem com água deionizada. Esta foi realizada até a condutividade do efluente apresentar-se menor que $3 \mu \mathrm{Scm}^{-1}$ e o COT menor que $0,8 \mathrm{mgL}^{-1}$, tendo em vista que o COT da água deionizada usada era de $0,6 \mathrm{mgL}^{-1}$. 


\section{APÊNDICE B - Resultados dos ensaios de coagulação e filtração para construção dos diagramas da Água de Estudo 1.}

Tabela B. 1: Ensaio 1 para Água de Estudo 1.

\begin{tabular}{|c|c|c|c|c|c|c|}
\hline \multirow{2}{*}{ Jarro } & \multicolumn{3}{|c|}{ Dosagem $(\mathrm{mg} / \mathrm{L})$} & \multirow{2}{*}{$\begin{array}{c}\mathrm{pH} \text { de } \\
\text { coagulação }\end{array}$} & \multirow{2}{*}{$\begin{array}{c}\text { Turbidez } \\
\text { final (uT) }\end{array}$} & \multirow{2}{*}{$\begin{array}{c}\text { Cor } \\
\text { Aparente } \\
\text { final (uH) }\end{array}$} \\
\hline & Hidroxicloreto de Alumínio & $\mathrm{HCl}$ & $\mathrm{NaOH}$ & & & \\
\hline 1 & 30 & 0,0 & 0,0 & 6,26 & 5,63 & 131 \\
\hline 2 & 40 & 0,0 & 0,0 & 6,16 & 6,00 & 138 \\
\hline 3 & 40 & 0,0 & 2,0 & 6,30 & 6,09 & 140 \\
\hline 4 & 50 & 0,0 & 0,0 & 6,08 & 6,58 & 142 \\
\hline 5 & 60 & 0,0 & 0,0 & 5,99 & 1,06 & 20 \\
\hline 6 & 70 & 0,0 & 0,0 & 5,90 & 0,59 & 5 \\
\hline
\end{tabular}

Tabela B. 2: Ensaio 2 para Água de Estudo 1.

\begin{tabular}{|c|c|c|c|c|c|c|}
\hline \multirow{2}{*}{ Jarro } & \multicolumn{3}{|c|}{ Dosagem $(\mathrm{mg} / \mathrm{L})$} & \multirow{2}{*}{$\begin{array}{c}\mathrm{pH} \text { de } \\
\text { coagulação }\end{array}$} & \multirow{2}{*}{$\begin{array}{l}\text { Turbidez } \\
\text { final (uT) }\end{array}$} & \multirow{2}{*}{$\begin{array}{c}\text { Cor } \\
\text { Aparente } \\
\text { final (uH) }\end{array}$} \\
\hline & Hidroxicloreto de Alumínio & $\mathrm{HCl}$ & $\mathrm{NaOH}$ & & & \\
\hline 1 & 50 & 1,2 & 0,0 & 6,10 & 6,20 & 130 \\
\hline 2 & 50 & 2,3 & 0,0 & 5,97 & 6,32 & 132 \\
\hline 3 & 50 & 3,5 & 0,0 & 5,85 & 1,78 & 41 \\
\hline 4 & 50 & 4,6 & 0,0 & 5,73 & 1,85 & 51 \\
\hline 5 & 50 & 5,8 & 0,0 & 5,57 & 0,93 & 10 \\
\hline 6 & 50 & 7,0 & 0,0 & 5,38 & 0,59 & 9 \\
\hline
\end{tabular}

Tabela B. 3Ensaio 3 para Água de Estudo 1.

\begin{tabular}{|c|c|c|c|c|c|c|}
\hline \multirow{2}{*}{ Jarro } & \multicolumn{3}{|c|}{ Dosagem (mg/L) } & \multirow{2}{*}{$\begin{array}{c}\mathrm{pH} \text { de } \\
\text { coagulação }\end{array}$} & \multirow{2}{*}{$\begin{array}{l}\text { Turbidez } \\
\text { final (uT) }\end{array}$} & \multirow{2}{*}{$\begin{array}{c}\text { Cor } \\
\text { Aparente } \\
\text { final (uH) } \\
\end{array}$} \\
\hline & Hidroxicloreto de Alumínio & $\mathrm{HCl}$ & $\mathrm{NaOH}$ & & & \\
\hline 1 & 50 & 8,1 & 0,0 & 5,02 & 0,53 & 2 \\
\hline 2 & 50 & 9,3 & 0,0 & 4,85 & 0,49 & $<1$ \\
\hline 3 & 50 & 10,4 & 0,0 & 4,58 & 0,45 & 1 \\
\hline 4 & 50 & 11,6 & 0,0 & 4,48 & 0,43 & 1 \\
\hline 5 & 60 & 1,7 & 0,0 & 5,80 & 0,50 & $<1$ \\
\hline 6 & 60 & 3,5 & 0,0 & 5,60 & 0,44 & $<1$ \\
\hline
\end{tabular}


Tabela B. 4: Ensaio 4 para Água de Estudo 1.

\begin{tabular}{|c|c|c|c|c|c|c|}
\hline \multirow{2}{*}{ Jarro } & \multicolumn{3}{|c|}{ Dosagem (mg/L) } & \multirow{2}{*}{$\begin{array}{c}\text { pH de } \\
\text { coagulação }\end{array}$} & \multirow{2}{*}{$\begin{array}{l}\text { Turbidez } \\
\text { final (uT) }\end{array}$} & \multirow{2}{*}{$\begin{array}{c}\text { Cor } \\
\text { Aparente } \\
\text { final }(\mathrm{uH})\end{array}$} \\
\hline & Hidroxicloreto de Alumínio & $\mathrm{HCl}$ & $\mathrm{NaOH}$ & & & \\
\hline 1 & 50 & 12,7 & 0,0 & 4,29 & 0,43 & 8 \\
\hline 2 & 50 & 13,9 & 0,0 & 4,17 & 0,52 & 6 \\
\hline 3 & 60 & 5,2 & 0,0 & 5,39 & 0,82 & 9 \\
\hline 4 & 60 & 7,0 & 0,0 & 4,68 & 0,40 & 2 \\
\hline 5 & 60 & 8,7 & 0,0 & 4,53 & 0,50 & \\
\hline 6 & 60 & 10,4 & 0,0 & 4,75 & 0,40 & 4 \\
\hline
\end{tabular}

Tabela B. 5: Ensaio 5 para Água de Estudo 1.

\begin{tabular}{|c|c|c|c|c|c|c|}
\hline \multirow{2}{*}{ Jarro } & \multicolumn{3}{|c|}{ Dosagem $(\mathrm{mg} / \mathrm{L})$} & \multirow{2}{*}{$\begin{array}{c}\text { pH de } \\
\text { coagulação }\end{array}$} & \multirow{2}{*}{$\begin{array}{l}\text { Turbidez } \\
\text { final (uT) }\end{array}$} & \multirow{2}{*}{$\begin{array}{c}\text { Cor } \\
\text { Aparente } \\
\text { final (uH }\end{array}$} \\
\hline & Hidroxicloreto de Alumínio & $\mathrm{HCl}$ & $\mathrm{NaOH}$ & & & \\
\hline 1 & 60 & 5,8 & 0,0 & 5,45 & 0,95 & 12 \\
\hline 2 & 60 & 6,4 & 0,0 & 5,30 & 0,63 & 5 \\
\hline 3 & 60 & 10,4 & 0,0 & 4,50 & 0,40 & 4 \\
\hline 4 & 60 & 11,6 & 0,0 & 4,41 & 0,49 & 6 \\
\hline 5 & 60 & 12,7 & 0,0 & 4,23 & 0,56 & 3 \\
\hline 6 & 60 & 0,0 & 3,0 & 6,24 & 2,02 & 65 \\
\hline
\end{tabular}

Tabela B. 6: Ensaio 6 para Água de Estudo 1.

\begin{tabular}{|c|c|c|c|c|c|c|}
\hline \multirow{2}{*}{ Jarro } & \multicolumn{3}{|c|}{ Dosagem $(\mathrm{mg} / \mathrm{L})$} & \multirow{2}{*}{$\begin{array}{c}\mathrm{pH} \mathrm{de} \\
\text { coagulação }\end{array}$} & \multirow{2}{*}{$\begin{array}{l}\text { Turbidez } \\
\text { final (uT) }\end{array}$} & \multirow{2}{*}{$\begin{array}{c}\text { Cor } \\
\text { Aparente } \\
\text { final }(\mathrm{uH})\end{array}$} \\
\hline & Hidroxicloreto de Alumínio & $\mathrm{HCl}$ & $\mathrm{NaOH}$ & & & \\
\hline 1 & 60 & 7,0 & 0,0 & 5,19 & 0,42 & 1 \\
\hline 2 & 60 & 7,8 & 0,0 & 5,00 & 0,51 & 1 \\
\hline 3 & 60 & 8,7 & 0,0 & 4,97 & 0,50 & 1 \\
\hline 4 & 40 & 0,0 & 0,0 & 5,81 & 6,10 & 150 \\
\hline 5 & 40 & 1,7 & 0,0 & 5,66 & 5,00 & 136 \\
\hline 6 & 40 & 3,5 & 0,0 & 5,27 & 1,10 & 28 \\
\hline
\end{tabular}

Tabela B. 7: Ensaio 7 para Água de Estudo 1.

\begin{tabular}{|c|c|c|c|c|c|c|}
\hline \multirow{2}{*}{ Jarro } & \multicolumn{3}{|c|}{ Dosagem $(\mathrm{mg} / \mathrm{L})$} & \multirow{2}{*}{$\begin{array}{c}\text { pH de } \\
\text { coagulação }\end{array}$} & \multirow{2}{*}{$\begin{array}{l}\text { Turbidez } \\
\text { final (uT) }\end{array}$} & \multirow{2}{*}{$\begin{array}{c}\text { Cor } \\
\text { Aparente } \\
\text { final }(\mathrm{uH})\end{array}$} \\
\hline & Hidroxicloreto de Alumínio & $\mathrm{HCl}$ & $\mathrm{NaOH}$ & & & \\
\hline 1 & 40 & 5,2 & 0,0 & & & \\
\hline 2 & 40 & 7,0 & 0,0 & 4,45 & 0,66 & 17 \\
\hline 3 & 40 & 8,1 & 0,0 & 4,35 & 0,82 & 16 \\
\hline 4 & 40 & 9,3 & 0,0 & 4,25 & 0,54 & 15 \\
\hline 5 & 40 & 10,4 & 0,0 & 4,16 & 0,49 & 13 \\
\hline 6 & 40 & 11,6 & 0,0 & 4,03 & 0,60 & 17 \\
\hline
\end{tabular}


Tabela B. 8: Ensaio 8 para Água de Estudo 1.

\begin{tabular}{|c|c|c|c|c|c|c|}
\hline \multirow{2}{*}{ Jarro } & \multicolumn{3}{|c|}{ Dosagem $(\mathrm{mg} / \mathrm{L})$} & \multirow{2}{*}{$\begin{array}{c}\mathrm{pH} \text { de } \\
\text { coagulação }\end{array}$} & \multirow{2}{*}{$\begin{array}{l}\text { Turbidez } \\
\text { final (uT) }\end{array}$} & \multirow{2}{*}{$\begin{array}{c}\text { Cor } \\
\text { Aparente } \\
\text { final (uH) } \\
\end{array}$} \\
\hline & Hidroxicloreto de Alumínio & $\mathrm{HCl}$ & $\mathrm{NaOH}$ & & & \\
\hline 1 & 40 & 4,1 & 0,0 & 5,10 & 0,96 & 18 \\
\hline 2 & 40 & 5,2 & 0,0 & 4,80 & 0,82 & 14 \\
\hline 3 & 40 & 6,4 & 0,0 & 4,53 & 0,67 & 11 \\
\hline 4 & 70 & 1,7 & 0,0 & 5,10 & 0,61 & $<1$ \\
\hline 5 & 70 & 3,5 & 0,0 & 4,90 & 0,51 & $<1$ \\
\hline 6 & 70 & 5,2 & 0,0 & 4,68 & 0,47 & $<1$ \\
\hline
\end{tabular}

Tabela B. 9: Ensaio 9 para Água de Estudo 1.

\begin{tabular}{|c|c|c|c|c|c|c|}
\hline \multirow{2}{*}{ Jarro } & \multicolumn{3}{|c|}{ Dosagem $(\mathrm{mg} / \mathrm{L})$} & \multirow{2}{*}{$\begin{array}{c}\mathrm{pH} \mathrm{de} \\
\text { coagulação }\end{array}$} & \multirow{2}{*}{$\begin{array}{l}\text { Turbidez } \\
\text { final (uT) }\end{array}$} & \multirow{2}{*}{$\begin{array}{c}\text { Cor } \\
\text { Aparente } \\
\text { final (uH) }\end{array}$} \\
\hline & Hidroxicloreto de Alumínio & $\mathrm{HCl}$ & $\mathrm{NaOH}$ & & & \\
\hline 1 & 70 & 0,0 & 0,0 & 5,42 & 0,54 & 2 \\
\hline 2 & 70 & 0,0 & 2,0 & 5,70 & 0,50 & 2 \\
\hline 3 & 70 & 0,0 & 4,0 & 5,97 & 0,64 & 6 \\
\hline 4 & 70 & 6,4 & 0,0 & 4,60 & 0,46 & 3 \\
\hline 5 & 70 & 8,1 & 0,0 & 4,50 & 0,52 & 1 \\
\hline 6 & 70 & 9,3 & 0,0 & 4,35 & 0,50 & 4 \\
\hline
\end{tabular}

Tabela B. 10: Ensaio 10 para Água de Estudo 1.

\begin{tabular}{ccccccc}
\hline \hline \multirow{2}{*}{ Jarro } & \multicolumn{2}{c}{ Dosagem (mg/L) } & & pH de & Turbidez \\
\cline { 2 - 3 } & Hidroxicloreto de Alumínio & $\mathrm{HCl}$ & $\mathrm{NaOH}$ & $\begin{array}{c}\text { Cor } \\
\text { coagulação }\end{array}$ & $\begin{array}{c}\text { Aparente } \\
\text { final (uT) }\end{array}$ \\
\hline \hline 1 & 80 & 0,0 & 0,0 & 5,32 & 0,47 & $<1$ \\
2 & 80 & 0,0 & 2,0 & 5,65 & 0,45 & 1 \\
3 & 80 & 0,0 & 4,0 & 5,90 & 0,41 & 1 \\
4 & 80 & 0,0 & 6,0 & 6,15 & 0,43 & 4 \\
5 & 70 & 0,0 & 7,0 & 6,57 & 0,74 & 17 \\
6 & 70 & 10,4 & 0,0 & 4,13 & 0,41 & 5 \\
\hline \hline
\end{tabular}

Tabela B. 11: Ensaio 11 para Água de Estudo 1.

\begin{tabular}{|c|c|c|c|c|c|c|}
\hline \multirow{2}{*}{ Jarro } & \multicolumn{3}{|c|}{ Dosagem $(\mathrm{mg} / \mathrm{L})$} & \multirow{2}{*}{$\begin{array}{c}\mathrm{pH} \text { de } \\
\text { coagulação }\end{array}$} & \multirow{2}{*}{$\begin{array}{l}\text { Turbidez } \\
\text { final (uT) }\end{array}$} & \multirow{2}{*}{$\begin{array}{c}\text { Cor } \\
\text { Aparente } \\
\text { final (uH) }\end{array}$} \\
\hline & Hidroxicloreto de Alumínio & $\mathrm{HCl}$ & $\mathrm{NaOH}$ & & & \\
\hline 1 & 80 & 0,0 & 8,0 & 6,40 & 0,50 & 2 \\
\hline 2 & 80 & 1,7 & 0,0 & 5,15 & 0,48 & $<1$ \\
\hline 3 & 80 & 3,5 & 0,0 & 4,94 & 0,46 & 1 \\
\hline 4 & 80 & 5,2 & 0,0 & 4,70 & 0,46 & $<1$ \\
\hline 5 & 80 & 7,0 & 0,0 & 4,50 & 0,48 & $<1$ \\
\hline 6 & 80 & 8,1 & 0,0 & 4,34 & 0,57 & 2 \\
\hline
\end{tabular}


Tabela B. 12: Ensaio 6 para Água de Estudo 1.

\begin{tabular}{|c|c|c|c|c|c|c|}
\hline \multirow{2}{*}{ Jarro } & \multicolumn{3}{|c|}{ Dosagem $(\mathrm{mg} / \mathrm{L})$} & \multirow{2}{*}{$\begin{array}{c}\mathrm{pH} \mathrm{de} \\
\text { coagulação }\end{array}$} & \multirow{2}{*}{$\begin{array}{l}\text { Turbidez } \\
\text { final (uT) }\end{array}$} & \multirow{2}{*}{$\begin{array}{c}\text { Cor } \\
\text { Aparente } \\
\text { final }(\mathrm{uH})\end{array}$} \\
\hline & Hidroxicloreto de Alumínio & $\mathrm{HCl}$ & $\mathrm{NaOH}$ & & & \\
\hline 1 & 90 & 0,0 & 0,0 & 5,01 & 0,47 & 2 \\
\hline 2 & 90 & 0,0 & 4,0 & 5,56 & 0,41 & 1 \\
\hline 3 & 90 & 0,0 & 8,0 & 6,26 & 0,40 & 4 \\
\hline 4 & 90 & 2,3 & 0,0 & 4,76 & 0,46 & 6 \\
\hline 5 & 90 & 5,2 & 0,0 & 4,40 & 0,47 & 3 \\
\hline 6 & 90 & 8,1 & 0,0 & 4,13 & 0,56 & 7 \\
\hline
\end{tabular}




\section{APÊNDICE C - Resultados dos ensaios de coagulação e filtração para construção dos diagramas da Água de Estudo 2.}

Tabela C. 1: Ensaio 1 para Água de Estudo 2.

\begin{tabular}{cccccccc}
\hline \multirow{2}{*}{ Jarro } & \multicolumn{2}{c}{ Dosagem (mg/L) } & & pH de \\
\cline { 2 - 4 } & Hidroxicloreto de Alumínio & $\mathrm{HCl}$ & $\mathrm{NaOH}$ & & $\begin{array}{c}\text { Turbidez } \\
\text { foagulaçãol (uT) }\end{array}$ & $\begin{array}{c}\text { Cor } \\
\text { Aparente } \\
\text { final (uH) }\end{array}$ \\
\hline \hline 1 & 70 & 0,0 & 0,0 & & 5,82 & 0,38 & $<1$ \\
2 & 80 & 0,0 & 0,0 & 5,64 & 0,46 & $<1$ \\
3 & 90 & 0,0 & 0,0 & 5,46 & 1,41 & 30 \\
4 & 100 & 0,0 & 0,0 & 5,33 & 3,18 & 51 \\
5 & 110 & 0,0 & 0,0 & 5,20 & 4,17 & 90 \\
6 & 120 & 0,0 & 0,0 & 5,11 & 5,94 & 111 \\
\hline \hline
\end{tabular}

Tabela C. 2: Ensaio 2 para Água de Estudo 2.

\begin{tabular}{|c|c|c|c|c|c|c|}
\hline \multirow{2}{*}{ Jarro } & \multicolumn{3}{|c|}{ Dosagem (mg/L) } & \multirow{2}{*}{$\begin{array}{c}\mathrm{pH} \text { de } \\
\text { coagulação }\end{array}$} & \multirow{2}{*}{$\begin{array}{l}\text { Turbidez } \\
\text { final (uT) }\end{array}$} & \multirow{2}{*}{$\begin{array}{c}\text { Cor } \\
\text { Aparente } \\
\text { final }(\mathrm{uH})\end{array}$} \\
\hline & Hidroxicloreto de Alumínio & $\mathrm{HCl}$ & $\mathrm{NaOH}$ & & & \\
\hline 1 & 70 & 2,3 & 0,0 & 5,65 & 0,41 & $<1$ \\
\hline 2 & 70 & 4,1 & 0,0 & 5,37 & 0,67 & $<1$ \\
\hline 3 & 70 & 6,4 & 0,0 & 5,13 & 2,59 & 61 \\
\hline 4 & 70 & 0,0 & 1,0 & 5,85 & 0,42 & $<1$ \\
\hline 5 & 70 & 0,0 & 3,0 & 6,03 & 0,36 & $<1$ \\
\hline 6 & 70 & 0,0 & 5,0 & 6,22 & 0,33 & $<1$ \\
\hline
\end{tabular}

Tabela C. 3: Ensaio 3 para Água de Estudo 2.

\begin{tabular}{|c|c|c|c|c|c|c|}
\hline \multirow{2}{*}{ Jarro } & \multicolumn{3}{|c|}{ Dosagem $(\mathrm{mg} / \mathrm{L})$} & \multirow{2}{*}{$\begin{array}{c}\mathrm{pH} \text { de } \\
\text { coagulação }\end{array}$} & \multirow{2}{*}{$\begin{array}{l}\text { Turbidez } \\
\text { final (uT) }\end{array}$} & \multirow{2}{*}{$\begin{array}{c}\text { Cor } \\
\text { Aparente } \\
\text { final }(\mathrm{uH})\end{array}$} \\
\hline & Hidroxicloreto de Alumínio & $\mathrm{HCl}$ & $\mathrm{NaOH}$ & & & \\
\hline 1 & 70 & 8,1 & 0,0 & 4,89 & 0,56 & 1 \\
\hline 2 & 70 & 0,0 & 8,0 & 6,69 & 0,44 & 1 \\
\hline 3 & 70 & 0,0 & 10,0 & 6,89 & 0,44 & 3 \\
\hline 4 & 70 & 0,0 & 12,0 & 7,08 & 0,68 & 9 \\
\hline 5 & 70 & 0,0 & 14,0 & 7,26 & 6,09 & 134 \\
\hline 6 & 70 & 0,0 & 16,0 & 7,59 & 5,68 & 135 \\
\hline
\end{tabular}


Tabela C. 4: Ensaio 4 para Água de Estudo 2.

\begin{tabular}{|c|c|c|c|c|c|c|}
\hline \multirow{2}{*}{ Jarro } & \multicolumn{3}{|c|}{ Dosagem (mg/L) } & \multirow{2}{*}{$\begin{array}{c}\mathrm{pH} \text { de } \\
\text { coagulação }\end{array}$} & \multirow{2}{*}{$\begin{array}{r}\text { Turbidez } \\
\text { final (uT) }\end{array}$} & \multirow{2}{*}{$\begin{array}{c}\text { Cor } \\
\text { Aparente } \\
\text { final }(\mathrm{uH})\end{array}$} \\
\hline & Hidroxicloreto de Alumínio & $\mathrm{HCl}$ & $\mathrm{NaOH}$ & & & \\
\hline 1 & 60 & 0,0 & 0,0 & 6,30 & 0,45 & $<1$ \\
\hline 2 & 60 & 0,0 & 2,0 & 6,46 & 0,45 & $<1$ \\
\hline 3 & 60 & 0,0 & 4,0 & 6,63 & 0,47 & $<1$ \\
\hline 4 & 60 & 0,0 & 6,0 & 6,84 & 0,52 & $<1$ \\
\hline 5 & 70 & 7,0 & 0,0 & 5,14 & 1,45 & 38 \\
\hline 6 & 70 & 9,3 & 0,0 & 4,70 & 0,52 & $<1$ \\
\hline
\end{tabular}

Tabela C. 5: Ensaio 5 para Água de Estudo 2.

\begin{tabular}{|c|c|c|c|c|c|c|}
\hline \multirow{2}{*}{ Jarro } & \multicolumn{3}{|c|}{ Dosagem (mg/L) } & \multirow{2}{*}{$\begin{array}{c}\mathrm{pH} \text { de } \\
\text { coagulação }\end{array}$} & \multirow{2}{*}{$\begin{array}{l}\text { Turbidez } \\
\text { final (uT) }\end{array}$} & \multirow{2}{*}{$\begin{array}{c}\text { Cor } \\
\text { Aparente } \\
\text { final }(\mathrm{uH}) \\
\end{array}$} \\
\hline & Hidroxicloreto de Alumínio & $\mathrm{HCl}$ & $\mathrm{NaOH}$ & & & \\
\hline 1 & 60 & 2,3 & 0,0 & 6,00 & 0,46 & $<1$ \\
\hline 2 & 60 & 4,1 & 0,0 & 5,62 & 0,50 & $<1$ \\
\hline 3 & 60 & 5,8 & 0,0 & 5,35 & 0,59 & $<1$ \\
\hline 4 & 60 & 0,0 & 8,0 & 6,94 & 0,62 & $<1$ \\
\hline 5 & 60 & 0,0 & 10,0 & 7,13 & 5,98 & 115 \\
\hline 6 & 60 & 0,0 & 12,0 & 7,34 & 5,55 & 118 \\
\hline
\end{tabular}

Tabela C. 6: Ensaio 6 para Água de Estudo 2.

\begin{tabular}{|c|c|c|c|c|c|c|}
\hline \multirow{2}{*}{ Jarro } & \multicolumn{3}{|c|}{ Dosagem $(\mathrm{mg} / \mathrm{L})$} & \multirow{2}{*}{$\begin{array}{c}\mathrm{pH} \text { de } \\
\text { coagulação }\end{array}$} & \multirow{2}{*}{$\begin{array}{l}\text { Turbidez } \\
\text { final (uT) }\end{array}$} & \multirow{2}{*}{$\begin{array}{c}\text { Cor } \\
\text { Aparente } \\
\text { final (uH) } \\
\end{array}$} \\
\hline & Hidroxicloreto de Alumínio & $\mathrm{HCl}$ & $\mathrm{NaOH}$ & & & \\
\hline 1 & 60 & 7,5 & 0,0 & 4,94 & 0,55 & $<1$ \\
\hline 2 & 60 & 9,3 & 0,0 & 4,63 & 0,56 & 4 \\
\hline 3 & 60 & 11,0 & 0,0 & 4,38 & 0,58 & 2 \\
\hline 4 & 50 & 0,0 & 0,0 & 6,24 & 0,78 & 2 \\
\hline 5 & 50 & 0,0 & 2,0 & 6,50 & 0,76 & 6 \\
\hline 6 & 50 & 0,0 & 4,0 & 6,69 & 1,48 & 40 \\
\hline
\end{tabular}

Tabela C. 7: Ensaio 7 para Água de Estudo 2.

\begin{tabular}{ccccccc}
\hline \multirow{2}{*}{ Jarro } & \multicolumn{2}{c}{ Dosagem (mg/L) } & & pH de & Turbidez & $\begin{array}{c}\text { Cor } \\
\text { coagulação }\end{array}$ \\
\cline { 2 - 3 } & Hidroxicloreto de Alumínio & $\mathrm{HCl}$ & $\mathrm{NaOH}$ & $\begin{array}{c}\text { Aparente } \\
\text { final (uH) }\end{array}$ \\
\hline \hline 1 & 50 & 1,7 & 0,0 & 5,17 & 0,56 & $<1$ \\
2 & 50 & 3,5 & 0,0 & 4,86 & 0,44 & $<1$ \\
3 & 50 & 5,2 & 0,0 & 4,55 & 0,60 & $<1$ \\
4 & 50 & 7,0 & 0,0 & 4,40 & 0,43 & 2 \\
5 & 50 & 8,7 & 0,0 & 4,04 & 0,59 & 3 \\
6 & 50 & 0,0 & 7,0 & 6,40 & 0,60 & 5 \\
\hline \hline
\end{tabular}


Tabela C. 8: Ensaio 8 para Água de Estudo 2.

\begin{tabular}{|c|c|c|c|c|c|c|}
\hline \multirow{2}{*}{ Jarro } & \multicolumn{3}{|c|}{ Dosagem $(\mathrm{mg} / \mathrm{L})$} & \multirow{2}{*}{$\begin{array}{c}\mathrm{pH} \text { de } \\
\text { coagulação }\end{array}$} & \multirow{2}{*}{$\begin{array}{l}\text { Turbidez } \\
\text { final (uT) }\end{array}$} & \multirow{2}{*}{$\begin{array}{c}\text { Cor } \\
\text { Aparente } \\
\text { final (uH) } \\
\end{array}$} \\
\hline & Hidroxicloreto de Alumínio & $\mathrm{HCl}$ & $\mathrm{NaOH}$ & & & \\
\hline 1 & 50 & 0,6 & 0,0 & 5,55 & 0,54 & $<1$ \\
\hline 2 & 50 & 0,0 & 0,0 & 5,66 & 0,55 & $<1$ \\
\hline 3 & 50 & 0,0 & 10,0 & 6,60 & 1,00 & 21 \\
\hline 4 & 50 & 0,0 & 12,0 & 6,80 & 6,03 & 133 \\
\hline 5 & 50 & 0,0 & 14,0 & 6,97 & 5,92 & 131 \\
\hline 6 & 40 & 0,0 & 0,0 & 5,80 & 0,67 & 8 \\
\hline
\end{tabular}

Tabela C. 9: Ensaio 9 para Água de Estudo 2.

\begin{tabular}{|c|c|c|c|c|c|c|}
\hline \multirow{2}{*}{ Jarro } & \multicolumn{3}{|c|}{ Dosagem $(\mathrm{mg} / \mathrm{L})$} & \multirow{2}{*}{$\begin{array}{c}\mathrm{pH} \mathrm{de} \\
\text { coagulação }\end{array}$} & \multirow{2}{*}{$\begin{array}{l}\text { Turbidez } \\
\text { final (uT) }\end{array}$} & \multirow{2}{*}{$\begin{array}{c}\text { Cor } \\
\text { Aparente } \\
\text { final (uH) }\end{array}$} \\
\hline & Hidroxicloreto de Alumínio & $\mathrm{HCl}$ & $\mathrm{NaOH}$ & & & \\
\hline 1 & 50 & 0,0 & 2,0 & 6,10 & 0,46 & $<1$ \\
\hline 2 & 50 & 0,0 & 4,0 & 6,20 & 0,60 & 5 \\
\hline 3 & 40 & 1,2 & 0,0 & 5,63 & 0,57 & 1 \\
\hline 4 & 40 & 2,3 & 0,0 & 5,47 & 0,59 & $<1$ \\
\hline 5 & 40 & 3,5 & 0,0 & 5,10 & 0,52 & $<1$ \\
\hline 6 & 40 & 0,0 & 2,0 & 6,00 & 0,95 & 16 \\
\hline
\end{tabular}

Tabela C. 10: Ensaio 10 para Água de Estudo 2.

\begin{tabular}{|c|c|c|c|c|c|c|}
\hline \multirow{2}{*}{ Jarro } & \multicolumn{3}{|c|}{ Dosagem $(\mathrm{mg} / \mathrm{L})$} & \multirow{2}{*}{$\begin{array}{c}\text { pH de } \\
\text { coagulação }\end{array}$} & \multirow{2}{*}{$\begin{array}{l}\text { Turbidez } \\
\text { final (uT) }\end{array}$} & \multirow{2}{*}{$\begin{array}{c}\text { Cor } \\
\text { Aparente } \\
\text { final }(\mathrm{uH})\end{array}$} \\
\hline & Hidroxicloreto de Alumínio & $\mathrm{HCl}$ & $\mathrm{NaOH}$ & & & \\
\hline 1 & 50 & 0,0 & 1,0 & 5,93 & 0,42 & $<1$ \\
\hline 2 & 40 & 4,1 & 0,0 & 5,00 & 0,66 & $<1$ \\
\hline 3 & 40 & 4,6 & 0,0 & 4,82 & 0,55 & 2 \\
\hline 4 & 40 & 5,2 & 0,0 & 4,70 & 0,48 & 5 \\
\hline 5 & 40 & 0,0 & 4,0 & 6,24 & 5,85 & 133 \\
\hline 6 & 40 & 0,0 & 6,0 & 6,45 & 6,29 & 138 \\
\hline
\end{tabular}

Tabela C. 11: Ensaio 11 para Água de Estudo 2.

\begin{tabular}{|c|c|c|c|c|c|c|}
\hline \multirow{2}{*}{ Jarro } & \multicolumn{3}{|c|}{ Dosagem $(\mathrm{mg} / \mathrm{L})$} & \multirow{2}{*}{$\begin{array}{c}\mathrm{pH} \text { de } \\
\text { coagulação }\end{array}$} & \multirow{2}{*}{$\begin{array}{l}\text { Turbidez } \\
\text { final (uT) }\end{array}$} & \multirow{2}{*}{$\begin{array}{c}\text { Cor } \\
\text { Aparente } \\
\text { final }(\mathrm{uH})\end{array}$} \\
\hline & Hidroxicloreto de Alumínio & $\mathrm{HCl}$ & $\mathrm{NaOH}$ & & & \\
\hline 1 & 40 & 6,4 & 0,0 & 4,40 & 0,62 & $<1$ \\
\hline 2 & 40 & 7,5 & 0,0 & 4,04 & 0,54 & $<1$ \\
\hline 3 & 30 & 0,0 & 0,0 & 5,60 & 5,60 & 124 \\
\hline 4 & 30 & 1,2 & 0,0 & 5,46 & 5,90 & 121 \\
\hline 5 & 30 & 2,3 & 0,0 & 5,25 & 5,79 & 123 \\
\hline 6 & 30 & 3,5 & 0,0 & 4,95 & 1,08 & 15 \\
\hline
\end{tabular}


Tabela C. 12: Ensaio 12 para Água de Estudo 2.

\begin{tabular}{|c|c|c|c|c|c|c|}
\hline \multirow{2}{*}{ Jarro } & \multicolumn{3}{|c|}{ Dosagem $(\mathrm{mg} / \mathrm{L})$} & \multirow{2}{*}{$\begin{array}{c}\mathrm{pH} \mathrm{de} \\
\text { coagulação }\end{array}$} & \multirow{2}{*}{$\begin{array}{c}\text { Turbidez } \\
\text { final (uT) }\end{array}$} & \multirow{2}{*}{$\begin{array}{c}\text { Cor } \\
\text { Aparente } \\
\text { final }(\mathrm{uH})\end{array}$} \\
\hline & Hidroxicloreto de Alumínio & $\mathrm{HCl}$ & $\mathrm{NaOH}$ & & & \\
\hline 1 & 30 & 4,3 & 0,0 & 4,98 & 0,74 & 10 \\
\hline 2 & 30 & 5,2 & 0,0 & 4,70 & 0,62 & 7 \\
\hline 3 & 30 & 6,1 & 0,0 & 4,52 & 0,55 & 6 \\
\hline 4 & 70 & 11,0 & 0,0 & 3,94 & 0,48 & $<1$ \\
\hline 5 & 70 & 12,2 & 0,0 & 3,88 & 0,50 & 1 \\
\hline 6 & 70 & 0,0 & 6,0 & 6,20 & 0,48 & 1 \\
\hline
\end{tabular}

Tabela C. 13: Ensaio 13 para Água de Estudo 2.

\begin{tabular}{|c|c|c|c|c|c|c|}
\hline \multirow{2}{*}{ Jarro } & \multicolumn{3}{|c|}{ "Dosagem $(\mathrm{mg} / \mathrm{L})$} & \multirow{2}{*}{$\begin{array}{c}\text { pH de } \\
\text { coagulação }\end{array}$} & \multirow{2}{*}{$\begin{array}{l}\text { Turbidez } \\
\text { final (uT) }\end{array}$} & \multirow{2}{*}{$\begin{array}{c}\text { Cor } \\
\text { Aparente } \\
\text { final }(\mathrm{uH})\end{array}$} \\
\hline & Hidroxicloreto de Alumínio & $\mathrm{HCl}$ & $\mathrm{NaOH}$ & & & \\
\hline 1 & 70 & 5,8 & 0,0 & 4,46 & 0,52 & $<1$ \\
\hline 2 & 80 & 0,0 & 2,0 & 5,28 & 2,61 & 72 \\
\hline 3 & 80 & 0,0 & 4,0 & 5,68 & 0,52 & $<1$ \\
\hline 4 & 80 & 0,0 & 6,0 & 5,98 & 0,56 & $<1$ \\
\hline 5 & 80 & 0,0 & 8,0 & 6,22 & 0,52 & $<1$ \\
\hline 6 & 80 & 0,0 & 10,0 & 6,50 & 0,54 & $<1$ \\
\hline
\end{tabular}

Tabela C. 14: Ensaio 14 para Água de Estudo 2.

\begin{tabular}{|c|c|c|c|c|c|c|}
\hline \multirow{2}{*}{ Jarro } & \multicolumn{3}{|c|}{ Dosagem (mg/L) } & \multirow{2}{*}{$\begin{array}{c}\mathrm{pH} \text { de } \\
\text { coagulação }\end{array}$} & \multirow{2}{*}{$\begin{array}{l}\text { Turbidez } \\
\text { final (uT) }\end{array}$} & \multirow{2}{*}{$\begin{array}{c}\text { Cor } \\
\text { Aparente } \\
\text { final }(\mathrm{uH})\end{array}$} \\
\hline & Hidroxicloreto de Alumínio & $\mathrm{HCl}$ & $\mathrm{NaOH}$ & & & \\
\hline 1 & 80 & 0,0 & 12,0 & 6,87 & & 26 \\
\hline 2 & 80 & 0,0 & 14,0 & 7,32 & 5,34 & 125 \\
\hline 3 & 80 & 0,0 & 16,0 & 7,50 & 4,92 & 124 \\
\hline 4 & 80 & 0,0 & 0,0 & 5,10 & 4,40 & 113 \\
\hline 5 & 80 & 2,0 & 0,0 & 4,85 & 4,24 & 108 \\
\hline 6 & 80 & 3,5 & 0,0 & 4,71 & 2,91 & 87 \\
\hline
\end{tabular}




\section{APÊNDICE D - Resultados dos ensaios de coagulação e filtração para construção dos diagramas da Água de Estudo 3.}

Tabela D. 1: Ensaio 1 para Água de Estudo 3.

\begin{tabular}{|c|c|c|c|c|c|c|}
\hline \multirow{2}{*}{ Jarro } & \multicolumn{3}{|c|}{ Dosagem $(\mathrm{mg} / \mathrm{L})$} & \multirow{2}{*}{$\begin{array}{c}\text { pH de } \\
\text { coagulação }\end{array}$} & \multirow{2}{*}{$\begin{array}{r}\text { Turbidez } \\
\text { final (uT) }\end{array}$} & \multirow{2}{*}{$\begin{array}{c}\text { Cor } \\
\text { Aparente } \\
\text { final }(\mathrm{uH})\end{array}$} \\
\hline & Hidroxicloreto de Alumínio & $\mathrm{HCl}$ & $\mathrm{NaOH}$ & & & \\
\hline 1 & 90 & 3,5 & 0,0 & 4,79 & 0,89 & 3 \\
\hline 2 & 90 & 1,7 & 0,0 & 5,06 & 1,27 & 20 \\
\hline 3 & 90 & 0,0 & 0,0 & 5,23 & 1,20 & 17 \\
\hline 4 & 90 & 0,0 & 2,0 & 5,60 & 0,77 & 3 \\
\hline 5 & 90 & 0,0 & 4,0 & 5,85 & 0,75 & 5 \\
\hline 6 & 90 & 0,0 & 6,0 & 6,13 & 0,69 & 5 \\
\hline
\end{tabular}

Tabela D. 2: Ensaio 2 para Água de Estudo 3.

\begin{tabular}{|c|c|c|c|c|c|c|}
\hline \multirow{2}{*}{ Jarro } & \multicolumn{3}{|c|}{ Dosagem (mg/L) } & \multirow{2}{*}{$\begin{array}{c}\mathrm{pH} \text { de } \\
\text { coagulação }\end{array}$} & \multirow{2}{*}{$\begin{array}{l}\text { Turbidez } \\
\text { final (uT) }\end{array}$} & \multirow{2}{*}{$\begin{array}{c}\text { Cor } \\
\text { Aparente } \\
\text { final }(\mathrm{uH})\end{array}$} \\
\hline & Hidroxicloreto de Alumínio & $\mathrm{HCl}$ & $\mathrm{NaOH}$ & & & \\
\hline 1 & 90 & 5,2 & 0,0 & 4,73 & 0,89 & 3 \\
\hline 2 & 90 & 7,0 & 0,0 & 4,45 & 0,95 & 8 \\
\hline 3 & 90 & 0,0 & 8,0 & 6,32 & 0,71 & $<1$ \\
\hline 4 & 90 & 0,0 & 10,0 & 6,53 & 0,69 & 4 \\
\hline 5 & 90 & 0,0 & 12,0 & 6,64 & 0,71 & 3 \\
\hline 6 & 80 & 0,0 & 0,0 & 5,40 & 0,68 & $<1$ \\
\hline
\end{tabular}

Tabela D. 3: Ensaio 3 para Água de Estudo 3.

\begin{tabular}{|c|c|c|c|c|c|c|}
\hline \multirow{2}{*}{ Jarro } & \multicolumn{3}{|c|}{ Dosagem $(\mathrm{mg} / \mathrm{L})$} & \multirow{2}{*}{$\begin{array}{c}\mathrm{pH} \text { de } \\
\text { coagulação }\end{array}$} & \multirow{2}{*}{$\begin{array}{l}\text { Turbidez } \\
\text { final (uT) }\end{array}$} & \multirow{2}{*}{$\begin{array}{c}\text { Cor } \\
\text { Aparente } \\
\text { final }(\mathrm{uH}) \\
\end{array}$} \\
\hline & Hidroxicloreto de Alumínio & $\mathrm{HCl}$ & $\mathrm{NaOH}$ & & & \\
\hline 1 & 90 & 0,0 & 15,0 & 6,90 & 1,95 & 68 \\
\hline 2 & 90 & 0,0 & 17,0 & 7,11 & 5,67 & 130 \\
\hline 3 & 80 & 0,0 & 2,0 & 5,73 & 0,95 & $<1$ \\
\hline 4 & 80 & 0,0 & 4,0 & 6,00 & 0,68 & 1 \\
\hline 5 & 80 & 0,0 & 6,0 & 6,25 & 0,69 & 2 \\
\hline 6 & 80 & 0,0 & 8,0 & 6,40 & 0,76 & 2 \\
\hline
\end{tabular}


Tabela D. 4: Ensaio 4 para Água de Estudo 3.

\begin{tabular}{|c|c|c|c|c|c|c|}
\hline \multirow{2}{*}{ Jarro } & \multicolumn{3}{|c|}{ Dosagem $(\mathrm{mg} / \mathrm{L})$} & \multirow{2}{*}{$\begin{array}{c}\mathrm{pH} \mathrm{de} \\
\text { coagulação }\end{array}$} & \multirow{2}{*}{$\begin{array}{c}\text { Turbidez } \\
\text { final (uT) }\end{array}$} & \multirow{2}{*}{$\begin{array}{c}\text { Cor } \\
\text { Aparente } \\
\text { final }(\mathrm{uH})\end{array}$} \\
\hline & Hidroxicloreto de Alumínio & $\mathrm{HCl}$ & $\mathrm{NaOH}$ & & & \\
\hline 1 & 80 & 7,0 & 0,0 & 4,58 & 0,83 & $<1$ \\
\hline 2 & 80 & 5,2 & 0,0 & 4,76 & 0,74 & $<1$ \\
\hline 3 & 80 & 3,5 & 0,0 & 4,89 & 0,75 & $<1$ \\
\hline 4 & 80 & 1,7 & 0,0 & 5,12 & 0,72 & $<1$ \\
\hline 5 & 80 & 0,0 & 11,0 & 6,67 & 0,95 & 12 \\
\hline 6 & 80 & 0,0 & 14,0 & 7,02 & 5,45 & 131 \\
\hline
\end{tabular}

Tabela D. 5: Ensaio 5 para Água de Estudo 3.

\begin{tabular}{|c|c|c|c|c|c|c|}
\hline \multirow{2}{*}{ Jarro } & \multicolumn{3}{|c|}{ "Dosagem (mg/L) } & \multirow{2}{*}{$\begin{array}{c}\text { pH de } \\
\text { coagulação }\end{array}$} & \multirow{2}{*}{$\begin{array}{l}\text { Turbidez } \\
\text { final (uT) }\end{array}$} & \multirow{2}{*}{$\begin{array}{c}\text { Cor } \\
\text { Aparente } \\
\text { final (uH) }\end{array}$} \\
\hline & Hidroxicloreto de Alumínio & $\mathrm{HCl}$ & $\mathrm{NaOH}$ & & & \\
\hline 1 & 80 & 9,3 & 0,0 & 4,27 & 0,96 & 1 \\
\hline 2 & 70 & 0,0 & 0,0 & 5,65 & 0,84 & 3 \\
\hline 3 & 70 & 0,0 & 2,0 & 5,95 & 1,02 & 3 \\
\hline 4 & 70 & 0,0 & 4,0 & 6,32 & 0,85 & 7 \\
\hline 5 & 70 & 0,0 & 6,0 & 6,48 & 0,91 & 12 \\
\hline 6 & 70 & 0,0 & 9,0 & 6,70 & 1,90 & 45 \\
\hline
\end{tabular}

Tabela D. 6: Ensaio 6 para Água de Estudo 3.

\begin{tabular}{ccccccc}
\hline \multirow{2}{*}{ Jarro } & \multicolumn{2}{c}{ Dosagem (mg/L) } & & $\begin{array}{c}\text { pH de } \\
\text { coagulação }\end{array}$ & $\begin{array}{c}\text { Turbidez } \\
\text { final (uT) }\end{array}$ & $\begin{array}{c}\text { Cor } \\
\text { Aparente } \\
\text { final (uH) }\end{array}$ \\
\cline { 2 - 5 } 1 & Hidroxicloreto de Alumínio & $\mathrm{HCl}$ & $\mathrm{NaOH}$ & & & \\
2 & 70 & 8,7 & 0,0 & 4,10 & 0,89 & $<1$ \\
3 & 70 & 7,0 & 0,0 & 4,47 & 0,99 & $<1$ \\
4 & 70 & 5,2 & 0,0 & 4,80 & 0,99 & $<1$ \\
5 & 70 & 3,5 & 0,0 & 5,12 & 0,89 & $<1$ \\
6 & 70 & 1,7 & 0,0 & 5,34 & 0,89 & 2 \\
\hline \hline
\end{tabular}

Tabela D. 7: Ensaio 7 para Água de Estudo 3.

\begin{tabular}{|c|c|c|c|c|c|c|}
\hline \multirow{2}{*}{ Jarro } & \multicolumn{3}{|c|}{ Dosagem (mg/L) } & \multirow{2}{*}{$\begin{array}{c}\mathrm{pH} \text { de } \\
\text { coagulação }\end{array}$} & \multirow{2}{*}{$\begin{array}{l}\text { Turbidez } \\
\text { final (uT) }\end{array}$} & \multirow{2}{*}{$\begin{array}{c}\text { Cor } \\
\text { Aparente } \\
\text { final (uH) }\end{array}$} \\
\hline & Hidroxicloreto de Alumínio & $\mathrm{HCl}$ & $\mathrm{NaOH}$ & & & \\
\hline 1 & 60 & 3,5 & 0,0 & 5,01 & 0,95 & 4 \\
\hline 2 & 60 & 1,7 & 0,0 & 5,28 & 1,08 & 7 \\
\hline 3 & 60 & 0,0 & 0,0 & 5,63 & 1,28 & 12 \\
\hline 4 & 60 & 0,0 & 2,0 & 5,92 & 1,43 & 18 \\
\hline 5 & 60 & 0,0 & 4,0 & 6,08 & 1,55 & 24 \\
\hline 6 & 60 & 0,0 & 6,0 & 6,38 & 4,15 & 110 \\
\hline
\end{tabular}


Tabela D. 8: Ensaio 8 para Água de Estudo 3.

\begin{tabular}{|c|c|c|c|c|c|c|}
\hline \multirow{2}{*}{ Jarro } & \multicolumn{3}{|c|}{ Dosagem $(\mathrm{mg} / \mathrm{L})$} & \multirow{2}{*}{$\begin{array}{c}\mathrm{pH} \text { de } \\
\text { coagulação }\end{array}$} & \multirow{2}{*}{$\begin{array}{l}\text { Turbidez } \\
\text { final (uT) }\end{array}$} & \multirow{2}{*}{$\begin{array}{c}\text { Cor } \\
\text { Aparente } \\
\text { final (uH) } \\
\end{array}$} \\
\hline & Hidroxicloreto de Alumínio & $\mathrm{HCl}$ & $\mathrm{NaOH}$ & & & \\
\hline 1 & 60 & 5,2 & 0,0 & 4,65 & 0,65 & $<1$ \\
\hline 2 & 60 & 7,0 & 0,0 & 4,35 & 0,72 & 2 \\
\hline 3 & 60 & 8,7 & 0,0 & 4,14 & 0,57 & 4 \\
\hline 4 & 50 & 0,0 & 0,0 & 5,68 & 1,71 & 42 \\
\hline 5 & 50 & 1,7 & 0,0 & 5,38 & 0,94 & 13 \\
\hline 6 & 50 & 3,5 & 0,0 & 5,02 & 0,71 & 1 \\
\hline
\end{tabular}

Tabela D. 9: Ensaio 9 para Água de Estudo 3.

\begin{tabular}{|c|c|c|c|c|c|c|}
\hline \multirow{2}{*}{ Jarro } & \multicolumn{3}{|c|}{ Dosagem $(\mathrm{mg} / \mathrm{L})$} & \multirow{2}{*}{$\begin{array}{c}\mathrm{pH} \mathrm{de} \\
\text { coagulação }\end{array}$} & \multirow{2}{*}{$\begin{array}{l}\text { Turbidez } \\
\text { final (uT) }\end{array}$} & \multirow{2}{*}{$\begin{array}{c}\text { Cor } \\
\text { Aparente } \\
\text { final (uH) }\end{array}$} \\
\hline & Hidroxicloreto de Alumínio & $\mathrm{HCl}$ & $\mathrm{NaOH}$ & & & \\
\hline 1 & 50 & 4,6 & 0,0 & 4,94 & 0,67 & $<1$ \\
\hline 2 & 50 & 6,4 & 0,0 & 4,58 & 0,59 & 1 \\
\hline 3 & 50 & 8,1 & 0,0 & 4,24 & 0,62 & 3 \\
\hline 4 & 40 & 1,7 & 0,0 & 5,60 & 4,20 & 116 \\
\hline 5 & 40 & 3,5 & 0,0 & 5,20 & 2,04 & 54 \\
\hline 6 & 40 & 5,2 & 0,0 & 4,80 & 0,60 & 2 \\
\hline
\end{tabular}

Tabela D. 10: Ensaio 10 para Água de Estudo 3.

\begin{tabular}{|c|c|c|c|c|c|c|}
\hline \multirow{2}{*}{ Jarro } & \multicolumn{3}{|c|}{ Dosagem $(\mathrm{mg} / \mathrm{L})$} & \multirow{2}{*}{$\begin{array}{c}\mathrm{pH} \text { de } \\
\text { coagulação }\end{array}$} & \multirow{2}{*}{$\begin{array}{l}\text { Turbidez } \\
\text { final (uT) }\end{array}$} & \multirow{2}{*}{$\begin{array}{c}\text { Cor } \\
\text { Aparente } \\
\text { final }(\mathrm{uH})\end{array}$} \\
\hline & Hidroxicloreto de Alumínio & $\mathrm{HCl}$ & $\mathrm{NaOH}$ & & & \\
\hline 1 & 40 & 6,4 & 0,0 & 4,62 & 0,67 & 5 \\
\hline 2 & 40 & 8,1 & 0,0 & 4,29 & 0,62 & 7 \\
\hline 3 & 30 & 5,2 & 0,0 & 4,98 & 4,14 & 102 \\
\hline 4 & 30 & 7,0 & 0,0 & 4,53 & 0,97 & 17 \\
\hline 5 & 30 & 8,1 & 0,0 & 4,37 & 0,73 & 11 \\
\hline 6 & 30 & 9,3 & 0,0 & 4,23 & 0,75 & 16 \\
\hline
\end{tabular}

Tabela D. 11: Ensaio 11 para Água de Estudo 3.

\begin{tabular}{|c|c|c|c|c|c|c|}
\hline \multirow{2}{*}{ Jarro } & \multicolumn{3}{|c|}{ Dosagem (mg/L) } & \multirow{2}{*}{$\begin{array}{c}\mathrm{pH} \text { de } \\
\text { coagulação }\end{array}$} & \multirow{2}{*}{$\begin{array}{l}\text { Turbidez } \\
\text { final (uT) }\end{array}$} & \multirow{2}{*}{$\begin{array}{c}\text { Cor } \\
\text { Aparente } \\
\text { final (uH) }\end{array}$} \\
\hline & Hidroxicloreto de Alumínio & $\mathrm{HCl}$ & $\mathrm{NaOH}$ & & & \\
\hline 1 & 100 & 3,5 & 0,0 & 4,85 & & $<1$ \\
\hline 2 & 100 & 1,7 & 0,0 & 4,98 & & 23 \\
\hline 3 & 100 & 0,0 & 0,0 & 5,17 & & 48 \\
\hline 4 & 100 & 0,0 & 2,0 & 5,34 & & 26 \\
\hline 5 & 100 & 0,0 & 4,0 & 5,67 & & $<1$ \\
\hline 6 & 100 & 0,0 & 6,0 & 5,98 & & $<1$ \\
\hline
\end{tabular}


Tabela D. 12: Ensaio 12 para Água de Estudo 3.

\begin{tabular}{ccccccc}
\hline \multirow{2}{*}{ Jarro } & \multicolumn{2}{c}{ Dosagem (mg/L) } & & pH de & Turbidez & $\begin{array}{c}\text { Cor } \\
\text { coagulação }\end{array}$ \\
\cline { 2 - 4 } & Hidroxicloreto de Alumínio & $\mathrm{HCl}$ & $\mathrm{NaOH}$ & $\begin{array}{c}\text { Aparente } \\
\text { final (uH) }\end{array}$ \\
\hline \hline 1 & 30 & 6,1 & 0,0 & 4,77 & 21 \\
2 & 100 & 5,8 & 0,0 & 4,56 & $<1$ \\
3 & 100 & 8,1 & 0,0 & 4,31 & 1 \\
4 & 100 & 0,0 & 8,0 & 6,32 & $<1$ \\
5 & 100 & 0,0 & 10,0 & 6,53 & 1 \\
6 & 100 & 0,0 & 12,0 & 6,76 & 1 \\
\hline \hline
\end{tabular}




\section{APÊNDICE E - Resultados dos ensaios de coagulação e filtração para construção dos diagramas da Água de Estudo 4.}

Tabela E. 1: Ensaio 1 para Água de Estudo 4.

\begin{tabular}{|c|c|c|c|c|c|c|}
\hline \multirow{2}{*}{ Jarro } & \multicolumn{3}{|c|}{ Dosagem $(\mathrm{mg} / \mathrm{L})$} & \multirow{2}{*}{$\begin{array}{c}\mathrm{pH} \mathrm{de} \\
\text { coagulaçãao }\end{array}$} & \multirow{2}{*}{$\begin{array}{l}\text { Turbidez } \\
\text { final (uT) }\end{array}$} & \multirow{2}{*}{$\begin{array}{c}\text { Cor } \\
\text { Aparente } \\
\text { final }(\mathrm{uH})\end{array}$} \\
\hline & Hidroxicloreto de Alumínio & $\mathrm{HCl}$ & $\mathrm{NaOH}$ & & & \\
\hline 1 & 50 & 0,0 & 2,0 & 5,90 & 5,90 & 148 \\
\hline 2 & 50 & 0,0 & 4,0 & 6,16 & 5,84 & 150 \\
\hline 3 & 50 & 0,0 & 0,0 & 5,77 & 6,34 & 145 \\
\hline 4 & 50 & 1,7 & 0,0 & 5,40 & 6,04 & 145 \\
\hline 5 & 50 & 3,5 & 0,0 & 5,00 & 6,48 & 149 \\
\hline 6 & 50 & 5,2 & 0,0 & 4,67 & 0,57 & 25 \\
\hline
\end{tabular}

Tabela E. 2: Ensaio 1 para Água de Estudo 4.

\begin{tabular}{|c|c|c|c|c|c|c|}
\hline \multirow{2}{*}{ Jarro } & \multicolumn{3}{|c|}{ Dosagem $(\mathrm{mg} / \mathrm{L})$} & \multirow{2}{*}{$\begin{array}{c}\mathrm{pH} \mathrm{de} \\
\text { coagulação }\end{array}$} & \multirow{2}{*}{$\begin{array}{l}\text { Turbidez } \\
\text { final (uT) }\end{array}$} & \multirow{2}{*}{$\begin{array}{c}\text { Cor } \\
\text { Aparente } \\
\text { final }(\mathrm{uH}) \\
\end{array}$} \\
\hline & Hidroxicloreto de Alumínio & $\mathrm{HCl}$ & $\mathrm{NaOH}$ & & & \\
\hline 1 & 80 & 0,0 & 0,0 & 5,60 & 4,85 & 52 \\
\hline 2 & 80 & 0,0 & 2,0 & 5,89 & 3,61 & 81 \\
\hline 3 & 80 & 0,0 & 4,0 & 6,10 & 5,83 & 137 \\
\hline 4 & 80 & 0,0 & 6,0 & 6,25 & 8,29 & 166 \\
\hline 5 & 80 & 1,7 & 0,0 & 5,25 & 2,20 & 40 \\
\hline 6 & 80 & 3,5 & 0,0 & 4,90 & 1,93 & 33 \\
\hline
\end{tabular}

Tabela E. 3: Ensaio 3 para Água de Estudo 4.

\begin{tabular}{|c|c|c|c|c|c|c|}
\hline \multirow{2}{*}{ Jarro } & \multicolumn{3}{|c|}{ Dosagem $(\mathrm{mg} / \mathrm{L})$} & \multirow{2}{*}{$\begin{array}{c}\mathrm{pH} \mathrm{de} \\
\text { coagulação }\end{array}$} & \multirow{2}{*}{$\begin{array}{l}\text { Turbidez } \\
\text { final (uT) }\end{array}$} & \multirow{2}{*}{$\begin{array}{c}\text { Cor } \\
\text { Aparente } \\
\text { final }(\mathrm{uH})\end{array}$} \\
\hline & Hidroxicloreto de Alumínio & $\mathrm{HCl}$ & $\mathrm{NaOH}$ & & & \\
\hline 1 & 100 & 0,0 & 0,0 & 5,22 & & 44 \\
\hline 2 & 100 & 1,2 & 0,0 & 5,11 & 2,34 & 32 \\
\hline 3 & 100 & 2,9 & 0,0 & 4,91 & 3,09 & 44 \\
\hline 4 & 100 & 4,6 & 0,0 & 4,72 & 1,50 & 20 \\
\hline 5 & 100 & 6,4 & 0,0 & 4,58 & 1,01 & 9 \\
\hline 6 & 100 & 8,1 & 0,0 & 4,44 & 1,20 & 12 \\
\hline
\end{tabular}


Tabela E. 4: Ensaio 4 para Água de Estudo 4.

\begin{tabular}{|c|c|c|c|c|c|c|}
\hline \multirow{2}{*}{ Jarro } & \multicolumn{3}{|c|}{ Dosagem $(\mathrm{mg} / \mathrm{L})$} & \multirow{2}{*}{$\begin{array}{c}\mathrm{pH} \mathrm{de} \\
\text { coagulação }\end{array}$} & \multirow{2}{*}{$\begin{array}{c}\text { Turbidez } \\
\text { final (uT) }\end{array}$} & \multirow{2}{*}{$\begin{array}{c}\text { Cor } \\
\text { Aparente } \\
\text { final }(\mathrm{uH})\end{array}$} \\
\hline & Hidroxicloreto de Alumínio & $\mathrm{HCl}$ & $\mathrm{NaOH}$ & & & \\
\hline 1 & 120 & 0,0 & 0,0 & 5,00 & 1,85 & 30 \\
\hline 2 & 120 & 1,7 & 0,0 & 4,93 & 0,95 & 9 \\
\hline 3 & 120 & 3,5 & 0,0 & 4,80 & 1,15 & 13 \\
\hline 4 & 120 & 5,2 & 0,0 & 4,65 & 1,15 & 15 \\
\hline 5 & 120 & 0,0 & 2,0 & 5,26 & 0,66 & 3 \\
\hline 6 & 120 & 0,0 & 4,0 & 5,58 & 1,12 & 13 \\
\hline
\end{tabular}

Tabela E. 5: Ensaio 5 para Água de Estudo 4.

\begin{tabular}{|c|c|c|c|c|c|c|}
\hline \multirow{2}{*}{ Jarro } & \multicolumn{3}{|c|}{ Dosagem $(\mathrm{mg} / \mathrm{L})$} & \multirow{2}{*}{$\begin{array}{c}\text { pH de } \\
\text { coagulação }\end{array}$} & \multirow{2}{*}{$\begin{array}{l}\text { Turbidez } \\
\text { final (uT) }\end{array}$} & \multirow{2}{*}{$\begin{array}{c}\text { Cor } \\
\text { Aparente } \\
\text { final (uH) }\end{array}$} \\
\hline & Hidroxicloreto de Alumínio & $\mathrm{HCl}$ & $\mathrm{NaOH}$ & & & \\
\hline 1 & 120 & 0,0 & 6,0 & 5,76 & 1,55 & 13 \\
\hline 2 & 120 & 0,0 & 8,0 & 6,04 & 0,65 & 1 \\
\hline 3 & 130 & 0,0 & 0,0 & 5,02 & 1,26 & 14 \\
\hline 4 & 130 & 2,3 & 0,0 & 4,90 & 1,22 & 13 \\
\hline 5 & 130 & 4,1 & 0,0 & 4,72 & 1,55 & 20 \\
\hline 6 & 130 & 5,8 & 0,0 & 4,58 & 1,13 & 22 \\
\hline
\end{tabular}

Tabela E. 6: Ensaio 6 para Água de Estudo 4.

\begin{tabular}{ccccccc}
\hline \multirow{2}{*}{ Jarro } & \multicolumn{2}{c}{ Dosagem (mg/L) } & & pH de & Turbidez & $\begin{array}{c}\text { Cor } \\
\text { coagulação }\end{array}$ \\
\cline { 2 - 3 } & Hidroxicloreto de Alumínio & $\mathrm{HCl}$ & $\mathrm{NaOH}$ & $\begin{array}{c}\text { Aparente } \\
\text { final (uH) }\end{array}$ \\
\hline \hline 1 & 100 & 0,0 & 2,0 & 5,50 & 3,05 & 52 \\
2 & 100 & 0,0 & 4,0 & 5,93 & 2,12 & 34 \\
3 & 100 & 0,0 & 6,0 & 6,22 & 3,17 & 59 \\
4 & 100 & 0,0 & 8,0 & 6,46 & 2,16 & 44 \\
5 & 100 & 0,0 & 10,0 & 6,68 & 3,16 & 87 \\
6 & 80 & 5,2 & 0,0 & 4,50 & 0,97 & 13 \\
\hline \hline
\end{tabular}

Tabela E. 7: Ensaio 7 para Água de Estudo 4.

\begin{tabular}{|c|c|c|c|c|c|c|}
\hline \multirow{2}{*}{ Jarro } & \multicolumn{3}{|c|}{ Dosagem $(\mathrm{mg} / \mathrm{L})$} & \multirow{2}{*}{$\begin{array}{c}\mathrm{pH} \text { de } \\
\text { coagulação }\end{array}$} & \multirow{2}{*}{$\begin{array}{l}\text { Turbidez } \\
\text { final (uT) }\end{array}$} & \multirow{2}{*}{$\begin{array}{c}\text { Cor } \\
\text { Aparente } \\
\text { final (uH) }\end{array}$} \\
\hline & Hidroxicloreto de Alumínio & $\mathrm{HCl}$ & $\mathrm{NaOH}$ & & & \\
\hline 1 & 130 & 0,0 & 2,0 & 5,04 & 1,29 & 27 \\
\hline 2 & 130 & 0,0 & 4,0 & 5,32 & 0,59 & 5 \\
\hline 3 & 130 & 0,0 & 6,0 & 5,71 & 0,71 & 4 \\
\hline 4 & 120 & 0,0 & 12,0 & 6,40 & 1,36 & 22 \\
\hline 5 & 90 & 3,5 & 0,0 & 4,93 & 1,60 & 23 \\
\hline 6 & 90 & 5,2 & 0,0 & 4,71 & 0,78 & 6 \\
\hline
\end{tabular}


Tabela E. 8: Ensaio 8 para Água de Estudo 4.

\begin{tabular}{|c|c|c|c|c|c|c|}
\hline \multirow{2}{*}{ Jarro } & \multicolumn{3}{|c|}{ Dosagem $(\mathrm{mg} / \mathrm{L})$} & \multirow{2}{*}{$\begin{array}{c}\mathrm{pH} \text { de } \\
\text { coagulação }\end{array}$} & \multirow{2}{*}{$\begin{array}{l}\text { Turbidez } \\
\text { final (uT) }\end{array}$} & \multirow{2}{*}{$\begin{array}{c}\text { Cor } \\
\text { Aparente } \\
\text { final (uH) }\end{array}$} \\
\hline & Hidroxicloreto de Alumínio & $\mathrm{HCl}$ & $\mathrm{NaOH}$ & & & \\
\hline 1 & 110 & 0,0 & 0,0 & 5,11 & 2,19 & 40 \\
\hline 2 & 110 & 1,7 & 0,0 & 5,00 & 0,94 & 12 \\
\hline 3 & 110 & 3,5 & 0,0 & 4,83 & 1,26 & 17 \\
\hline 4 & 110 & 5,2 & 0,0 & 4,69 & 0,88 & 13 \\
\hline 5 & 110 & 7,0 & 0,0 & 4,48 & 0,82 & 14 \\
\hline 6 & 110 & 0,0 & 2,0 & 5,39 & 1,26 & 20 \\
\hline
\end{tabular}

Tabela E. 9: Ensaio 9 para Água de Estudo 4.

\begin{tabular}{|c|c|c|c|c|c|c|}
\hline \multirow{2}{*}{ Jarro } & \multicolumn{3}{|c|}{ Dosagem (mg/L) } & \multirow{2}{*}{$\begin{array}{c}\mathrm{pH} \text { de } \\
\text { coagulação }\end{array}$} & \multirow{2}{*}{$\begin{array}{c}\text { Turbidez } \\
\text { final (uT) }\end{array}$} & \multirow{2}{*}{$\begin{array}{c}\text { Cor } \\
\text { Aparente } \\
\text { final }(\mathrm{uH})\end{array}$} \\
\hline & Hidroxicloreto de Alumínio & $\mathrm{HCl}$ & $\mathrm{NaOH}$ & & & \\
\hline 1 & 110 & 0,0 & 4,0 & 5,69 & 2,40 & 40 \\
\hline 2 & 110 & 0,0 & 6,0 & 5,99 & 1,23 & 17 \\
\hline 3 & 110 & 0,0 & 8,0 & 6,20 & 1,59 & 25 \\
\hline 4 & 110 & 0,0 & 10,0 & 6,36 & 1,51 & 25 \\
\hline 5 & 90 & 1,7 & 0,0 & 5,14 & 0,93 & 7 \\
\hline 6 & 90 & 7,0 & 0,0 & 4,53 & 0,80 & 13 \\
\hline
\end{tabular}

Tabela E. 10: Ensaio 10 para Água de Estudo 4.

\begin{tabular}{|c|c|c|c|c|c|c|}
\hline \multirow{2}{*}{ Jarro } & \multicolumn{3}{|c|}{ Dosagem (mg/L) } & \multirow{2}{*}{$\begin{array}{c}\mathrm{pH} \text { de } \\
\text { coagulação }\end{array}$} & \multirow{2}{*}{$\begin{array}{l}\text { Turbidez } \\
\text { final (uT) }\end{array}$} & \multirow{2}{*}{$\begin{array}{c}\text { Cor } \\
\text { Aparente } \\
\text { final (uH } \\
\end{array}$} \\
\hline & Hidroxicloreto de Alumínio & $\mathrm{HCl}$ & $\mathrm{NaOH}$ & & & \\
\hline 1 & 90 & 0,0 & 0,0 & 5,37 & 2,48 & 41 \\
\hline 2 & 90 & 0,0 & 2,0 & 5,71 & 1,13 & 15 \\
\hline 3 & 90 & 0,0 & 4,0 & 5,92 & 1,68 & 26 \\
\hline 4 & 90 & 0,0 & 6,0 & 6,21 & 1,82 & 41 \\
\hline 5 & 130 & 0,0 & 12,0 & 6,37 & 0,68 & 3 \\
\hline 6 & 130 & 0,0 & 14,0 & 6,54 & 0,92 & 9 \\
\hline
\end{tabular}

Tabela E. 11: Ensaio 11 para Água de Estudo 4.

\begin{tabular}{|c|c|c|c|c|c|c|}
\hline \multirow{2}{*}{ Jarro } & \multicolumn{3}{|c|}{ Dosagem $(\mathrm{mg} / \mathrm{L})$} & \multirow{2}{*}{$\begin{array}{c}\mathrm{pH} \mathrm{de} \\
\text { coagulaçãao }\end{array}$} & \multirow{2}{*}{$\begin{array}{l}\text { Turbidez } \\
\text { final (uT) }\end{array}$} & \multirow{2}{*}{$\begin{array}{c}\text { Cor } \\
\text { Aparente } \\
\text { final }(\mathrm{uH})\end{array}$} \\
\hline & Hidroxicloreto de Alumínio & $\mathrm{HCl}$ & $\mathrm{NaOH}$ & & & \\
\hline 1 & 130 & 0,0 & 8,0 & 5,96 & 0,77 & 4 \\
\hline 2 & 130 & 0,0 & 10,0 & 6,20 & 0,58 & 2 \\
\hline 3 & 140 & 0,0 & 0,0 & 5,00 & 1,00 & 10 \\
\hline 4 & 140 & 0,0 & 3,0 & 5,20 & 1,59 & 26 \\
\hline 5 & 140 & 0,0 & 6,0 & 5,63 & 0,51 & $<1$ \\
\hline 6 & 140 & 0,0 & 9,0 & 5,97 & 0,53 & $<1$ \\
\hline
\end{tabular}


Tabela E. 12: Ensaio 12 para Água de Estudo 4.

\begin{tabular}{ccccccc}
\hline \multirow{2}{*}{ Jarro } & \multicolumn{2}{c}{ Dosagem (mg/L) } & & pH de & Turbidez & $\begin{array}{c}\text { Cor } \\
\text { coagulação }\end{array}$ \\
\cline { 2 - 3 } & Hidroxicloreto de Alumínio & $\mathrm{HCl}$ & $\mathrm{NaOH}$ & $\begin{array}{c}\text { Aparente } \\
\text { final (uH) }\end{array}$ \\
\hline \hline 1 & 140 & 0,0 & 5,0 & 5,42 & 0,71 & 3 \\
2 & 140 & 0,0 & 11,0 & 6,23 & 0,66 & 4 \\
3 & 140 & 0,0 & 13,0 & 6,42 & 0,68 & 3 \\
4 & 130 & 0,0 & 16,0 & 6,82 & 0,81 & 15 \\
5 & 130 & 0,0 & 18,0 & 7,00 & 1,42 & 45 \\
6 & 140 & 2,3 & 0,0 & 4,88 & 0,88 & 11 \\
\hline \hline
\end{tabular}

Tabela E. 13: Ensaio 13 para Água de Estudo 4.

\begin{tabular}{ccccccc}
\hline \multirow{2}{*}{ Jarro } & \multicolumn{2}{c}{ Dosagem (mg/L) } & & pH de & Turbidez & $\begin{array}{c}\text { Cor } \\
\text { coagulação }\end{array}$ \\
\cline { 2 - 3 } & Hidroxicloreto de Alumínio & $\mathrm{HCl}$ & $\mathrm{NaOH}$ & $\begin{array}{c}\text { Aparente } \\
\text { final (uH) }\end{array}$ \\
\hline \hline 1 & 150 & & & 4,80 & 0,83 & 4 \\
2 & 150 & 0,0 & 3,0 & 4,95 & 2,21 & 48 \\
3 & 150 & 0,0 & 6,0 & 5,17 & 3,36 & 75 \\
4 & 150 & 0,0 & 9,0 & 5,60 & 0,98 & 1 \\
5 & 150 & 0,0 & 12,0 & 6,15 & 0,83 & 1 \\
6 & 150 & 0,0 & 15,0 & 6,50 & 0,91 & 6 \\
\hline \hline
\end{tabular}

Tabela E. 14: Ensaio 14 para Água de Estudo 4.

\begin{tabular}{|c|c|c|c|c|c|c|}
\hline \multirow{2}{*}{ Jarro } & \multicolumn{3}{|c|}{ Dosagem $(\mathrm{mg} / \mathrm{L})$} & \multirow{2}{*}{$\begin{array}{c}\mathrm{pH} \text { de } \\
\text { coagulação }\end{array}$} & \multirow{2}{*}{$\begin{array}{l}\text { Turbidez } \\
\text { final (uT) }\end{array}$} & \multirow{2}{*}{$\begin{array}{c}\text { Cor } \\
\text { Aparente } \\
\text { final }(\mathrm{uH}) \\
\end{array}$} \\
\hline & Hidroxicloreto de Alumínio & $\mathrm{HCl}$ & $\mathrm{NaOH}$ & & & \\
\hline 1 & 160 & 0,0 & 4,0 & 4,77 & 3,48 & 85 \\
\hline 2 & 160 & 0,0 & 7,0 & 5,18 & 4,05 & 98 \\
\hline 3 & 160 & 0,0 & 9,0 & 5,45 & 1,78 & 34 \\
\hline 4 & 160 & 0,0 & 11,0 & 5,75 & 0,74 & $<1$ \\
\hline 5 & 160 & 0,0 & 14,0 & 6,25 & 0,80 & 3 \\
\hline 6 & 160 & 0,0 & 16,0 & 6,67 & 1,15 & 7 \\
\hline
\end{tabular}

Tabela E. 15: Ensaio 15 para Água de Estudo 4.

\begin{tabular}{ccccccc}
\hline \hline \multirow{2}{*}{ Jarro } & \multicolumn{2}{c}{ Dosagem (mg/L) } & & pH de & Turbidez & $\begin{array}{c}\text { Cor } \\
\text { coagulação }\end{array}$ \\
\cline { 2 - 3 } & Hidroxicloreto de Alumínio & $\mathrm{HCl}$ & $\mathrm{NaOH}$ & $\begin{array}{c}\text { Aparente } \\
\text { final (uH) }\end{array}$ \\
\hline \hline 1 & 170 & 0,0 & 10,0 & 5,69 & 0,78 & $<1$ \\
2 & 170 & 0,0 & 12,0 & 5,80 & 0,73 & $<1$ \\
3 & 170 & 0,0 & 14,0 & 6,05 & 0,72 & $<1$ \\
4 & 170 & 0,0 & 16,0 & 6,24 & 0,66 & $<1$ \\
5 & 170 & 0,0 & 18,0 & 6,54 & 0,61 & 2 \\
6 & 170 & 0,0 & 20,0 & 6,62 & 0,61 & 13 \\
\hline \hline
\end{tabular}


Tabela E. 16: Ensaio 16 para Água de Estudo 4.

\begin{tabular}{ccccccc}
\hline \hline \multirow{2}{*}{ Jarro } & \multicolumn{2}{c}{ Dosagem (mg/L) } & & pH de & Turbidez \\
\cline { 2 - 3 } & Hidroxicloreto de Alumínio & $\mathrm{HCl}$ & $\mathrm{NaOH}$ & $\begin{array}{c}\text { Cor } \\
\text { coagulaçãon } \\
\text { final (uT) }\end{array}$ & $\begin{array}{c}\text { Aparente } \\
\text { final (uH) }\end{array}$ \\
\hline \hline 1 & 170 & 0,0 & 0,0 & 5,25 & 5,00 & 117 \\
2 & 170 & 0,0 & 0,0 & 5,09 & 6,25 & 127 \\
3 & 140 & 0,0 & 0,0 & 6,46 & 0,59 & 1 \\
4 & 140 & 0,0 & 0,0 & 6,62 & 0,55 & 3 \\
5 & 150 & 0,0 & 0,0 & 6,65 & 0,53 & 4 \\
6 & 160 & 0,0 & 0,0 & 6,68 & 0,60 & 2 \\
\hline \hline
\end{tabular}

Tabela E. 17: Ensaio 17 para Água de Estudo 4.

\begin{tabular}{|c|c|c|c|c|c|c|}
\hline \multirow{2}{*}{ Jarro } & \multicolumn{3}{|c|}{ Dosagem (mg/L) } & \multirow{2}{*}{$\begin{array}{c}\text { pH de } \\
\text { coagulação }\end{array}$} & \multirow{2}{*}{$\begin{array}{l}\text { Turbidez } \\
\text { final (uT) }\end{array}$} & \multirow{2}{*}{$\begin{array}{c}\text { Cor } \\
\text { Aparente } \\
\text { final }(\mathrm{uH})\end{array}$} \\
\hline & Hidroxicloreto de Alumínio & $\mathrm{HCl}$ & $\mathrm{NaOH}$ & & & \\
\hline 1 & 180 & 0,0 & 9,0 & 5,47 & 5,49 & 116 \\
\hline 2 & 180 & 0,0 & 12,0 & 5,75 & 0,55 & $<1$ \\
\hline 3 & 180 & 0,0 & 15,0 & 6,14 & 0,61 & $<1$ \\
\hline 4 & 180 & 0,0 & 18,0 & 6,40 & 0,49 & 2 \\
\hline 5 & 180 & 0,0 & 21,0 & 6,65 & 0,60 & 4 \\
\hline 6 & 180 & 0,0 & 24,0 & 6,93 & 0,50 & 6 \\
\hline
\end{tabular}

Tabela E. 18: Ensaio 18 para Água de Estudo 4.

\begin{tabular}{|c|c|c|c|c|c|c|}
\hline \multirow{2}{*}{ Jarro } & \multicolumn{3}{|c|}{ Dosagem $(\mathrm{mg} / \mathrm{L})$} & \multirow{2}{*}{$\begin{array}{c}\mathrm{pH} \text { de } \\
\text { coagulação }\end{array}$} & \multirow{2}{*}{$\begin{array}{l}\text { Turbidez } \\
\text { final (uT) }\end{array}$} & \multirow{2}{*}{$\begin{array}{c}\text { Cor } \\
\text { Aparente } \\
\text { final }(\mathrm{uH})\end{array}$} \\
\hline & Hidroxicloreto de Alumínio & $\mathrm{HCl}$ & $\mathrm{NaOH}$ & & & \\
\hline 1 & 140 & 0,0 & 20,0 & 7,13 & & 127 \\
\hline 2 & 150 & 0,0 & 21,0 & 7,11 & & 124 \\
\hline 3 & 160 & 0,0 & 21,0 & 7,00 & 1,65 & 43 \\
\hline 4 & 160 & 0,0 & 13,0 & 6,20 & 0,48 & 1 \\
\hline 5 & 160 & 0,0 & 16,0 & 6,46 & 0,69 & 3 \\
\hline 6 & 170 & 0,0 & 22,0 & 6,94 & 1,12 & 27 \\
\hline
\end{tabular}

